2017

\title{
Critiquing Physical Prototypes for a Remote Audience
}

\author{
Mok, Terrance
}

Mok, T. (2017). Critiquing Physical Prototypes for a Remote Audience (Unpublished master's thesis). University of Calgary, Calgary, AB. doi:10.11575/PRISM/25491

http://hdl.handle.net/11023/4248

Downloaded from PRISM Repository, University of Calgary 


\title{
UNIVERSITY OF CALGARY
}

Critiquing Physical Prototypes for a Remote Audience

by

Terrance Mok

\begin{abstract}
A THESIS
SUBMITTED TO THE FACULTY OF GRADUATE STUDIES

IN PARTIAL FULFILMENT OF THE REQUIREMENTS FOR THE

DEGREE OF MASTER OF SCIENCE
\end{abstract}

GRADUATE PROGRAM IN COMPUTER SCIENCE

CALGARY, ALBERTA

November, 2017

(C) Terrance Mok 2017 


\begin{abstract}
I present an observational study of physical prototype critique that highlights some of the challenges of communicating physical behaviors and materiality at a distance. Geographically distributed open hardware communities often conduct user feedback and peer critique sessions via video conference. However, people have difficulty using current video conferencing tools to demonstrate and critique physical designs. To examine the challenges of remote critique, I conducted an observational lab study in which participants critiqued pairs of physical prototypes (prosthetic hands) for a face-toface or remote collaborator. In both conditions, participants' material experiences were an important part of their critique, however their attention was divided between interacting with the prototype and finding strategies to communicate 'invisible' features. Based on my findings, I propose design implications for remote collaboration tools that support the sharing of material experiences and prototype critique.
\end{abstract}




\section{Publications}

Some figures and material in this thesis has previously appeared in prior work:

Mok, T., Oehlberg, L. (2017) Critiquing physical prototypes for a remote audience. Proceedings of the 2017 ACM Conference on Designing Interactive Systems (pp 1295-1307). New York, New York, USA: ACM Press. 


\section{Acknowledgements}

I first would like to acknowledge the support and guidance of my supervisor Dr. Lora Oehlberg throughout my master's degree. I was lucky to be a part of the Curio group that Dr. Oehlberg formed. I want to thank all the members of the Curio (?) group that shared their diverse interests in both research and life, and were always willing to help by giving their unique perspectives and opinions; David Ledo, Gabriele Kuzabaviciute, Peyman Poostchi, Kevin Ta, Fateme Rajabiyazdi, Tiffany Wun, Claire Mikalauskas, Justin Quaintance and Michael Hung.

I also want to thank the whole of the Interactions Lab at the University of Calgary. Working alongside the skilled people of the iLab has improved my own work and everyone was always available to aid me when needed.

Finally, I thank Jenn and Autumn - for everything. 


\section{Table of Contents}

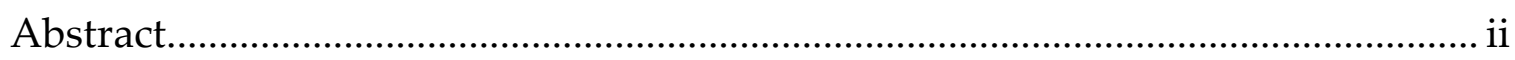

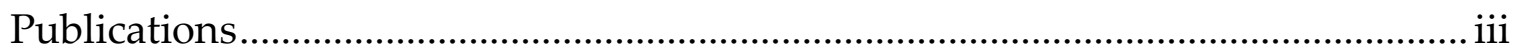

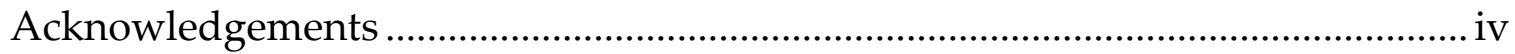

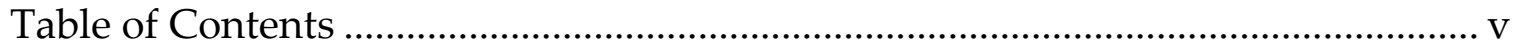

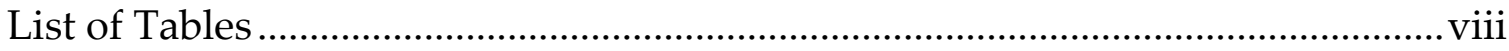

List of Figures and Illustrations ..................................................................... ix

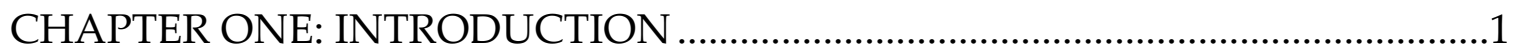

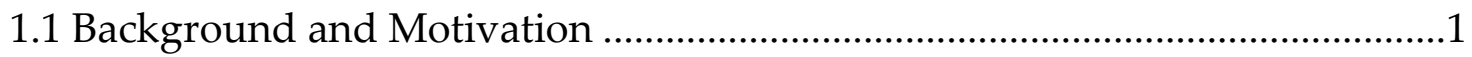

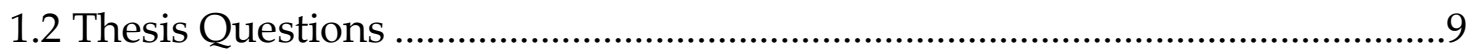

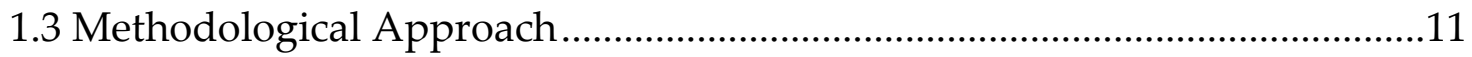

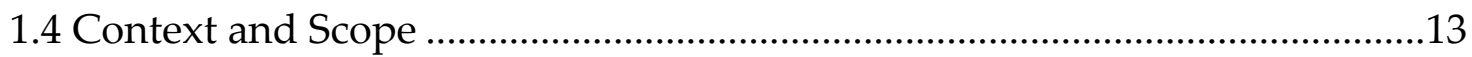

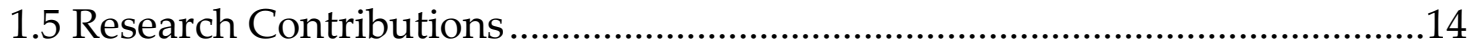

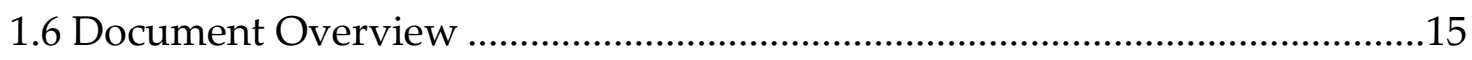

CHAPTER TWO: RELATED WORK …………….............................................18

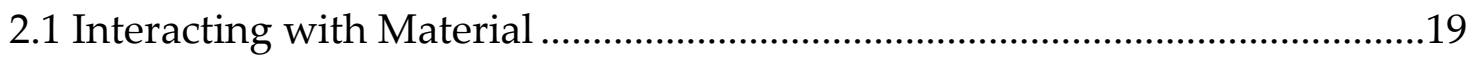

2.2 Remote Communication Systems for Physical Tasks........................................21

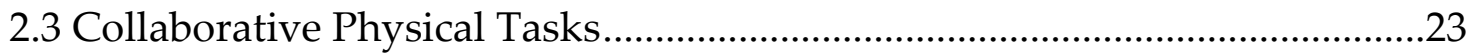

2.4 Prototype Critique in Collaborative Design ..................................................26

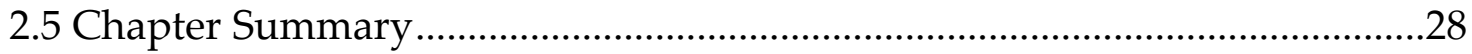

CHAPTER THREE: AN OBSERVATION OF REMOTE CRITIQUE IN PRACTICE:

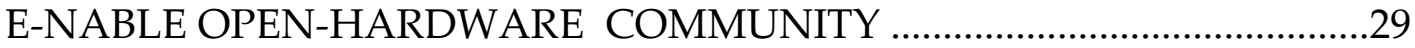

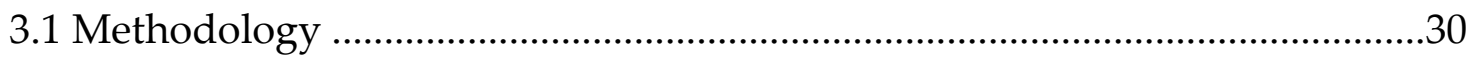

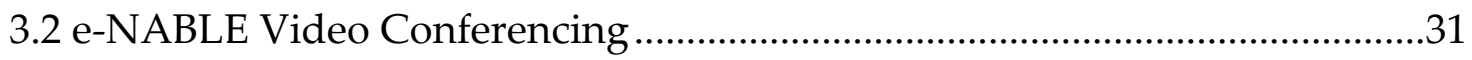

3.3 Chapter Summary ............................................................................................

CHAPTER FOUR: STUDY DESIGN AND PROCEDURE .........................................

4.1 Study Design Rationale...............................................................................

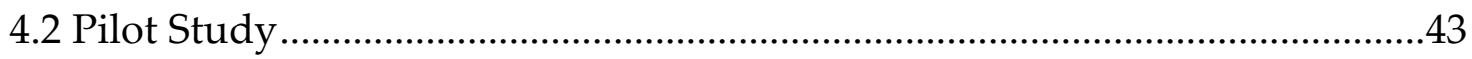

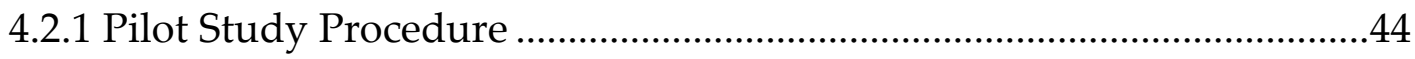

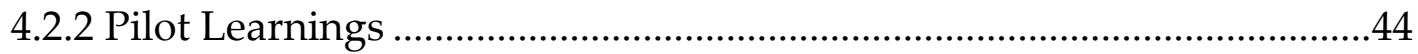

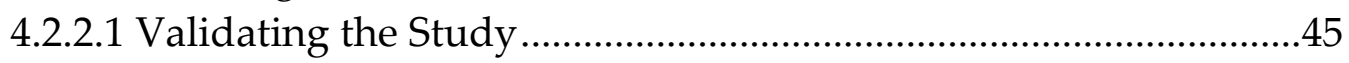

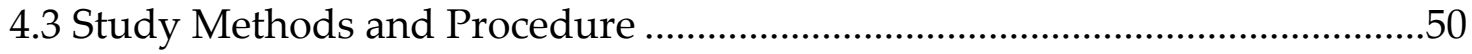

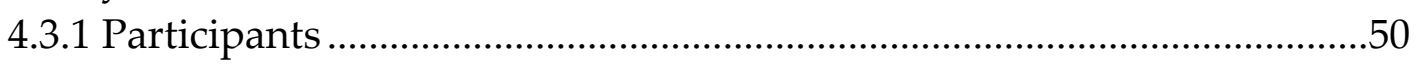

4.3.2 Physical Prototypes: e-NABLE Prosthetic Hands....................................50 


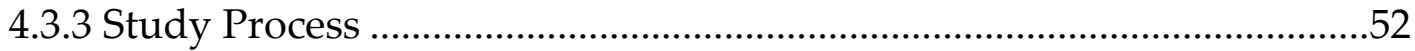

4.3.3.1 Task: Structured Critique................................................................54

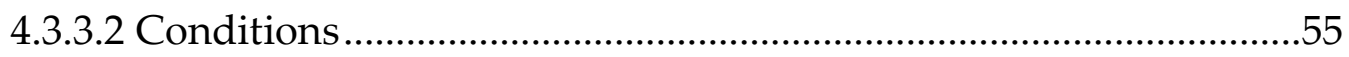

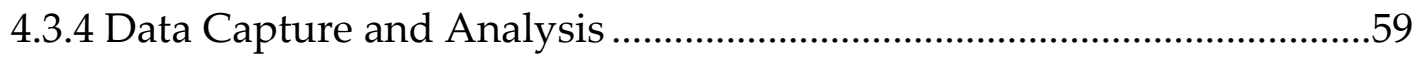

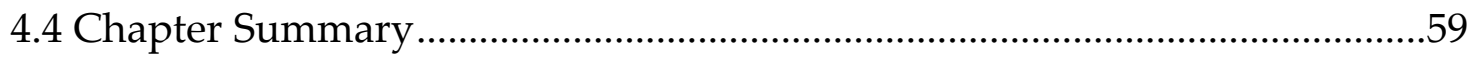

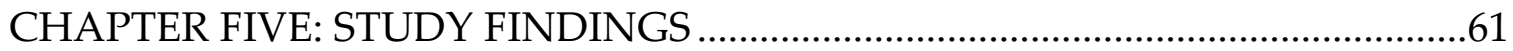

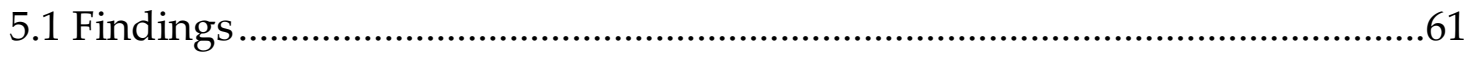

5.1.1 Epistemic and Pragmatic Action .........................................................62

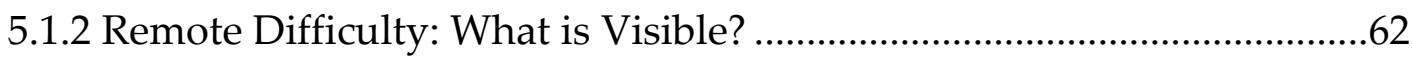

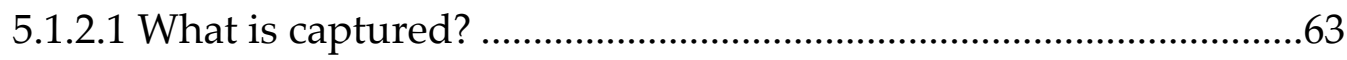

5.1.2.2 Where is my collaborator looking?...................................................68

5.1.2.3 Who is responsible for the view?....................................................

5.1.3 Communicating with and about Prototypes ............................................

5.1.3.1 Communicating Physical Detail .......................................................

5.1.3.2 Focus and Attention ......................................................................

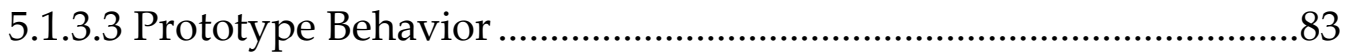

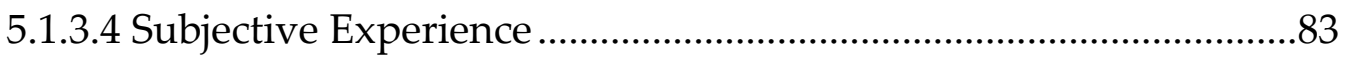

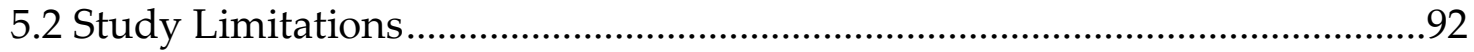

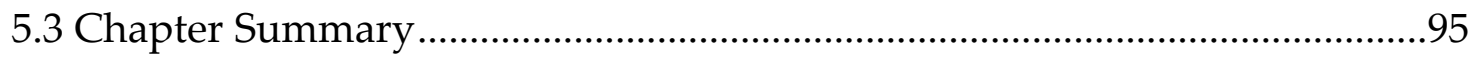

CHAPTER SIX: IMPLICATIONS FOR DESIGN AND RESEARCH......................96

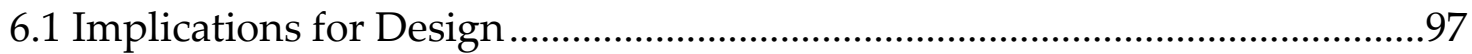

6.1.1 Build Visual Context around Material Experience ...................................97

6.1.2 Prioritize Camera Preview …………………........................................100

6.1.3 Provide Means for Close-up Communication.........................................104

6.1.4 Leverage Pragmatic Action ..................................................................106

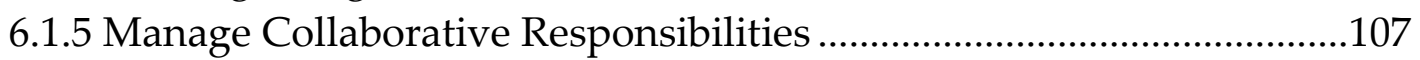

6.2 Implications for Research .................................................................110

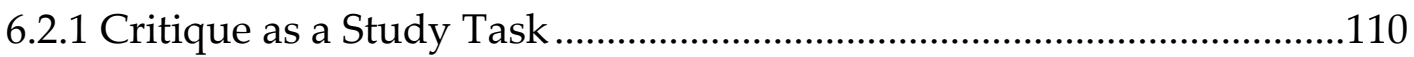

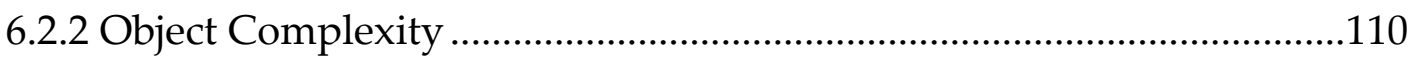

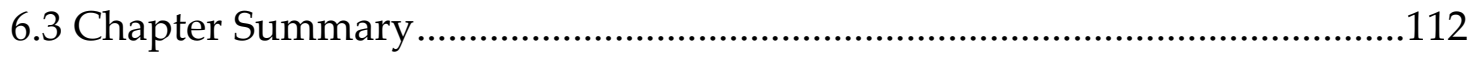

CHAPTER SEVEN: CONCLUSIONS AND FUTURE WORK ……………............113

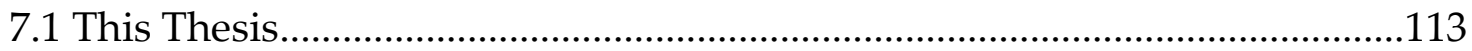

7.1.1 Returning to the Thesis Questions ......................................................113

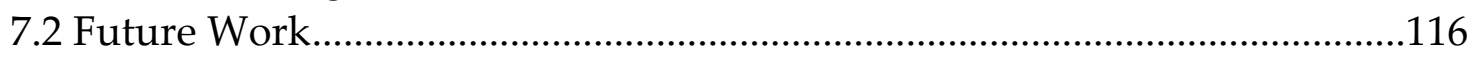

7.2.1 Remote Communication of Material Experience …….............................116

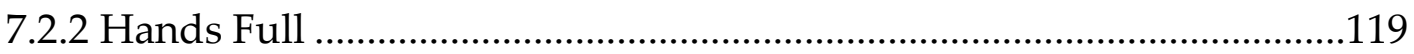




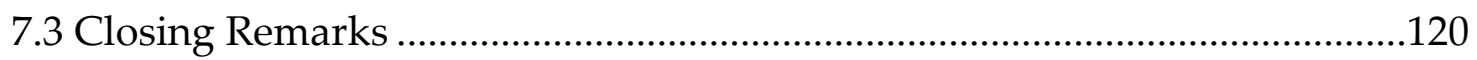

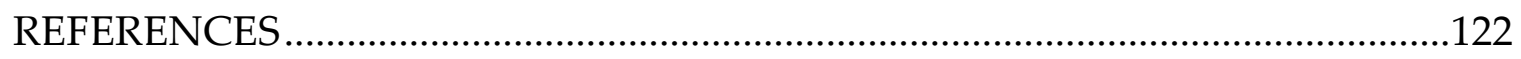

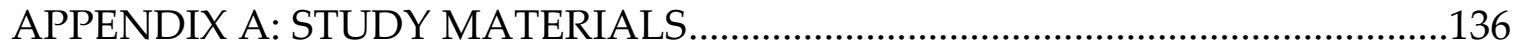

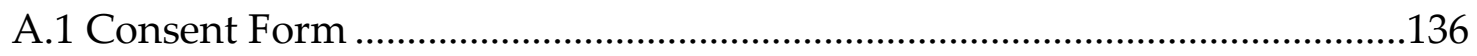

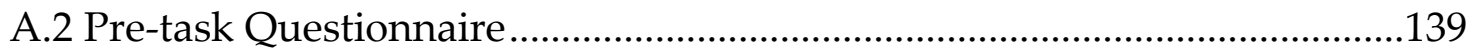

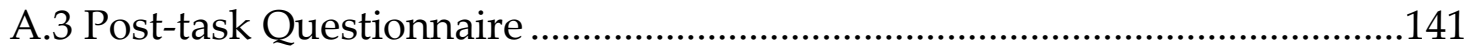

A.4 Study Prosthetic Interviewer Protocol........................................................144

A.5 Pilot Study Interviewer Protocol ..................................................................145

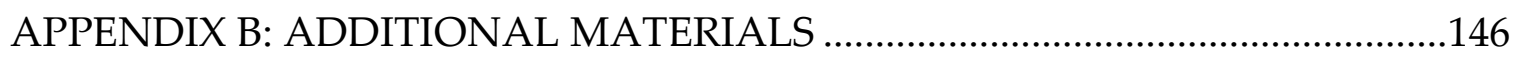

B.1 Cyborg Beast Hand Materials Kit List...............................................................146

B.2 List of e-NABLE Town Hall and Research and Development Meetings Observed

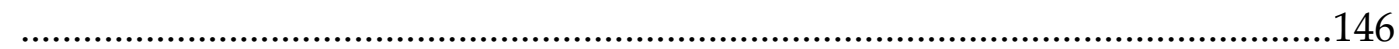

B.3 List of e-NABLE Community Videos Observed ............................................147 


\section{List of Tables}

Table 1. Text descriptions of two 3D printing defects, "Over-extrusion" and "Blobs and Zits", from the Simplify3D online 3D print quality troubleshooting guide ${ }^{9} . . . . . .4$

Table 2. Methodological approach to each of my thesis questions. ...................................... 11

Table 3. My thesis contributions which address each thesis question................................ 15

Table 4. Key features of the four hands 3D printed, assembled, and used for the study. I gave participants the hands in the pairs shown here (Top) Pair 1 and (Bottom) Pair 2 for comparison.

Table 5. Post-task questionnaire medians of 5-point Likert scale ranging from 'strongly disagree' (0) to 'strongly agree' (4) ................................................................. 53 


\section{List of Figures and Illustrations}

Figure 1.1. Gauntlet of a 3D printed prosthetic shaped through thermoforming. (Left) shows the original flat 3D print and (Right) shows the result of thermoforming the plastic by making the material malleable with hot water and manually shaping it.

Figure 1.2. Example 3D printing defect images and text from an online 3D print quality troubleshooting guide: www.simplify3d.com/support/print-qualitytroublshooting. (Bottom Right) "Over-extrusion" and (Top Left) "Blobs and Zits" text-only description of these print defects are in Table 1.

Figure 1.3. Human-computer Interaction (HCI) is the overarching domain of this thesis. My work lies in the cross section of collaborative prototype critique, remote collaboration on physical tasks, and material experience.

Figure 2.1. Karana et al. (2016) depiction of a designer exploring a variety of material experiences to help design a radio tuner. (Top) Kneading of foam attached to the radio. (Middle) Kneading and squeezing of foam that could be detached from the radio. (Bottom) Bristles or hairs that can be swiped or caressed from side to side.. 19

Figure 2.2. Wrigglo by Y.-W. Park et al. (2014). Physical movements of Wrigglo can be used to communicate expressions: (a) forward and backward (Yes), (b) side to side (No), (c) expansion (So what?), (d) forward (Huh? or Pointing right), (e) shrinking (Overwhelmed), (f) facing each other, (g) outwards, (h) crossing............... 22

Figure 2.3. Views from a drone video conferencing system by Jones et al. (2016). Colors are only visible to the person in the field (Right) but not from the drone camera view (Left).

Figure 2.4. Workspace for local "worker". The worker uses an AR system developed by Tait and Billinghurst (2015) to help them place the objects on the desk in correct positions.

Figure 2.5. Projected hands developed by Suzuki et al. (2016). Hands of the 'helper' collaborator projected into the workspace of a 'worker' to support a worker in a Lego block assembly task. 
Figure 2.6. AutoDesk Design Review allows for additions such as comments, markup, and drawings to be on top of existing 2D (left) and 3D (right) CAD files. Collaborators can share the resulting files that include the additions.

Figure 2.7. Example of design process from sketch (Left) to prototype (Right) produced in a one-day design charrette. Bousseau et al. (2016) studied how participants communicated critique and feedback with collocated partners.

Figure 3.1. A partially assembled 3D printed prosthetic hand - the Raptor Reloaded design from e-NABLE.

Figure 3.2. 3D printed parts reference for the Raptor Hand from http://enablingthefuture.org/upper-limb-prosthetics/the-raptor-hand. This is an example of the complexity of the e-NABLE prosthetic hands by number (30) of required 3D printed parts.

Figure 3.3. The Raptor Hand ${ }^{32}$ with labelled parts common to all e-NABLE prosthetic hand designs. The gauntlet and palm are fastened to the user's arm and residual limb. The user bends their wrist to pull fishing line held in place by the tensioner block which pulls on the fingers to form a closed grip (active). When the user is not bending their wrist, elastics pull the prosthetic fingers to an open position (passive).

Figure 3.4. Still image ${ }^{32}$ from a video discussing two different styles of tensioner blocks and how they operate. Fabricated examples of each version are used for demonstration.

1.1 Figure 4.1. Three simple 3D printed bottle opener designs from Thingiverse ${ }^{34}$ used in my pilot study. (Left) Thing 269463 by Kart5a. (Middle) Thing 1842 by Starno. (Right) Thing 1097099 by In3Designs.

Figure 4.2. Example parts used to assembled e-NABLE prosthetic hands. (Left) Offthe-shelf screws used in the hand joints. (Right) 3D Printed proximal phalanges. . 50

Figure 4.3. Participants could test the prosthetic hands by attempting to grasp the provided study objects: (Left) a glue stick, (Middle) a full $200 \mathrm{~mL}$ juice box, and (Right) an empty plastic water bottle. 
Figure 4.4. Participant P13 critiques prosthetic hands for a researcher in two conditions. (Top) Sitting face-to-face across from the researcher, and (Bottom) using a webcam to video conference with a remote researcher.

Figure 4.5. (Top) The view that the participant sees on their computer. The small bottom right corner shows a preview window of the participant's camera. (Bottom) The view on the researcher's screen. The small bottom right corner shows a preview window of the researcher.

Figure 5.1. (Top) Webcam view and (Bottom) workspace view of P12 (VC) demonstrating actions with the white prosthetic hand as they realize the prosthetic is out of frame. P12 exclaims, "Ah, I don't know where the camera is," as they then lift their shoulders to bring the prosthetic hand back into frame.

Figure 5.2. P3 (VC) inspects and compares the prosthetics, holding them such that the majority of the prosthetics are not visible due to occlusion from P3's own hands and perspective foreshortening.

Figure 5.3. P18 (VC) holds the blue prosthetic hand close to the camera attempting to show details of the fingertips. Unfortunately, the webcam remains focused on the P18; the image of the prosthetic is blurry to the viewer. They remark, "I don't know if you can see the surface texture."

Figure 5.4. P10 (VC) holds up prototypes to the camera, gestures to prototypes oncamera, and references their own physical geometry to describe the precise location of elastics on a prosthetic hand.

Figure 5.5. (Top) P16 (F2F) with their attention focused down at the prosthetics as they inspect the straps. (Right) Selected transcript from P16, when comparing each prosthetic. While the entire response takes 36 seconds, they only switch attention from the prosthetics to the researcher for 2 seconds

Figure 5.6. While communicating, P2 (VC) holds up two prosthetic hands close to the camera (pragmatic showing action) obscuring their own view of the video communication interface.

Figure 5.7. P5 (VC) shows prosthetic behavior while discussing string tension and joints. "If I'm closing this one and I touch it like this, they kind of bounce around a bit.". 84 
Figure 5.8. P14 (VC) narrates their own actions as they wave the prosthetics and then their own hand to describe how the prosthetics move and bounce in comparison to each other and to their own hand.

Figure 5.9. P14 (VC) narrates their off camera actions. (Left) View from the study camera overlooking the entire workspace shows the participant working with prototypes on the table. The prototypes discussed are not visible to the audience in the webcam view (Right).

Figure 5.10. (Top) P19 (VC) and (Bottom) P14 (VC) explain the actions users of the prosthetic need to close and open the hand by performing an up and down motion with their own hand as a surrogate. P14 (VC) also narrates their actions "When they press down their palm like this."

Figure 5.11. Participant P3 (VC) uses their hand as a stand-in for a child's hand to discuss the shape of the prosthetic. "Here the [palm] is more like the shape of a child's hand."

Figure 6.1. Sketch of a possible layout for a tabletop display to support a presenter during video conferencing, as they review physical prototypes. The presenter's preview video lies within their field of view as they are focused downwards on the objects in their hands.

Figure 6.2. The t-room (Hirata et al., 2008) captures and displays remote collaborators at life-size proportions. From this example we see that their is no video preview available to the "At-local" collaborators of themselves.

Figure 6.3. A physical slider puzzle in the solved end-goal position. The 8 tiles can be moved to create a scrambled puzzle instance.

Figure 6.4. (Left) Using an off-the-shelf USB endoscope to capture detailed close-up of the fingers of a prosthetic prototype. (Right) The video capture of the endoscope camera shows small bumps on the plastic fingertips. Details like these are not normally visible with standard video conferencing webcams. Yet, the closer portion of the fingertips are still out of focus.

Figure 6.5. Example of retroreflective markers (white balls) attached directly to an object, person, or sticks. Tracking systems such as Vicon use these markers to identify and follow objects or people. 
Figure 7.1. Sketch of a theoretical remote weight communication system. Local weight of an object is measured on a network connected weigh scale. The weight is communicated to a remote site where an object adjusts its weight by picking up or more (Bottom) or less (Top) magnetic material

Figure 7.2. Sketch of a theoretical "mirror" hands system. Person (Left) records their hand movements (A) as the handle an object. (B) mirror hands replay the recorded actions $(\mathrm{C})$ once given the object. This frees up the person (Right) to gesture or point to the object as it is manipulated..... 


\section{List of Symbols, Abbreviations, and Nomenclature}

Symbol

3D

CAD

TQ

CB

$\mathrm{R} \& \mathrm{D}$

F2F

VC

AR
Definition

Three dimensions or Three dimensional Computer Aided Design

Thesis Question

Contribution

Research \& Development

Face-to-face

Video Conferencing

Augmented Reality 


\section{Chapter One: Introduction}

This thesis explores how to support remote collaboration through video conferencing in the design and creation of physically fabricated objects. Online open-hardware communities formed around projects for 3D printable tools and objects remotely work together on improving designs, critiquing physical prototypes, and troubleshooting issues with 3D printing fabrication. Currently this remote communication commonly takes place via asynchronous text posts or live synchronous video conferencing. Thus, my thesis addresses how technology can support synchronous remote critique of physical prototypes. In this chapter, I provide background information on existing online communities and their communication challenges as motivation (1.1) to inform my thesis questions (1.2). I then discuss my methodological approach (1.3), and the scope (1.4) of this research. Finally, I outline my research contributions (1.5) and summarize the structure of this thesis document by describing the remaining chapters (1.6).

\section{I.I Background and Motivation}

\section{Online Digital Fabrication Communities}

Traditional design and manufacture of physical products requires specialized manufacturing equipment or tools not available to the average consumer due to cost, size, and required domain knowledge. Recently, access to tools such as desktop 3D printers 
(e.g., Makerbot ${ }^{1}$ ) has given everyday people the ability to produce physical objects at home or in "maker spaces". As at-home manufacturing has become more available, online open-hardware communities have formed around projects to share ideas, designs, design files, and experience using prototypes. Community members remotely work together on designing physical objects such as musical instruments (e.g., FFFiddle²), 3D printers (e.g., RepRap Project $\left.{ }^{3}\right)$, or prosthetic limbs (e.g., e-NABLE ${ }^{4}$ ). Their remote communication can take several forms each with differing strengths and weaknesses:

1. Computer Aided Design (CAD) Software. Designers use CAD software (e.g., AutoCAD ${ }^{5}$ ) to create and modify virtual 2D and 3D design files. Updated CAD files are shared through common file sending methods such as email or on filesharing services like Dropbox ${ }^{6}$. In addition, some commercial CAD software support collaboration through supplementary features, for example, real-time shared editing in OnShape ${ }^{7}$ or object version tracking in Fusion $360^{8}$. However, CAD software presents idealized virtual objects (e.g., perfect geometry and

\footnotetext{
${ }^{1}$ https://www.makerbot.com

${ }^{2}$ http://openfabpdx.com/fffiddle

${ }^{3} \mathrm{http}: / /$ reprap.org

${ }^{4} \mathrm{http}: / /$ enablingthefuture.org

${ }^{5}$ https://www.autodesk.ca/en/products/autocad/overview

${ }^{6}$ https://www.dropbox.com

7 https://www.onshape.com

${ }^{8}$ https://www.autodesk.com/products/fusion-360/overview
} 
clearances) and fabricated objects may differ from the ideal digital 3D model. Open-hardware communities need to share information from the physical world to help iterate on designs and troubleshoot fabricated objects.

Once a maker has fabricated a prototype, he or she needs ways to communicate about its physical properties (e.g., friction, surface quality) to others. 3D printed objects may vary from printer to printer due to a variety of real-world variables (e.g., temperature, vibration) not easily accounted for with CAD software. A common next step to provide additional detail and description of those physical properties and real-world variables is through text and/or images.

2. Text. Open hardware communities hold a variety of remote discussions through conventional online text-based mediums such as email or community forum websites. Community members seek help with fabrication issues (e.g., 3D print defects, 3D printer troubleshooting), propose new designs or modifications to existing designs, and provide feedback on the prototypes they are creating. One illustrative example is the popular online $3 \mathrm{D}$ printing troubleshooting guide ${ }^{9}$ created by the company Simplify3D.

${ }^{9}$ https://www.simplify3d.com/support/print-quality-troubleshooting/ 
Over-extrusion

Extruding too much plastic. This over-extrusion will result in excess plastic that can ruin the outer dimensions of your part.

Blobs and Zits Small blobs on the surface of print otherwise known as zits.

Table 1. Text descriptions of two 3D printing defects, "Over-extrusion" and "Blobs and Zits", from the Simplify3D online 3D print quality troubleshooting guide ${ }^{9}$.

Table 1 provides only portions of the text descriptions of two defects from the Simplify3D troubleshooting guide. It is difficult to distinguish between the defects as the text descriptions are similar; without accompanying images the text may lack enough detail to easily identify a defect. In the case of over-extrusion and blobs and zits from Table 1 the actual Simplify3D guide overcomes this potential issue by providing images for each defect that provide additional information in online communication about physical objects.

3. Static Images. Makers in open-hardware communities often share pictures of their fabrications (e.g., 3D printed parts, assembled prototypes). These pictures complement text communication and provide additional information such as an objects scale, close-ups of small or detailed features, or complex shapes. Figure $1.2^{10}$ adds images to the text descriptions of over-extrusion and blobs and zits

${ }^{10}$ Images reproduced from https://www.simplify3d.com/support/print-quality-troubleshooting/with permission 
previously discussed. Images allow for easy identification and comparison of 3D parts.

However, it can be difficult to rely on still images to depict other aspects of physical prototypes such as movement, assembly, or changing shapes. For instance, the one instruction guide for thermoforming ${ }^{11}$ (heat, shape, and form) the palm or gauntlet of a 3D printed e-NABLE prosthetic hand (gauntlet shown in Figure $1.1^{12}$ ) uses multiple images alongside detailed text instructions. The shaping requires working with malleable materials whose stiffness changes over time. When static images are insufficient in showing temporal effects it may be preferable to share video of the prototype.

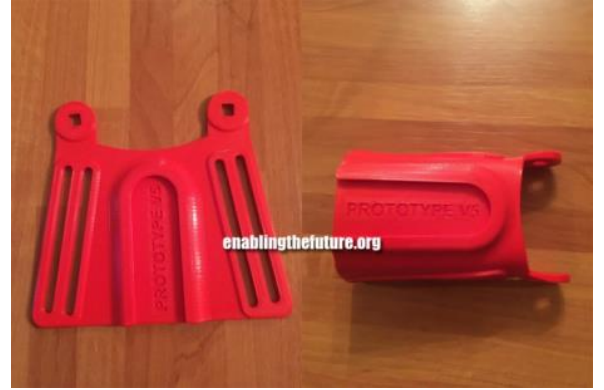

Figure 1.1. Gauntlet of a 3D printed prosthetic shaped through thermoforming. (Left) shows the original flat 3D print and (Right) shows the result of thermoforming the plastic by making the material malleable with hot water and manually shaping it.

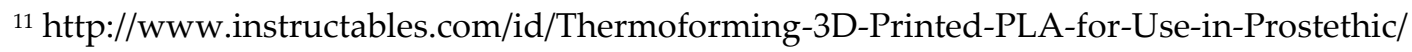

12 Image reproduced from http://enablingthefuture.org/2015/05/04/enabling-rd-thermo-forming-trials/ with permission 


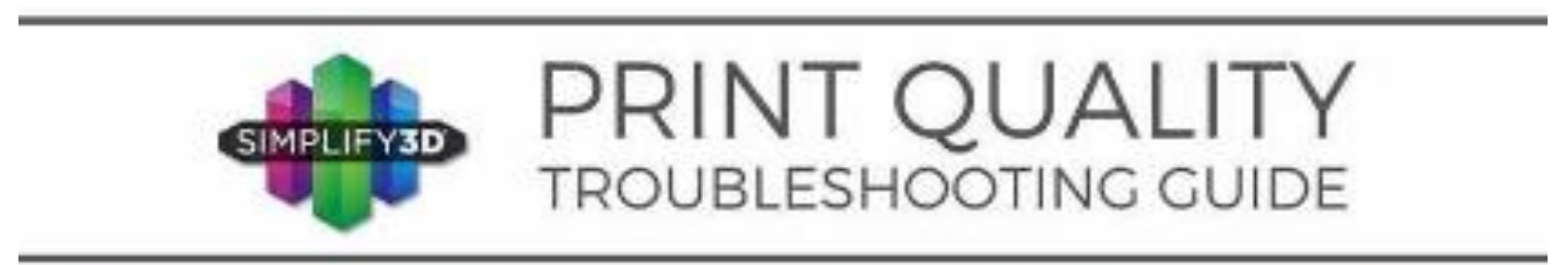

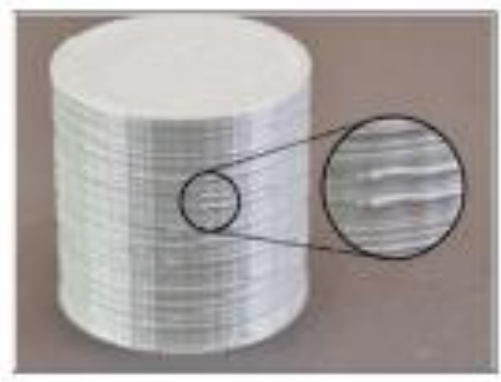

Blobs and Zits

Sertat tobes co the surtace at prink utherwee kanden as ms

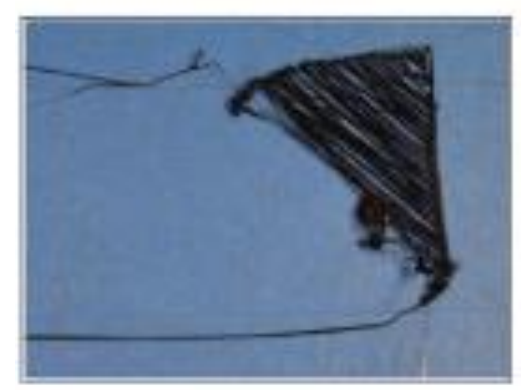

Not Sticking To Bed

The frst laser does not stici in she bet and the pont quadoy tass

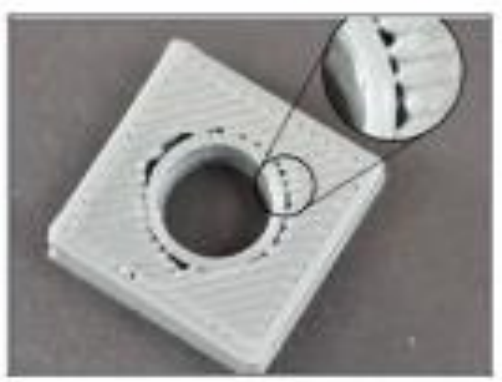

Gaps Between Infill and Outline Gaps neween the outine of ne part and the culer solin inte lyets

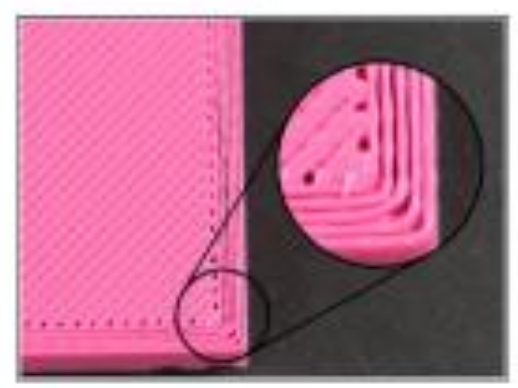

\section{Under-Extrusion}

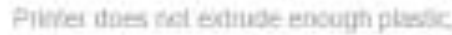
gaps helween perimerters asd infl

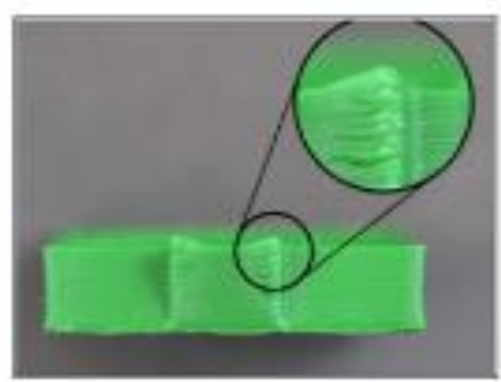

\section{Curling or Rough Corners}

Comess of the print iend la cin and oefom afler they are prikiet

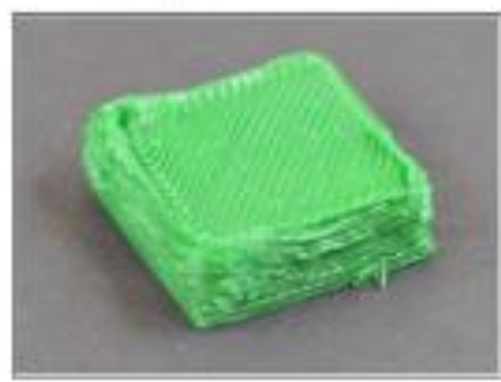

\section{Over-Extrusion}

Priefer eatudes bo fach plastic, pinis locks very measy

www.simplify3d.com/support'print-quality-troublcshooting'

Figure 1.2. Example 3D printing defect images and text from an online 3D print quality troubleshooting guide: www.simplify3d.com/support/print-qualitytroublshooting. (Bottom Right) "Over-extrusion" and (Top Left) "Blobs and Zits" textonly description of these print defects are in Table 1. 
4. Pre-recorded Videos. In some cases, community members record and share videos of fabricated objects. Videos let makers show objects in action, such as showing a prosthetic grabbing and picking up a bottle. In previous example of the thermoformed gauntlet (Figure 1.1), instructions are given through recorded video. The online repository ${ }^{13}$ for the thermoformed gauntlet provides CAD files along with video instructions ${ }^{14}$ (length 5 min $26 \mathrm{sec}$ ) without additional static text, captions, or image instructions.

Yet, pre-recorded video limits feedback and discussion to asynchronous responses through text, images, or additional pre-recorded videos. In some scenarios, asynchronous responses may be slower than needed. For instance, when a designer is trying to quickly iterate on a new feature they may not want to wait for delayed feedback to their recorded video. If the feedback is important to the designer they may have to stop work on the product while they wait for responses. In cases like this it may be beneficial to work through live video conferencing rather than recorded videos.

5. Live Video Conferencing. Live video links are used for general communication as well as to communicate with and about physical objects. For example, the

${ }^{13}$ https://www.thingiverse.com/thing:1391441

${ }^{14}$ https://youtu.be/BihhKHjguZY 
e-NABLE open-hardware project designs and prints prosthetic upper limbs for children with upper limb differences. The group holds live 'Town Hall' meetings via Google Hangouts ${ }^{15}$ video conferencing software where members discuss topics such as education or community outreach. In addition, e-NABLE also discusses and critiques 3D printed prototypes in Town Hall and Research and Development (R\&D) video conferencing meetings.

It is this last item-live videoconferencing - that I focus on in this thesis. While video conferencing provides a good opportunity to communicate prototype critique, it can still be challenging to effectively show physical object behavior and material aspects of a prototype. I focus on the critique of fabricated physical prototypes via live synchronous video conferencing for an audience where the audience does not have access to the physical prototype under critique. To explore this, I look to critique in the world of openhardware, where hobbyists, novices, and a myriad of professions collaborate and work together to design one thing. Research on this emerging field of online collaboration is substantial, covering a range of topics such as crowdsourcing critique for graphic designs (e.g, Luther et al., 2014, Yuan et al., 2016), or communicating about physical objects (e.g., 
Licoppe et al., 2017). Thus far no research has addressed the specific context of my research problem-communication in remote critique of physical prototypes.

Getting feedback and critique of prototypes is an important part of the design process. Because open-hardware community members are geographically distant from each other, they resort to video communication. This presents a set of challenges that I detail and describe in Chapter Three and Chapter Five. To focus my thesis within the broader topic of critique and communicating about physical prototypes, I present several focused thesis questions in the next section.

\section{I.2 Thesis Questions}

The overarching research question of this thesis is-how can technology support synchronous remote critique of physical prototypes? To address this question, I explored how people critique prototypes using current video conferencing systems. My thesis details how people communicate using current systems and proposes ways to improve such systems. Here I provide specific research questions to support my overall research problem:

Thesis Question 1: How do end-users communicate critique of physical prototypes over video conference? 
By determining how end-users use existing technology to perform their critique in remote situations I can identify existing issues that new technology may be able to address.

Thesis Question 2: How do end-users communicate physical details through video conferencing? Video communication is a broad topic. I focus on my research problem by concentrating on the points that specifically matter to critique and physical objects - physical details and prototype performance.

Thesis Question 3: How should technology be designed to support remote collaboration around physical prototypes?

In this thesis, I address this question informed by answers to my first two thesis questions. I discuss key factors that system designers should account for to better support video communication around physical objects. Moreover, I answer this thesis question by outlining implications on research-how is research in this domain impacted by this thesis-and not purely system design. 


\section{I.3 Methodological Approach}

The thesis questions described previously are all related to aspects of communication in dealing with physical products. In Table 2, I list how I dealt with each of my thesis questions. To address my thesis questions, I used qualitative methods for much of my analysis. Critique, especially the informal critique discussed in a previous section, is not well suited to quantitative measurements such as task completion time or error rate. As critique is subjective and based on opinion it is difficult to measure and compare one person's performance as there is no definitive answer or truth to a design problem (i.e., a wicked problem (Buchanan, 1992; Rittel \& Webber, 1973)) and thus a critique cannot be more or less correct.

Thesis Question Methodological Approach

TQ1. How do end-users communicate Observation of real world practice critique of physical prototypes over video conference?

TQ2. How do end-users communicate Observation of real world practice and physical details through video observational lab study conferencing?

TQ3. How should technology be designed to support remote collaboration around physical prototypes?

Table 2. Methodological approach to each of my thesis questions. 
To connect my thesis back to a real-world context I looked to existing collaborative online communities as discussed in the background and motivation earlier in this chapter. I observed video conferences and videos from e-NABLE, an online open-hardware community that designs, prints, and produces 3D printed prosthetic limbs for children with upper limb differences.

Ultimately, the observation of an open-hardware community gave me a starting pointI could see that members of the community had difficulty delivering feedback and critique about physical details to their remote audience and managing the remote experience (e.g., not keeping the prototype in frame). However, my observations of e-NABLE were insufficient to answer thesis questions $T Q 2$ and $T Q 3$ properly. In addition, my observations did not include any co-located critique as a point of comparison. To address my thesis questions, I wanted to observe repeated discussion of the same physical details to look for patterns. However, e-NABLE discussed different objects with each new conversation. As people fabricated, assembled, and used their own local prototypes, physical qualities were often unique and only available at their location. For example, two different prosthetic users may have the same version of hand prototype, but each prototype has unique physical details, and will fit differently on their respective residual limb. 
Informed by my observations of e-NABLE, I designed and ran an observational lab study to address $T Q 2$ and $T Q 3$. I further explored the specific scenario of critiquing physically printed prototypes by having participants give their feedback and opinions on pairs of 3D printed prosthetic limbs to a co-present audience and a remote audience. This more tightly controlled the scenario of a physical prototype critique to encourage repeated discussion of physical components.

\section{I.4 Context and Scope}

The content of this thesis lies at the intersection (as shown in Figure 1.3) of:

1. Collaborative Prototype Critique

2. Material Experience

3. Remote Collaboration on Physical Tasks

Overall, I tackle a scenario of collaboration that includes critique of physical objects in remote situations. Each of these research domains covers a wide range of fields but contain subsets of research that exist within the overarching Human-Computer Interaction (HCI) field within computer science that I am focused on. 


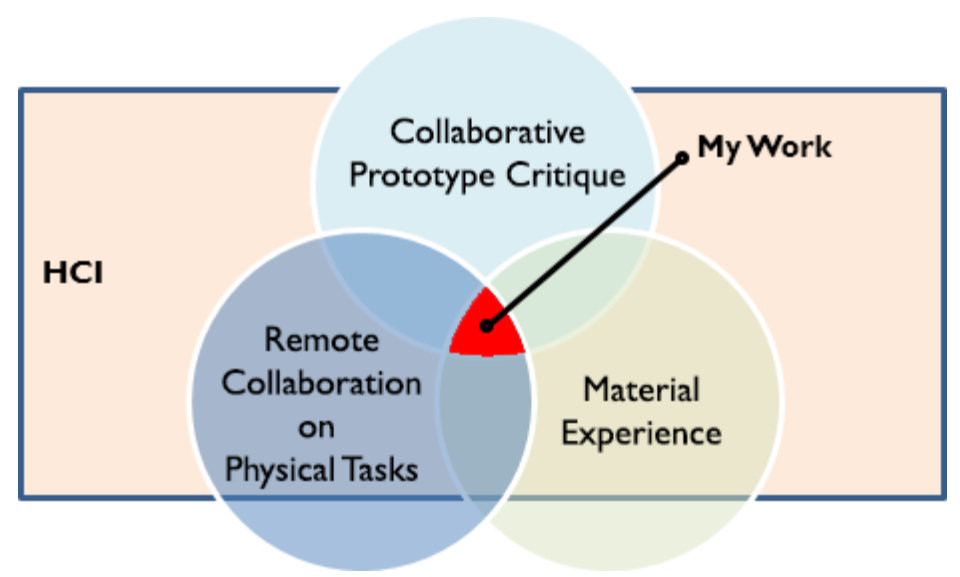

Figure 1.3. Human-computer Interaction $(\mathrm{HCl})$ is the overarching domain of this thesis. My work lies in the cross section of collaborative prototype critique, remote collaboration on physical tasks, and material experience.

\section{I.5 Research Contributions}

This thesis has four main contributions within the domain of critiquing physical prototypes for a remote audience. The contributions of this thesis are based on my findings and discussions of 1) an observational account of real-world remote communications around physical prototypes and 2) an observational laboratory study of participants providing critique of physical prototypes for a remote audience.

- Contribution 1 (CB1): An observational account of how critique of physical prototypes takes place within e-NABLE, an open-hardware community that designs, prints, and delivers 3D printed prosthetics to children with upper limb differences. 
- Contribution 2 (CB2): A description of the challenges of performing critique on a physical prototype for a remote audience based on the results from an observational lab study of participants.

- Contribution 3 (CB3): Details of how participants communicated about aspects of physical prototypes when performing critique for a remote audience. This includes strategies that participants used to overcome the challenges described by $C B 2$

- Contribution 4 (CB4): Design implications for future technology and research dealing with remote communication about physical prototypes and material experience.

Thesis Question

TQ1. How do end-users communicate critique of physical prototypes over video conference?

TQ2. How do end-users communicate physical details through video conferencing?

TQ3. How should technology be designed to support remote collaboration around physical prototypes?

\section{Contribution}

CB1

CB2, $C B 3$

CB4

Table 3. My thesis contributions which address each thesis question.

\section{I.6 Document Overview}

Chapter One: Introduction provides the context, motivation, and accompanying thesis questions for the main question that this thesis addresses-how can technology support synchronous remote critique of physical prototypes? This thesis continues as follows:

Chapter Two: Related Work presents an overview of previously published work related to the topic of remote critique of physical prototypes. I discuss the opportunity to 
apply the lens of material experience to remote communication. Next, I provide an account of how research-to-date has looked to address remote collaboration on physical tasks. I detail how the tasks used in this past work may fail to address the subjective openended communication found in a prototype critique scenario. Finally, I discuss the nature of current technology that supports prototype critique in collaborative environments.

\section{Chapter Three: An Observation of Remote Critique in Practice: e-NABLE Open-}

Hardware Community gives an account of how e-NABLE makes use of video conferencing to discuss fabricated prototype prosthetic hands. I discuss key aspects that shape the show-and-tell remote communications of e-NABLE as a range of contributors share their thoughts, feedback, ideas, and opinions on a variety of e-NABLE designed prosthetics.

Chapter Four: Study Design and Procedure provides a detailed description of the observational lab study that I designed and ran. In this chapter, I also provide rationale for my study methods and how I chose to capture and analyze collected data.

Chapter Five: Study Findings presents the results of my study from Chapter Four. I discuss the difficulties that participants faced when giving critique such as the challenge of splitting attention between the physical prototype, the remote audience, and the video conferencing software. Furthermore, I depict behaviors that participants exhibited during their critique. In some cases, these behaviours worked as strategies to overcome 
challenges with performing for a remote audience. At other times, participant behaviour hindered their presentations or highlight difficulties.

Chapter Six: Implications for Design and Research begins by laying out key aspects of critique of physical prototypes for a remote audience that can be supported by technology. I offer examples for how current technology may be applied to the context of remote critique with a focus on the end-user performing and delivering their critique. Finally, I look at how my methodological choices, such as using complex rather than simple study objects, can be usefully applied to future research dealing with collaborating around physical prototypes.

Chapter Seven: Conclusions and Future Work concludes this thesis by revisiting the thesis questions and contributions introduced in Chapter One. In addition, I provide forward looking possible future technologies that allow better communication of remote material experiences and more effectively support remote collaboration around physical objects. 


\section{Chapter Two: Related Work}

In this chapter, I provide an account of past research relevant to my thesis and discuss how it relates to my work. I discuss related work on materiality, remote collaboration around physical objects, typical physical study tasks, and collaborative prototype critique in practise.

I begin with a discussion of literature on materiality and material experience. Understanding how people experience and interact with materials provides a basis for considering how to handle and communicate about physical objects.

Next, I show how past research systems that support remote communication with physical objects while performing physical tasks. First, I describe several research systems that allow for remote communication of physical properties (e.g., position, bending). Then, I discuss how these systems are commonly tested and evaluated through physical study tasks.

Finally, I discuss how collaborative critique of prototypes currently takes place in professional and novice settings, including the types of technology used and the ways in which critique or feedback are communicated. 


\section{I Interacting with Material}

Experiences with material forms and properties are a fundamental part of how we understand and interact with objects (e.g., Giaccardi \& Karana, 2015; Karana, Giaccardi, Stamhuis, \& Goossensen, 2016; Wiberg et al., 2013). Materiality or the material experience is an emergent topic of interest in $\mathrm{HCI}$ research, highlighting how designers might leverage physical materiality to construct an end-users experience of an interface or tool.

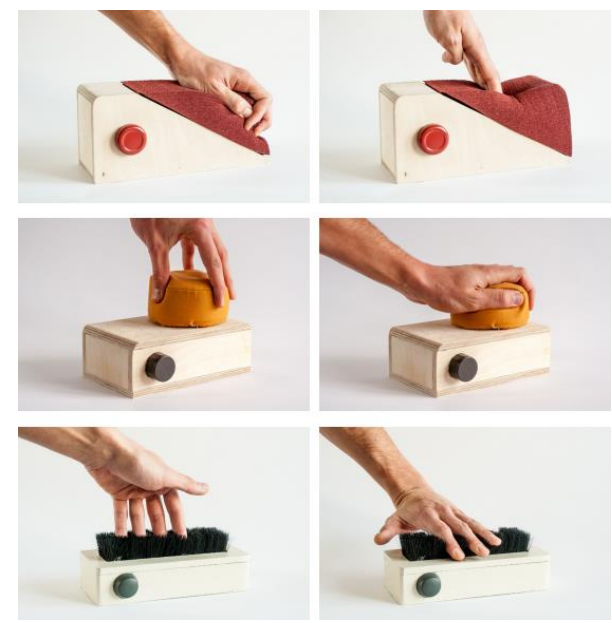

Figure 2.1. Karana et al. (2016) depiction of a designer exploring a variety of material experiences to help design a radio tuner. (Top) Kneading of foam attached to the radio. (Middle) Kneading and squeezing of foam that could be detached from the radio. (Bottom) Bristles or hairs that can be swiped or caressed from side to side.

For instance, Karana et al. (2016) discussed a designer's exploration of possible material interaction for tuning a radio as shown in Figure 2.1 ${ }^{16}$.

In Karana et al.'s discussion, they proposed a framework of four material experiential levels: sensorial (e.g., warm), interpretive (e.g., calming), affective (e.g., desire), and performative (e.g., stroking, caressing). As a way to show how a designer explores those material qualities for tuning a radio they show 18 different material examples (e.g., silicon

${ }^{16}$ Figure reproduced from Karana et al. (2016) (p. 629) 
cup, metal colander, low density foam). This work highlights how understanding material experience within $\mathrm{HCI}$ can lead to interesting and new physical interface design. Outside of the realm of $\mathrm{HCI}$ other domains are also interested in the discussion of material experience. For instance, Dant, (2008) identified ways in which a consumer interacts with the materiality of a product-pausing for thought, perception and interpretation, orientation, gesturing, and manipulating. Dant explored the interactions people have with physical materials and objects through two detailed examples of the personas Rachel and Roger.

First, he depicted Rachel's struggle to assemble flat-pack furniture. Second, he described the difficulties encountered by Roger in changing a cam-belt without access to a special tool normally required for the work. In both cases, Dant describes how the objects in each task, such as a bolt or belt, are understood and experienced, and what gestures surround them. Rachel uses the diagram instructions to make sense of the individual furniture parts, such as knobs and screws. Then, based on her knowledge from the diagrams, she reaches out to the available Allen keys and bolts to explore which key fits in to the heads of which bolts. Roger also needs to use touch and feel to understand parts of the car as many components, such as a rubber belt that is wound around various pulleys, are not visible due to occlusion from other car parts. Roger's understanding of the rubber material is important because if he takes it off the pulleys it reverts to a "featureless 
ellipse". Dant's work shows the importance of understanding how a product is experienced through its physical features.

My work addresses how an individual's 'conversation with materials' is communicated to another person. Specifically, my study expands on past work by observing how material experiences inform prototype critique and are conveyed in video-mediated settings.

\subsection{Remote Communication Systems for Physical Tasks}

HCI researchers have long been interested in developing technology to support remote collaboration on physical tasks-specifically addressing the challenge of grounding communication based on locally-present physical objects. For environments with multiple cameras, algorithms for automatic camera control (e.g., Ranjan, Birnholtz, \& Balakrishnan, 2007) can detect which parts of a space contain action, and switch to that view. Alternatively, a shared virtual representation can act as the basis for communication ( $\mathrm{O}^{\prime}$ Neill et al., 2005). While simple, this approach requires each participant to translate local experiences (e.g., troubleshooting a photocopier $\left(\mathrm{O}^{\prime} \mathrm{Neill}\right.$ et al., 2005)) into a representational abstraction. Instead of sharing a view, the remote helper could also control an independent view, for example, using robotic telepresence (e.g., Rae et al., 2014) or a drone (e.g., Jones et al., 2016). Highlighting objects within a scene can also ground conversation. For example, Fakourfar et al. (2016) evaluated different 
annotation techniques that are shared with a worker via head-mounted display and Norris et al. (2012) created CamBlend, which allows for pointing gestures between remote collaborators via selective focus and blurring techniques.

Tangibles (i.e. physical components) can synchronize physical attributes such as movement and rotation (e.g., Benavides et al., 2015; Pedersen \& Hornbæk, 2011), size (e.g., Mi \& Sugimoto, 2011), or shape (e.g., Leithinger et al., 2014) through physical components of corresponding objects at distributed work sites.

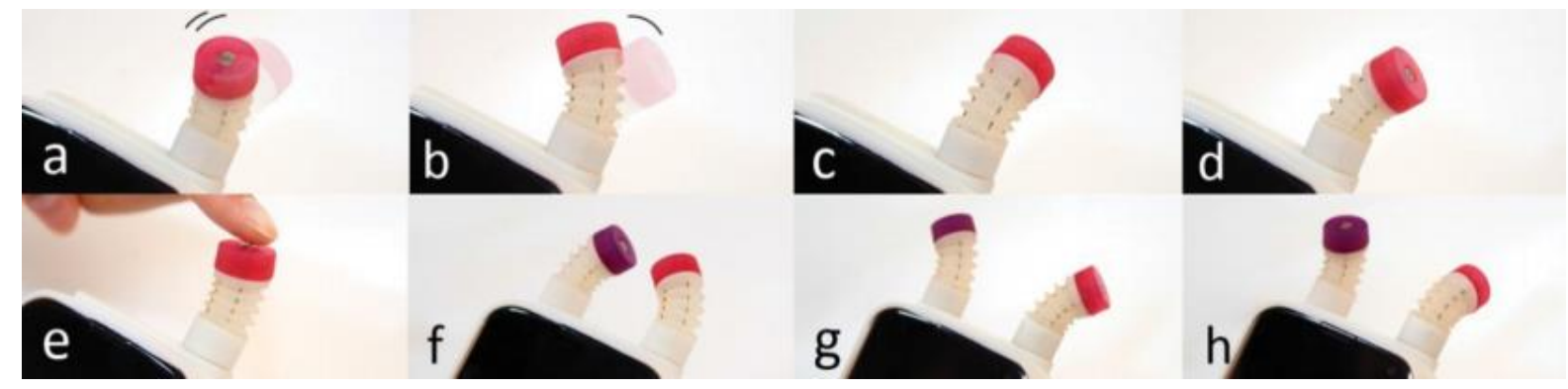

Figure 2.2. Wrigglo by Y.-W. Park et al. (2014). Physical movements of Wrigglo can be used to communicate expressions: (a) forward and backward (Yes), (b) side to side (No), (c) expansion (So what?), (d) forward (Huh? or Pointing right), (e) shrinking (Overwhelmed), (f) facing each other, (g) outwards, (h) crossing.

Tangible communication interfaces such as Wrigglo (J. Park et al., 2014) shown in Figure $2.2^{17}$ and Bendi (Y.-W. Park et al., 2015) allow users to communicate via synchronized tangible devices. In the context of discussing prototypes, the objects are actively being designed and iterated upon; the objects are often one-off fabrications or contain unique 
end-user customizations. In these settings, the object's unique materiality and response to human action is exactly what is unknown and under discussion. This makes it difficult to apply tangible systems such as Wrigglo or Bendi.

Many of the issues dealing with remote collaboration on physical tasks identified by past work remain relevant for remote critique; I situate and contrast many of my findings in this wider body of work. However, my physical task-prototype critique-is fundamentally different from typical "helper-worker" collaboration on an instructional or systematic task.

\subsection{Collaborative Physical Tasks}

Most studies of remote communication with physical objects use construction or assembly tasks. In these tasks, an "expert" or "helper" typically provides step-by-step instructions or a description of a known end-state to a remote "worker" who assembles, fixes, or modifies physical materials at their location. These physical tasks may include building block assembly (e.g., Amores et al., 2015; Fakourfar et al., 2016; Higuch et al., 2016; Suzuki et al., 2016), construction tasks (e.g., Fussell, Setlock, \& Kraut, 2003; Fussell et al., 2004), repair tasks (e.g., Gauglitz, Nuernberger, Turk, \& Höllerer, 2014; Kraut, Fussell, \& Siegel, 2003), or object placement (e.g., Jones et al., 2016; Tait \& Billinghurst, 2015). While the helper has access to information about instructions or an end-state or 
goal, the worker lacks this information but instead has access to the physical media needed to complete the task.

There are a few examples where both collaborators contribute knowledge to the problem or solution. For example, Jones et al. (2016) evaluated a drone video conferencing system by having participants perform a "scan and search" task. While the remote helper was able to identify locations of markers from their aerial drone view, only the on-the-ground worker could identify the color of each object as shown in Figure 2.3 ${ }^{18}$. Thus, the pair needed to combine their expertise to complete the task successfully.

Tait and Billinghurst (2015) evaluated an

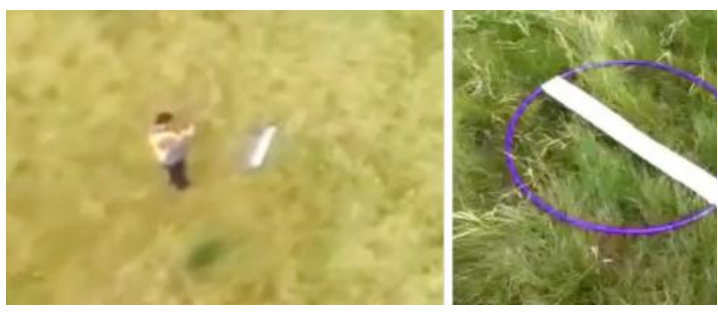

Figure 2.3. Views from a drone video conferencing system by Jones et al. (2016). Colors are only visible to the person in the field (Right) but not from the drone camera view (Left).

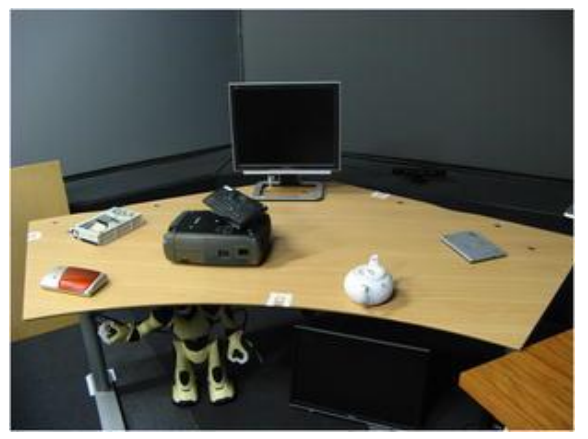

Figure 2.4. Workspace for local "worker". The worker uses an AR system developed by Tait and Billinghurst (2015) to help them place the objects on the desk in correct positions.

augmented reality (AR) system where a local "worker" uses an AR display that is annotated by a remote "expert" to help them place physical objects on a desk as seen in

\footnotetext{
${ }^{18}$ Figure reproduced from Jones et al. (2016) (p. 1128)
} 
Figure $2.4^{19}$. The task used six objects that were chosen because they were easy to distinguish visibly: a teapot, a DVD player, a conference controller, a projector, a hard drive case and a print server. The task of placing the objects could be completed in a stepby-step fashion, dealing with and placing a single object at a time. Each stage of the taskplacing the next object-can be performed independently from placing the other objects and it was easy to decide whether an object was placed correctly for the final goal state. The results of the study focus on aspects of accuracy and time performance, like many other studies that have collaborative physical tasks.

In this thesis, I look at people providing feedback on hand-held physical prototypes. Unlike assembly such as the Lego block assembly task shown in Figure $2.5^{20}$ or the object placement task in the study performed by Tait and Billinghurst (2015), prototype critique does not have a pre-determined process or outcome. Instead, participants were free to share their thoughts and opinions as they saw fit. Unlike a "helperworker" task, the person giving the review

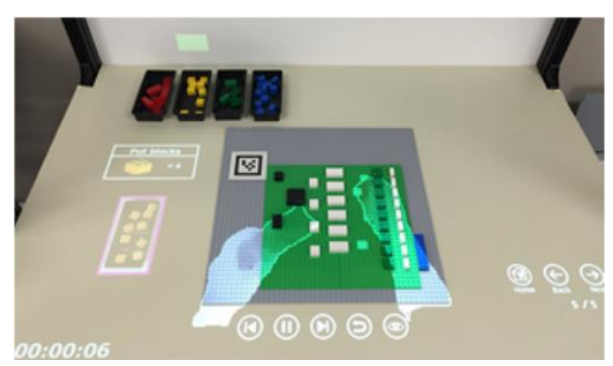

Figure 2.5. Projected hands developed by Suzuki et al. (2016). Hands of the 'helper' collaborator projected into the workspace of a 'worker' to support a worker in a Lego block assembly task.

${ }^{19}$ Figure reproduced from Tait \& Billinghurst (2015) (p. 571)

${ }^{20}$ Figure reproduced from Suzuki et al. (2016) (p. 13) 
has access to both key knowledge (their insights gained through material experience) and the physical artifact - the collaborator is primarily an audience.

\subsection{Prototype Critique in Collaborative Design}

Design critique is key to the collaborative design process. Critique often occurs during a design review - a meeting where the team assesses and discusses design documents in reference to expectations, requirements, and goals (Sater-Black \& Iversen, 1994). Both professional software (e.g., Autodesk Design Review ${ }^{21}$ shown in Figure 2.6) and research systems (e.g., DDRIVE (Daily et al., 2000)) that support design reviews are often centered around virtual CAD models. However, not all features of a design can be fully captured or evaluated in a virtual representation. Physical prototypes are still important to check real-world performance, tolerance, clearance, manufacturing precision, and ease of human assembly (Bousseau et al., 2016; Brereton \& McGarry, 2000; Faas et al., 2014; McKoy et al., 2001).

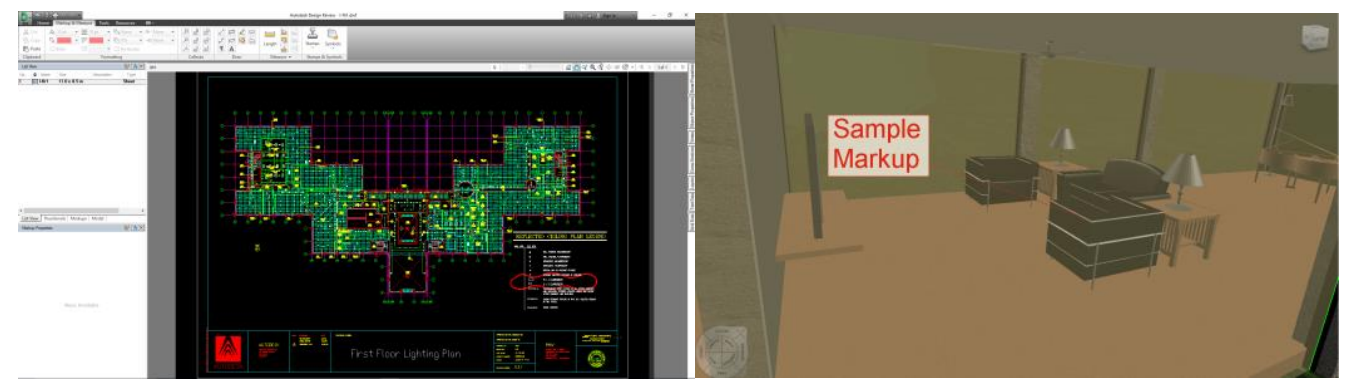

Figure 2.6. AutoDesk Design Review allows for additions such as comments, markup, and drawings to be on top of existing 2D (left) and 3D (right) CAD files.

Collaborators can share the resulting files that include the additions.

${ }^{21}$ http://www.autodesk.com/products/design-review/overview 
Bousseau et al. (2016) observed fabrication and prototyping conversations between collocated novice 'prototypers' working in leader-assistant pairs. Study participants took part in a one-day design charrette where they ideated concepts, presented their concepts to a jury, documented the concept for fabrication, and finally fabricated the object together with an assistant (Figure $2.7^{22}$ shows example output from each step in the process). Bousseau et al. (2016) found that participants' conversations alternated between one-way presentations of design concepts and back-and-forth critiques. They suggest that remote collaboration tools support these shifting modes by including "specialized visualization, pointing, and annotation tools." These are potentially good suggestions for supporting remote critique and collaboration, but the study did not have participants participate in a remote condition. In this thesis, I focus on the remote aspects of collaborating around fabrication.
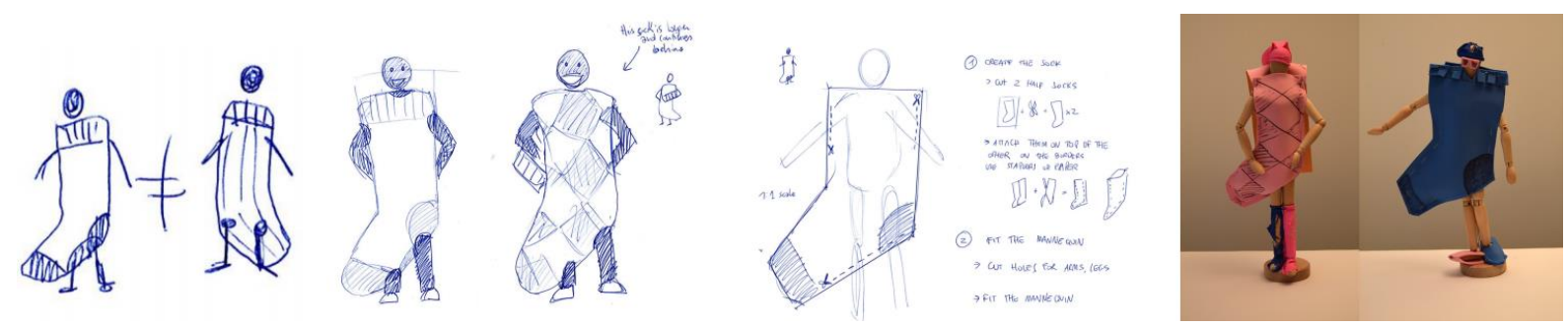

Figure 2.7. Example of design process from sketch (Left) to prototype (Right) produced in a one-day design charrette. Bousseau et al. (2016) studied how participants communicated critique and feedback with collocated partners.

22 Figure reproduced from Bousseau et al. (2016) (p. 401) 


\subsection{Chapter Summary}

In this chapter, I outlined and discussed related work pertaining to my thesis; materiality, technologies supporting physical communication, physical study tasks, and collaborative prototype critique in practise.

To begin, I outlined the literature on interacting with and experiencing materials. I showed that the literature presents material experience as an important aspect of understanding how people work with and experience objects. Material experience is an emerging topic of importance in HCI and my thesis extends this work into the domain of remote collaboration with physical prototypes.

Next, I described several technologies developed in past research to provide remote physical communication in some form. I discussed some of the limitations those technologies have in terms of dealing with physically fabricated (e.g., 3D printed) prototypes. Following discussion of the technology I then gave an overview of the common types of physical study tasks used to assess these types of systems.

Finally, I presented past research and real-world system support showing the importance of including feedback and critique as part of the collaborative process of designing physical products.

In the next chapter, I discuss an observational account of real world critique of physical prototypes in the open-hardware community e-NABLE. 


\section{Chapter Three: An Observation of Remote Critique in Practice: e-NABLE Open-Hardware Community}

To properly address my overarching thesis problem-how can technology support synchronous remote critique of physical prototypes - I first needed to understand how people communicated critique of physical prototypes. This led to my first thesis question. TQ1: How do end-users communicate critique of physical prototypes over video conference? To answer this, I looked to existing prototype critiques from e-NABLE, an open hardware community. I chose to look at e-NABLE as it is a large active open-hardware community (9657 Google+ members $\left.{ }^{23}\right)$. e-NABLE functions as a group of distributed volunteers that design, fabricate, and deliver 3D printable prosthetic limbs to children with upper limb differences (Figure $3.1^{24}$ shows the Raptor Reloaded,

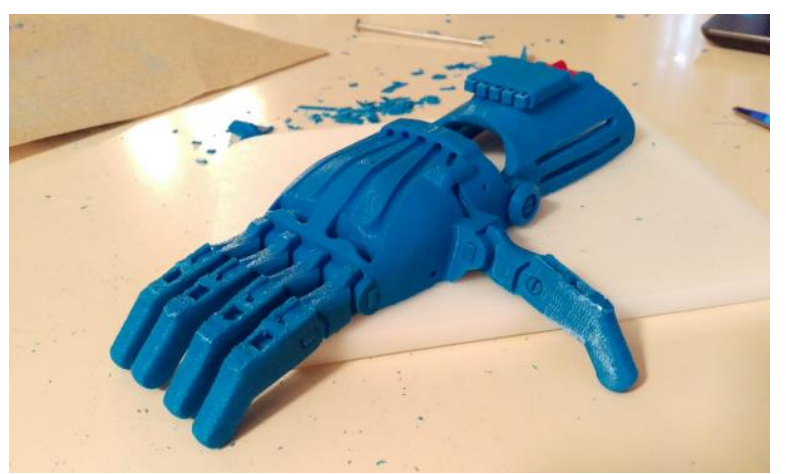

Figure 3.1. A partially assembled 3D printed prosthetic hand-the Raptor Reloaded design from e-NABLE.

${ }^{23}$ Number of members as of April 20, 2017

${ }^{24}$ Photo by Kevin Jarrett from https://flic.kr/p/ALZ6Ux. Creative Commons:https://creativecommons.org/licenses/by/2.0/legalcode 
an example of one of e-NABLE's designs). In the following sections of this chapter I discuss e-NABLE and their video conferencing practises when dealing with physical prototypes.

\section{I Methodology}

I examined the five most recent (as of August 31, 2016) available Town Hall videos from the e-NABLE Google+ Community and the five most recent (as of August 31, 2016) R\&D videos recorded by R\&D member "Trouble Sturm" 25 (full list in Appendix B.2). Trouble Sturm hosts the R\&D video conferences and records and posts some of the recorded videos to their Youtube account. Furthermore, I generated an additional sample list of 17 videos (full list in Appendix B.3), duration average $=4 \mathrm{~m} 22 \mathrm{~s}$, $\min =20 \mathrm{~s}, \max =12 \mathrm{~m} 58 \mathrm{~s}$ ) by looking through the e-NABLE Google+ community postings as well as searching Youtube for keywords related to the e-NABLE community such as 'e-NABLE', '3D printed prosthetic', and ' $3 \mathrm{D}$ printed hand'. In addition, I searched for videos using the names of popular e-NABLE recommended prosthetic hand designs such as 'raptor reloaded', 'phoenix hand', and 'cyborg beast'. From the results, I focused on those videos shared by e-NABLE community members that focused on discussing physical prototypes where the physical prototype was present in the video.

${ }_{25}$ Trouble Sturm's Youtube channel https://www.youtube.com/channel/UCj-DMhfRmg1nWelE8AaE7lg 


\section{2 e-NABLE Video Conferencing}

The e-NABLE Town Hall and R\&D meetings can have 20 or more virtual attendees. The Town Hall meetings include topics such as general discussion about the community, talking about e-NABLE in the news, or having prosthetic end-users share their experience. R\&D meetings tend to be more focused on the prosthetic prototypes with discussion of subjects such as considering new materials, showcasing new designs, and giving feedback on prototypes. When someone shows off a new design or critiques a prototype, it is generally a one-sided "show-and-tell" presentation, as opposed to a backand-forth dialogue. While members of the audience occasionally ask questions, they generally do not interrupt or interact with the presenter. I saw in the video conferencing software that the audience shared webcam views of their faces while they listened to the presentation quietly. Several factors contribute to this one-way presentation.

1. Presentations can occur at various points during a prototypes design and in many cases only the person presenting a modification or new design would have the fabricated prototype. Although e-NABLE is an open-hardware group and designs are shared openly and freely work may be done by an individual before sharing to the community. Thus, when an individual first shares their new or modified prototype as a fabricated object for the first time no one else would have yet had the opportunity to create that prototype for herself or himself. 
2. Even when a more developed prototype is under discussion not everyone may have fabricated that prototype in particular. There are many prototypes listed as options on the e-NABLE website-nine wrist-powered ${ }^{26}$, three elbow-powered ${ }^{27}$, two partial-finger variants ${ }^{28}$ etc. Community members cannot be expected to fabricate all versions of a prototype prior to remote discussion of a given prototype. In addition, certain prototypes are designed for children with different abilities and for specific tasks and members may have an interest in some prototypes over others, therefore, only producing a subset of prototypes.

3. Fabricating prototypes is not the same as compiling shared code open-source software. Open-source software allows for anyone compiling from the same source code to get an identically functioning program as any other person compiling the same source code. However, in the case of physical fabrication even when a prototype design is stable each person creating the prototype can encounter important differences in their produced objects. For example, one person's 3D printer might have cooling issues that causes plastic to droop into a joint during printing, thereby producing increased friction in the fingers or wrist

${ }^{26} \mathrm{http}: / /$ enablingthefuture.org/wrist-powered/

${ }^{27} \mathrm{http}: / /$ enablingthefuture.org/elbow-powered/

${ }^{28} \mathrm{http}$ ://enablingthefuture.org/single-finger-designs/ 
of a prosthetic. In other instances, how one person assembles their prototypepulling strings too tight, or bending a component too far or too little-results in their prototype behaving differently from others. Thus, when someone presents a prototype on video conference only that person has the full experience of the physical object.

I determined several key aspects of the "show-and-tell" presentations through repeated observation of e-NABLE video conferencing usage. I discuss each of these factors in the following sections: open-ended communication, range of contributor expertise, physical complexity of the objects, and prototype version comparisons.

Open-ended Communication. Presenters freely articulate their prototype critique. Whereas a product development team within a company might have formal methods of testing and planning around prototypes (Ulrich \& Eppinger, 2015), e-NABLE prototype presentation and discussion occur more "naturally". The unregimented meetings in an open-hardware community such as e-NABLE may not follow any formal methods of prototype critique found in professional settings. Presenters are free to share their thoughts, feelings, and opinions without any requirement to stay on track. 
Range of Contributor Expertise. Creating physical objects is no longer limited to design professionals or companies with manufacturing capabilities. For example, presenters in Town Hall meetings include hobbyist designers and makers, and prosthetic recipients (usually children). In addition, there are presenters, which are professional engineers, designers, and prosthetists. Thus, in many cases, both the person giving and receiving a critique have different forms of "expert" information about the prototype. A person receiving critique may be part of the design team and understand the rationale behind the current design; the person providing the critique may have real-world day-to-day experience with limb differences that needs to inform the next design iteration. A good example of this scenario within the e-NABLE video conferences is when children participate to give their feedback either as end-users of the prosthetics or as makers (some schools offer e-NABLE after school printing and assembly activities). This set of community members may not have expertise in engineering or design but still bring valuable information and experience on the use of the prototype and experience of creating and assembling the prototypes. End-users can discuss how they are able to use the prosthetic hands to perform certain tasks that may not have been considered by a non-user. For instance, in the video "e-NABLE Prosthetic Update: Tying My Shoes"29 an

${ }^{29}$ https://www.youtube.com/watch?v=AUgG6zNI9zU 
end-user compares tying their shoes using their "baby hand" (residual hand) and their e-NABLE prosthetic. The video shows the user having some difficulty using the prosthetic compared to their residual hand though they are optimistic that with practise they will improve on using the prosthetic hand. From my sample of e-NABLE Town Hall and R\&D meetings this type of task was not discussed as discussion seemed to tend towards tasks that included grasping such as picking up a cup or holding a toy.

Physical Complexity of Objects.

The e-NABLE prosthetic hands are physically complicated objects. One popular model, The Raptor Hand, has a reference website $^{30}$ which details 20 different off-the-shelf parts (full list in Appendix B.1 Cyborg Beast Hand Materials Kit List) to buy, a 3D printable parts reference for 30 parts (Figure 3.2), a one- hour instructional YouTube video

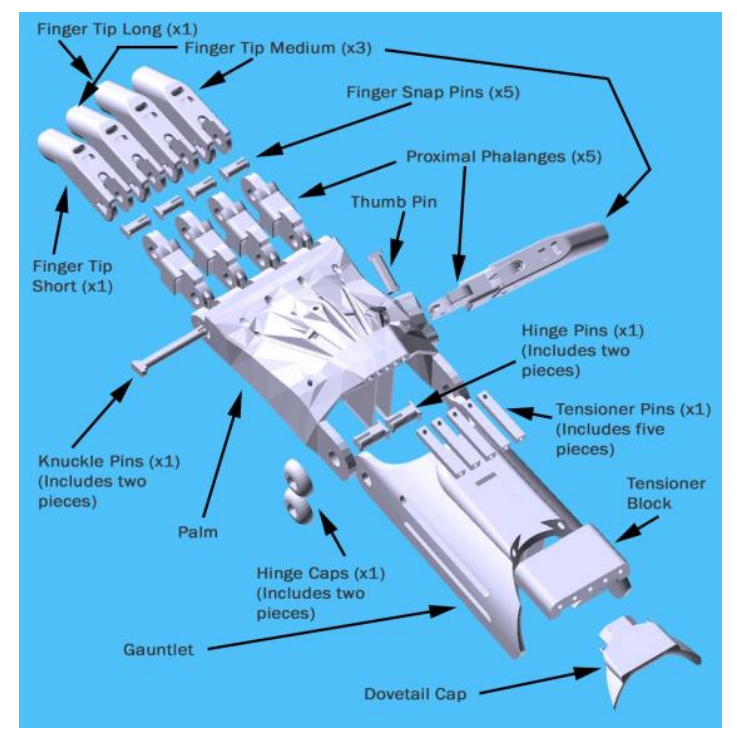

Figure 3.2. 3D printed parts reference for the Raptor Hand from

http://enablingthefuture.org/upper-limbprosthetics/the-raptor-hand. This is an example of the complexity of the e-NABLE prosthetic hands by number (30) of required 3D printed parts. 
on assembly, elastic tying instructions, and detailed 3D printing instructions and 3D printer settings.

Beyond the sheer number of parts and instructions for assembly required, the prosthetic hands are also complex in their behavior. I describe the functioning of the wrist-powered prosthetic hands below to emphasize the complex assembly, behavior, and usage that eNABLE members must deal with when communicating through video conferencing.

At a high level, the hands function via wrist-powered actuation. On a closer look, there are many components working together to achieve the desired grasping motion (parts labelled in Figure 3.3 on the following page). A user's arm is strapped into the "gauntlet" portion and their residual limb is placed and strapped into the palm area. As the wearer bends their wrist the palm of the prosthetic hand is pulled, thereby pulling thread attached through joints to the fingertips that forces the fingers closed. Holding the wrist bent in this active position (power is being actively applied by the wearer) keeps the fingers closed; upon relaxing the wrist back to a neutral or passive position, elastic threads pull the fingers back into an open passive position. 


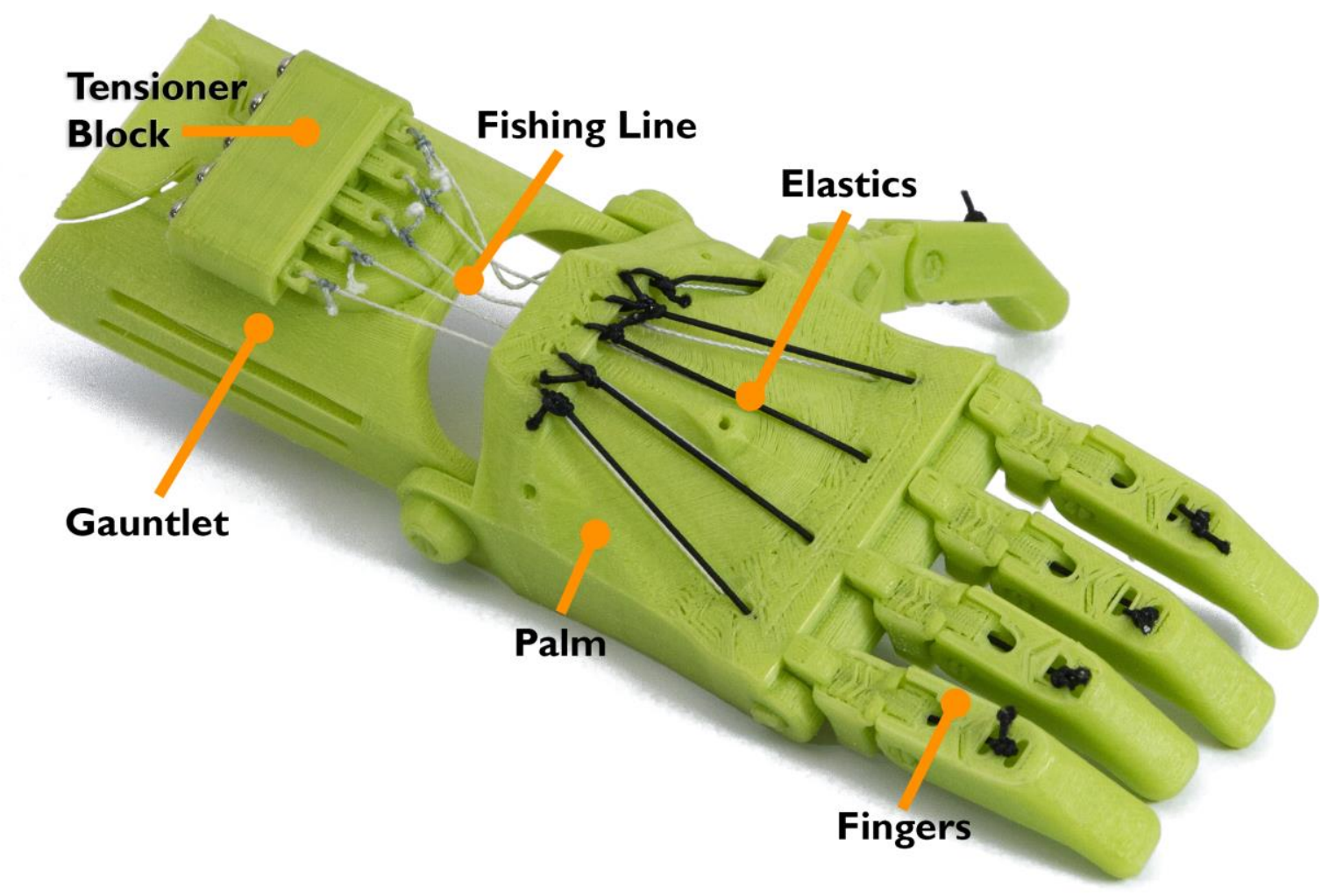

Figure 3.3. The Raptor Hand ${ }^{32}$ with labelled parts common to all e-NABLE prosthetic hand designs. The gauntlet and palm are fastened to the user's arm and residual limb. The user bends their wrist to pull fishing line held in place by the tensioner block which pulls on the fingers to form a closed grip (active). When the user is not bending their wrist, elastics pull the prosthetic fingers to an open position (passive).

Prototype Version Comparisons. The e-NABLE devices page lists nine wrist-powered prosthetics, three elbow actuated designs, as well as task specific prototypes (e.g., a trumpet holder $\left.{ }^{31}\right)$. Some of the prototypes are evolutions or are variations on each other.

\footnotetext{
${ }^{31} \mathrm{http}: / /$ enablingthefuture.org/upper-limb-prosthetics/trumpet-holder-device/
} 
For example, the Raptor Reloaded ${ }^{32}$ is an updated version of the Raptor and Cyborg Beast hands based on user feedback and design improvements. Variations in design can be quite small or unnoticeable. For instance, part of the Raptor Reloaded update included efficiency improvements in 3D printing (i.e., less material, less time)

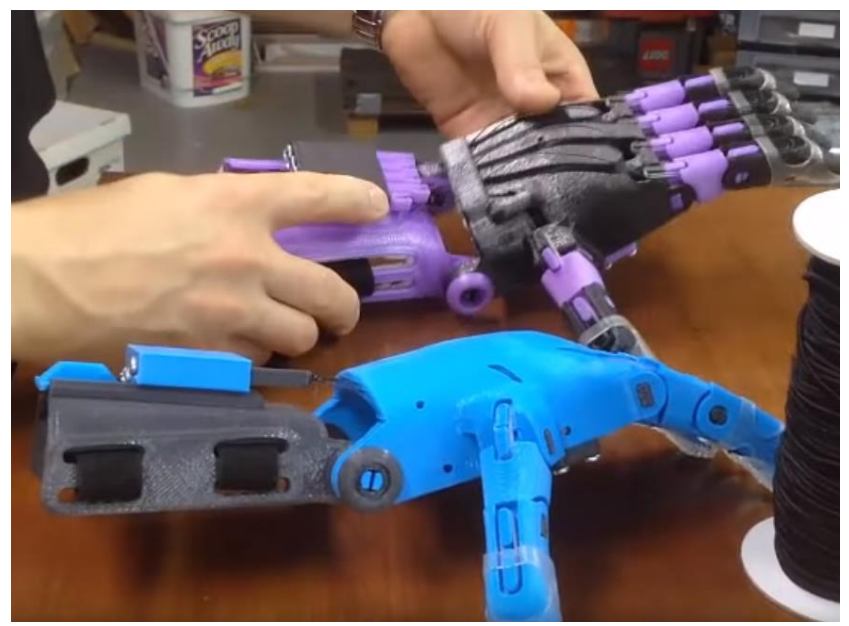

Figure 3.4. Still image ${ }^{32}$ from a video discussing two different styles of tensioner blocks and how they operate. Fabricated examples of each version are used for demonstration.

that are only seen by the person performing the fabrication of the prosthetic. Other design changes between prototypes are quite drastic such as the thumb orientation on the Phoenix hand that points away from the rest of the fingers (the bottom blue prosthetics in Figure $3.4^{33}$ shows this angle). When the thumb and fingers close this provides a different grip shape compared to other versions of the prosthetics.

e-NABLE community members sometimes provide feedback by comparing different designs or versions of prototypes during online meetings or videos (Figure 3.4 shows an example of comparison two physical prototypes on camera. However, managing

32 https://www.thingiverse.com/thing:476403

${ }^{33} \mathrm{https} / / / \mathrm{www} \cdot$.youtube.com/watch?v=dW5B_CeJtd8 
multiple prosthetics at once was a problematic task as presenters needed to be mindful of what was captured by their webcam.

\subsection{Chapter Summary}

In this chapter, I presented an observational account of remote critique of physical prototypes in practice. I focused on the use of live video conferencing by e-NABLE, an open-hardware community, that collaborates online as a group of volunteers to design, print, and assemble prosthetic hands for children with upper limb differences. I described and discussed five aspects of the remote critique I observed in this open-hardware community; show-and-tell critique, open-ended communication, range of contributor expertise, physical complexity of discussed objects and prototype version comparison. My observation of the e-NABLE community is a starting point to addressing my thesis problem-how can technology support remote collaboration for live critique of physical prototypes. By observing current remote critique practice we can find opportunities for technology to support "show-and-tell" critique presentations. However, it was difficult to answer my second targeted thesis questions. TQ2: How do end-users communicate physical details through video conferencing? In my observations of e-NABLE I witnessed discussion around many different prototypes and therefore a large variety of physical details. This made it difficult to come to conclusions on how people communicated about specific physical details as the details being discussed changed from conversation to 
conversation. To gather more consistent data, I designed and ran an observational lab study of critique of physical prototypes, where I controlled the physical prototypes and that I describe in the following chapter. 


\section{Chapter Four: Study Design and Procedure}

In the previous chapter, I provided motivation - the critique and communication practice of the online open-hardware community e-NABLE-for studying remote critique of physical prototypes. I found through observation that the community members of eNABLE had difficulty giving and receiving feedback on the various iterations of prosthetics. However, it is possible that the issues observed in e-NABLE are isolated to that group's communications. To build upon my understanding of physical critique at a distance, I designed an observational lab study, which I describe in this chapter, motivated by my second thesis question: how do end-users communicate physical details through video conferencing? (TQ2) I first discuss a pilot study, which helped inform my final study design. I then reiterate the goals of my study design based on my e-NABLE case study. Finally, I complete this chapter with a detailed description of my final study procedure including information on participants, materials, conditions, and data capture and analysis.

\section{I Study Design Rationale}

I discussed previously in Chapter One and Chapter Three that my observations of eNABLE were limited with respect to $T Q 2$ because of the variety of physical prototypes and therefore physical details being discussed. Additionally, to help answer TQ3, how can 
technology support remote critique, I wanted to study participants in a collocated scenario as an ideal situation for discussing physical prototypes. I was motivated to observe collocated communications and think of ways in which technology might bring elements from this collocated "gold standard" of communication to a remote setting.

To address my thesis questions, I wanted to provide a consistent set of physical objects as well as a consistent set of tasks. Using a consistent set of physical objects would let me see several participants working with the same physical details, thereby allowing me to see patterns and differences between participants as they communicated about a particular physical detail. In addition, I wanted to control the scenario so that I could focus on how the person with the prototype would communicate. I therefore, controlled one side of the communication by having only a single participant in each trial perform a critique for a researcher. This one-sided communication mimicked the "show-and-tell" style of video conference seen in e-NABLE meetings. In the following sections, I describe a pilot study I designed to take these factors into account and describe how I altered my study design based on learnings from the pilot. 


\subsection{Pilot Study}

I conducted pilot studies with three participants where I asked them to review and compare three types of 3D printed bottle openers. I chose bottle openers as the object to be critiqued as I could easily find unique designs, 3D print them as needed, they would likely be familiar to participants, and they were simple to operate and understand. I wanted simple objects because I felt that the complex nature of the prosthetic hands I saw in e-NABLE might be overwhelming for participants in my study. I thought that, for example, participants may have a difficult time inspecting all the various components and be unable to deliver meaningful critique. Figure 4.5 shows the three different types of bottle opener designs I retrieved from Thingiverse ${ }^{34}$ (a popular online portal for sharing 3D printing and other fabrication designs). I chose these designs by searching Thingiverse for "bottle opener", sorted by "\# of Makes" and taking the top three distinct
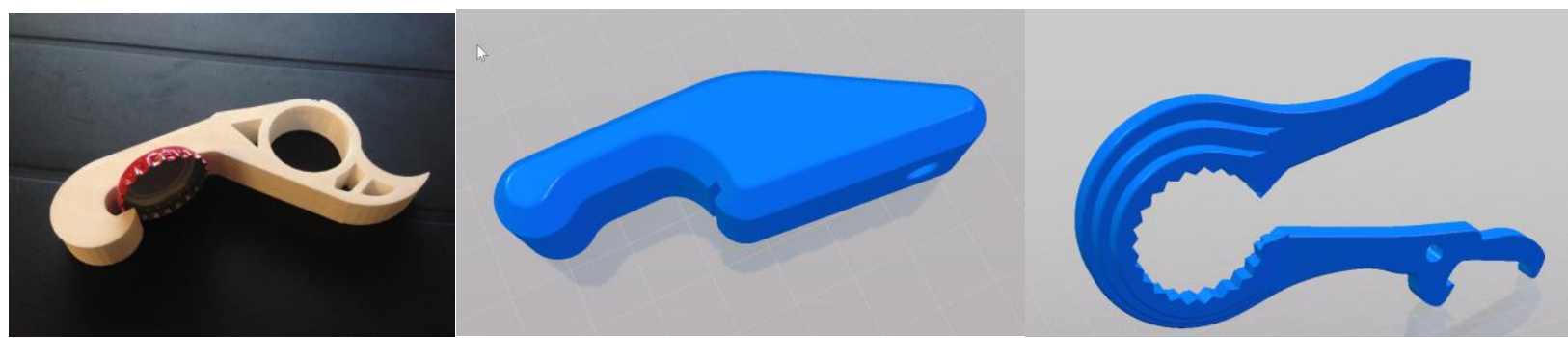

1.1 Figure 4.1. Three simple 3D printed bottle opener designs from Thingiverse ${ }^{34}$ used in my pilot study. (Left) Thing 269463 by Kart5a. (Middle) Thing 1842 by Starno.

(Right) Thing 1097099 by In3Designs.

${ }^{34}$ https://www.thingiverse.com/ 
designs within the top 10 results. I then 3D printed all three designs, each in a distinct colour.

\subsection{Pilot Study Procedure}

I ran each trial of the pilot with a single participant (three participants, one trial each). I first gave each participant the set of three 3D printed bottle openers and an empty glass beer bottle for reference. Each participant took a few minutes to become familiar with each design. As the participants explored the bottle openers, I answered any questions about how the openers were used. Once the pilot participants indicated they were ready to start, I briefed them on their tasks: "to provide opinions and feedback" on the bottle openers (i.e., critique) for another researcher. Each participant performed this critique in two conditions 1) face-to-face with the researcher and 2) video conferencing via Google Hangouts with the researcher. To elicit critique from the participants the researcher followed a set of questions asking about the bottle opener's usage, differences, and capabilities (researcher protocol in Appendix A.5 Pilot Study Interviewer Protocol). I informed the pilot participants that they would be delivering their critique to a researcher, not to another participant.

\subsubsection{Pilot Learnings}

In the pilot study, participants' brief, straightforward critiques no longer resembled the rich, complex presentations from the e-NABLE community. In the following section, I reflect on the design of my pilot study to determine why participants' critiques were so 
limited. While I validated many aspects of my study format, one key aspect from the eNABLE video conferences was missing - in my attempt to give participants an easy task I did not provide enough physical complexity.

\subsubsection{Validating the Study}

Show-and-Tell Critique. Although e-NABLE video conferencing had many members participating, the person with the physical object was the centre of attention. To replicate this one-sided presentation, I focused my study on the reviewer giving their critique.

Open-ended Communication My pilot participants were able to freely articulate their prototype critique, and not be confined to step-by-step instructions or a specific end goal. This allowed me to observe strategies or difficulties that only arise in relatively unstructured presentations.

Physical Comparisons. e-NABLE community members - especially prosthetic recipientsoften provide prototype feedback by comparing different designs or versions during online meetings. These comparisons provide valuable information on real-world usage to designers and help the community to iterate and develop on designs. In my study, I gave participants the task of comparing different bottle openers to help them form their critique. 
Range of Participant Expertise. Creating physical objects is no longer limited to design professionals or companies with manufacturing capabilities. For example, contributors in e-NABLE Town Hall meetings include hobbyist designers and makers, and prosthetic recipients. In the pilot study, I recruited novices who do not necessarily have experience with 3D printing or engineering design, to address how a non-expert end user might review a prototype.

Physical Complexity. The uncomplicated prototypes were based on a very simple mechanism (leverage to open a bottle) and a single, easy to perform interaction (all pilot participants mimed opening a bottle prop using the prototypes). The resulting simple conversations failed to sufficiently address my thesis questions from Chapter One: How do end-users communicate a critique of a physical prototype over video conference? (TQ1) The simplicity of the objects in the pilot study led to meager critique in terms of length (approximately 5 minutes) and depth. For my thesis question: How do end-users communicate physical details through video conferencing (TQ2), the bottle openers had few physical details, offering little basis for communication. Thus, to capture a more fully featured critique - that could address my thesis questions more wholly - I returned to my e-NABLE observations from the previous chapter. 
The e-NABLE community's nuanced remote prototype critiques are due in part to the complexity of the prototypes themselves. I needed to provide an opportunity for participants to work with non-static and less simple objects to answer my thesis questions about how people deliver critique and communicate about physical details remotely. This was the major lesson from my pilot study-using simple bottle openers failed to elicit a full or nuanced critique.

I improved my study design by having participants compare pairs of mechanically complex prototypes: e-NABLE prosthetic hands. These prosthetics are made of multiple parts, perform complex grasping functions that rely on physical properties (e.g., friction, resistance, material stiffness), and require hands-on experience to evaluate their effectiveness. I chose four e-NABLE prosthetic designs to use in my study (see Table 4) the Cyborg Beast ${ }^{35}$, Raptor Hand ${ }^{36}$, Raptor Reloaded ${ }^{37}$, and Phoenix Hand ${ }^{38}$. The e-NABLE community frequently discusses and recommends these designs and they represent a chronological sequence, each iterating and improving upon the previous design. In the following section, I describe how I setup and ran my final study; I include information

\footnotetext{
${ }^{35} \mathrm{http}: / /$ www.cyborgbeast.org/

${ }^{36} \mathrm{http}$ ://enablingthefuture.org/upper-limb-prosthetics/the-raptor-hand/

${ }^{37} \mathrm{http}$ ///enablingthefuture.org/upper-limb-prosthetics/raptor-reloaded/

${ }^{38} \mathrm{http}: / /$ enablingthefuture.org/phoenix-hand/
} 
about participants, details on the prosthetics used (parts, creation, and assembly), and the tasks and conditions I used. 


\section{Assembled e-NABLE Hands (Pair 1)}

\begin{tabular}{l|ll}
\hline Hand Name & Cyborg Beast & Raptor Hand \\
Published & March 2, 2014 & September 29, 2014 \\
Print Colour & Blue & Green \\
Joints & Metal screws & 3D Printed plastic pins \\
String Enclosure & Exposed groove & None \\
Straps & None & None \\
Fingertips & Hard plastic bumps & Smooth plastic \\
Thumb Orientation & $90^{\circ}$ Perpendicular to fingers & $90^{\circ}$ Perpendicular to fingers \\
\hline
\end{tabular}

Assembled e-NABLE Hands (Pair 2)

\begin{tabular}{|c|c|c|}
\hline Hand Name & Raptor Reloaded & Phoenix Hand \\
\hline Published & December 17, 2014 & March 30, 2016 \\
\hline Print Colour & Orange & White \\
\hline Joints & 3D Printed plastic pins & 3D Printed plastic pins \\
\hline String Enclosure & Exposed groove & Fully covered \\
\hline Straps & Single, large Velcro & Two, small Velcro \\
\hline Fingertips & Soft gel add-on & Soft gel add-on \\
\hline Thumb Orientation & $90^{\circ}$ Perpendicular to fingers & $120^{\circ}$ Away from fingers \\
\hline
\end{tabular}




\subsection{Study Methods and Procedure}

\subsection{Participants}

I recruited 20 participants - eight males, twelve females, aged 19-58 (mean=28.6 years) through poster ads on my university campus and email lists. I emphasized that no technical experience was necessary to participate. Each participant received \$20 CAD remuneration for his or her participation. I began each study with an initial questionnaire to gather demographic information, identify prior experience with designing physical objects, or experience with critique. Four participants worked at the university in various administrative positions while the rest were students in a variety of university departments. Only one participant had previous experience with prosthetic limbs. All participants indicated experience with video conferencing software. Two "daily" users, six that use video conferencing "several times a week", two "once a week" users and ten "less than once a week" users.

\subsubsection{Physical Prototypes: e-NABLE Prosthetic Hands}

I fabricated all 3D printed parts on the same

3D printer (Ditto Pro) using different colors

of $1.75 \mathrm{~mm}$ PLA plastic filament. Figure 4.2

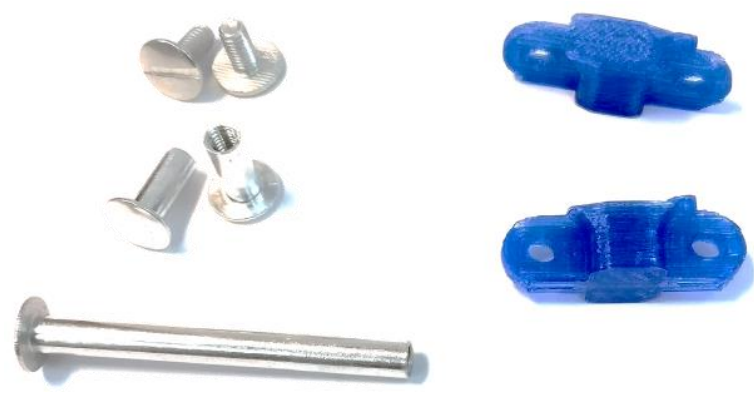

Figure 4.2. Example parts used to assembled e-NABLE prosthetic hands. (Left) Off-the-shelf screws used in the hand joints. (Right) 3D Printed proximal phalanges. 
(Right) shows an example of the parts that I 3D printed. I used the recommended 3D print settings included with the instructions ${ }^{39}$ for each prosthetic. I printed each hand in a different color so that participants could easily differentiate designs and refer to them by color during the study. Then, I assembled the 3D printed parts together with off-the-shelf parts (e.g., Chicago screws, elastic bands, fishing line) recommended

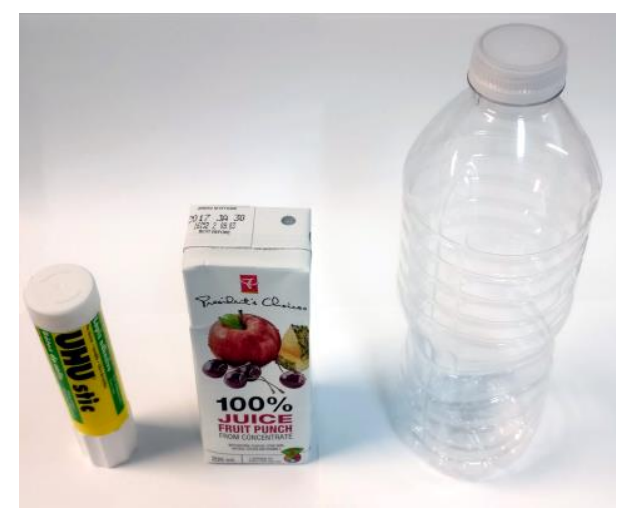

Figure 4.3. Participants could test the prosthetic hands by attempting to grasp the provided study objects: (Left) a glue stick, (Middle) a full $200 \mathrm{~mL}$ juice box, and (Right) an empty plastic water bottle.

by the instruction guides on the e-NABLE community website ${ }^{40}$. Figure 4.2 (Left) shows an example of the purchased off-the-shelf Chicago screws used. A full list of off-the-shelf parts is available in Appendix B.1 Cyborg Beast Hand Materials Kit List. I produced each

\footnotetext{
${ }^{39}$ https://www.thingiverse.com/thing:1453190

https://www.thingiverse.com/thing:261462

https://www.thingiverse.com/thing:596966

https://www.thingiverse.com/thing:476403

${ }^{40} \mathrm{http}$ ://enablingthefuture.org/upper-limb-prosthetics/the-raptor-hand/ http://enablingthefuture.org/upper-limb-prosthetics/cyborg-beast/ http://enablingthefuture.org/upper-limb-prosthetics/raptor-reloaded/ http://enablingthefuture.org/phoenix-hand/
} 
hand at $100 \%$ scale (sized for a small three-year-old child). All prosthetics were operational, but too small for any of the participants to wear. To give participants an opportunity to test grasping a range of objects, I also provided them with an empty plastic water bottle, a full $200 \mathrm{~mL}$ rectangular juice box, and a small glue stick (see Figure 4.3).

\subsubsection{Study Process}

I began by explaining the nature of study and obtaining participant consent to participate in the study and record video of the tasks to follow. I gave each participant as much time as they liked to explore all four prosthetic hands and invited them to physically handle and manipulate the hands. Participants could ask any questions about the prosthetics prior to beginning the study tasks.

Once participants were familiar with the hands, I asked them to present critiques of two pairs of e-NABLE hands (details of the task and conditions in the following sections) to me in two conditions. For all participants, I maintained the same ordering for hand comparisons (First pair: Cyborg Beast and Raptor Hand; Second pair: Raptor Reloaded and Phoenix Hand). This consistently presents the prosthetics in chronological order, such that the participant is always comparing a new pair of hands that represents a distinct evolution in the prosthetic hand designs. 
Each participant performed in both a face-to-face (F2F) condition and a video conferencing (VC) condition; I counterbalanced the order of these conditions across all participants. Finally, after completing both conditions, participants responded to a posttask questionnaire asking them to describe any difficulties they had in each condition. They rated their attitudes towards communication in each condition along a 5-point Likert scale (e.g., "How much do you agree with the following: I knew what my partner was looking at most of the time"). Table 5 has the complete list of Likert scale questions. While no time limit was enforced, each participant completed the study in under one hour.

\section{5-point Likert Agreement Medians by Condition}

\begin{tabular}{lll}
\hline Question & $\begin{array}{l}\text { Face-to- } \\
\text { Face }\end{array}$ & $\begin{array}{l}\text { Video } \\
\text { Conferencing }\end{array}$ \\
\hline I had an easy time communicating to my partner & 3.0 & 3.0 \\
It was easy to handle the prosthetic hands & 3.0 & 3.0 \\
$\begin{array}{l}\left(^{*}\right) \text { I felt like my partner was able to see what I wanted them to } \\
\text { see }\end{array}$ & 3.5 & 2.0 \\
$\left(^{*}\right)$ I knew what my partner was looking at most of the time & 3.0 & 2.0 \\
$\begin{array}{l}\left(^{*}\right) \text { My hands got in the way of showing things to my partner } \\
\text { The camera focused on what I wanted to show (VC only) }\end{array}$ & $\begin{array}{l}1.0 \\
\text { N/A }\end{array}$ & 2.0 \\
Table 5. Post-task questionnaire medians of 5-point Likert scale ranging from 'strongly \\
disagree' (0) to 'strongly agree' (4).
\end{tabular}




\subsubsection{Task: Structured Critique}

In each condition, I asked questions to assist the participant in providing a complete prototype review. These questions addressed (a) comparisons between prosthetics, (b) comfort, (c) functionality and usage, (d) assembly or print defects, and (e) improvements for the prosthetic hands (researcher protocol and interview guide in Appendix A.4 Study Prosthetic Interviewer Protocol). This structured format ensured that all participants consistently responded to similar issues across both conditions. Additionally, I ordered the questions to ease participants into the critique. I followed a sequential format of questioning similar to the model for crowdsourcing critique suggested by $\mathrm{Xu} \&$ Bailey, (2011): (1) questions about simple description of the prototypes (2) questions about comparing and identifying strengths and weaknesses of the prototypes and (3) requests for the participant to deliver new ideation, additional thoughts, or summary of their critique. I chose to have each participant provide his or her critique to a researcher playing the role of the audience. By controlling half of the conversation, I could gather consistent results from the perspective of the person presenting the critique.

Participants were encouraged to go beyond the questions and provide any additional thoughts or opinions they had. The researcher's behavioral protocol, while they asked questions and administered the tasks, allowed them to answer participants' questions on 
the visibility of various parts of the prosthetic (e.g., "Can you see this?") or to answer questions regarding the prosthetics (e.g., "Are these made for the same age?"), but not provide feedback on the content of the participant's analysis. I informed participants of this behavioral protocol prior to beginning the tasks.

\subsubsection{Conditions}

Each participant performed in both a face-to-face (F2F) condition and a video conferencing (VC) condition; I counterbalanced the order of these conditions across all participants.

Face-to-face (F2F). In the face-to-face condition, the collaborator sat directly across a table from the participant (see Figure 4.4 (Top)). In this collocated condition, the collaborator did not physically interact with the prosthetics as I did not want the collaborator's interactions with the prototypes to influence the participants' behavior or handling of the prosthetics. I informed participants of this behavioral protocol prior to asking questions and presenting the prosthetics.

Video Conferencing (VC). In the video conferencing condition, the participant communicated via Google Hangouts running on a laptop on the table (see Figure 4.4 (Bottom)). Figure 4.5 shows the layout for both the participant's screen (Bottom) and the collaborator's (researcher) screen (Top). The participant and researcher sat in the same 
room, facing away from each other; participants could only see the researcher through video chat, but could hear each other through ambient audio.

Finally, after completing both conditions, participants responded to a questionnaire asking them to describe any difficulties they had in each condition, and rate their experiences in each condition. 

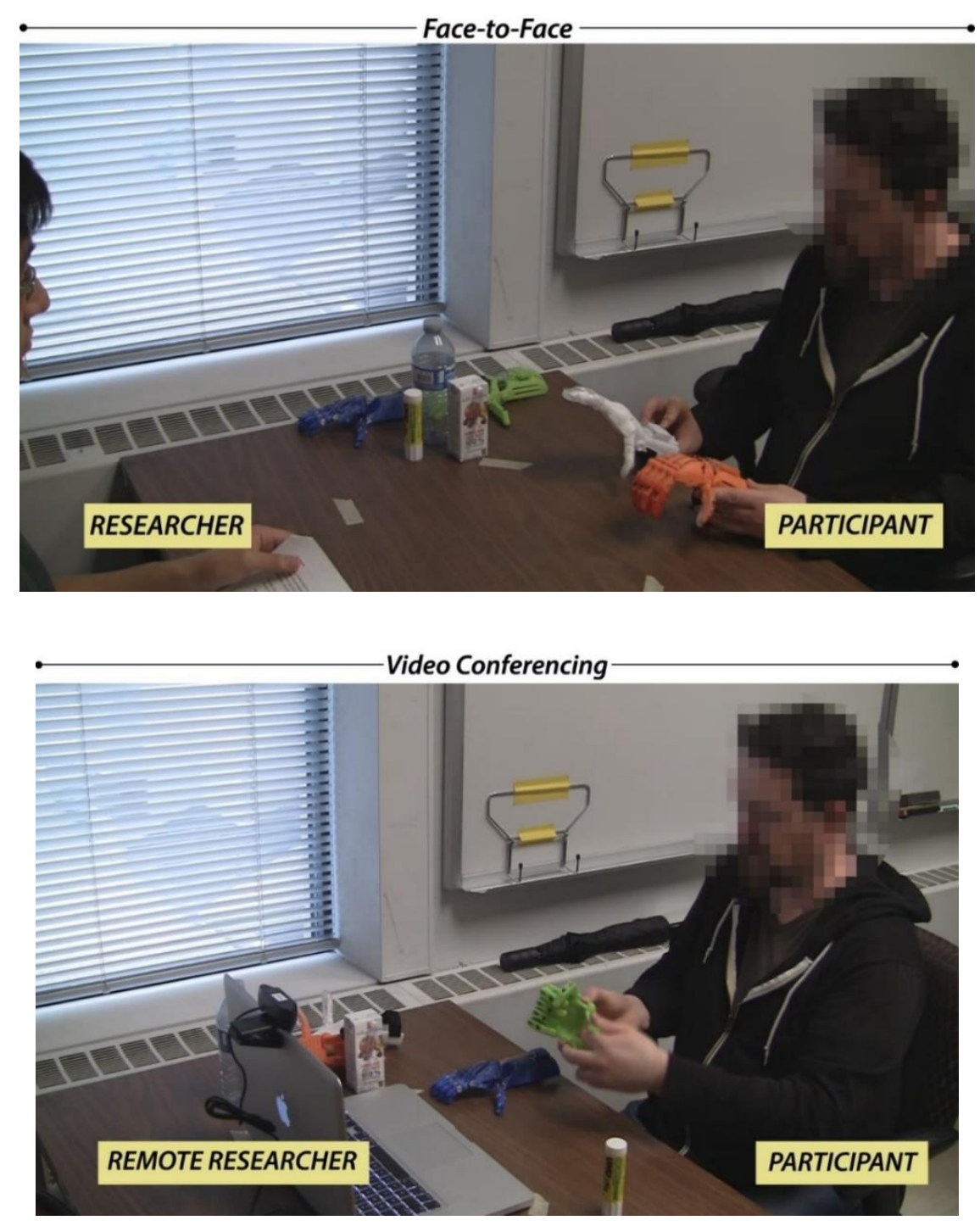

Figure 4.4. Participant $\mathrm{P} 13$ critiques prosthetic hands for a researcher in two conditions. (Top) Sitting face-to-face across from the researcher, and (Bottom) using a webcam to video conference with a remote researcher. 

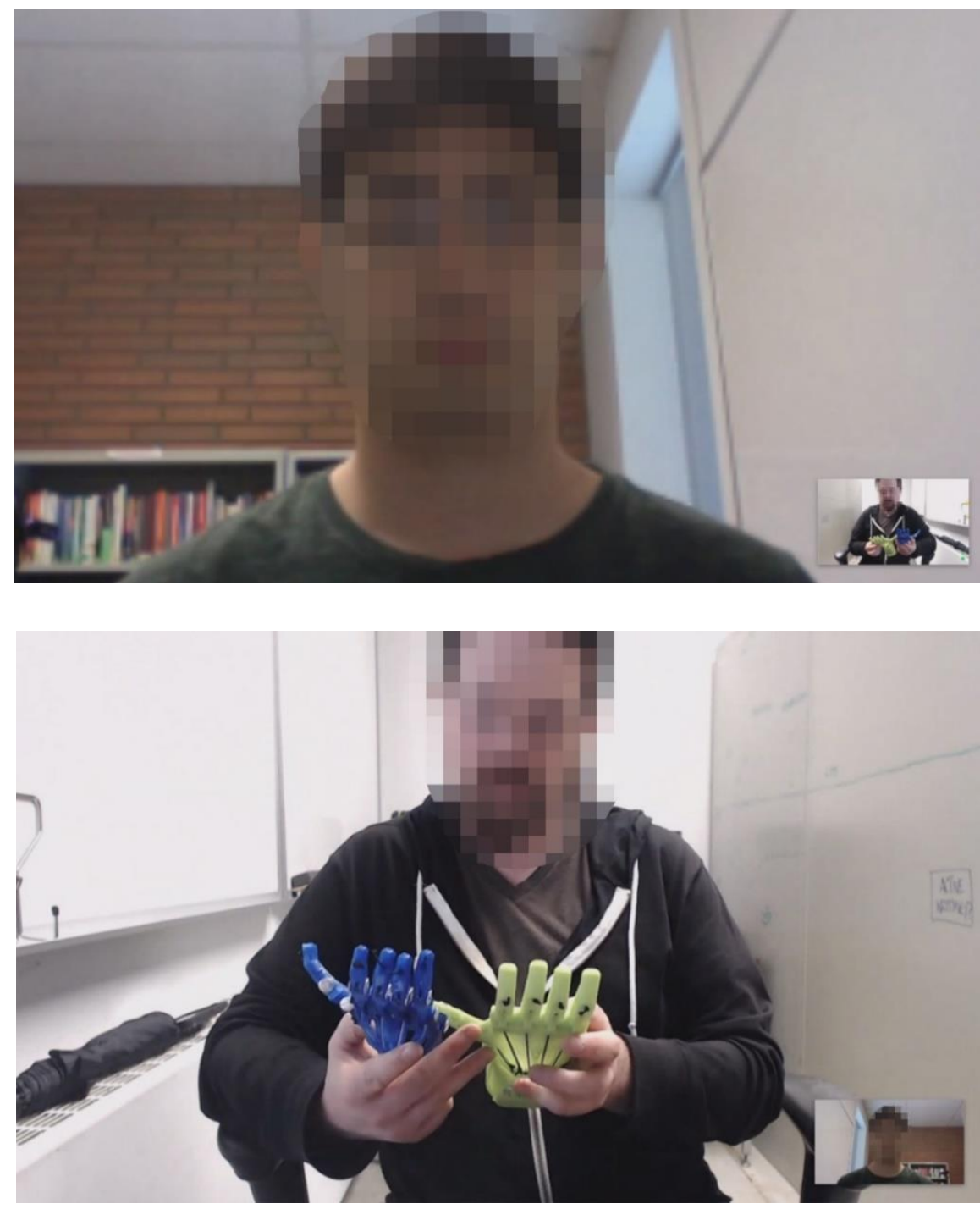

Figure 4.5. (Top) The view that the participant sees on their computer. The small bottom right corner shows a preview window of the participant's camera. (Bottom) The view on the researcher's screen. The small bottom right corner shows a preview window of the researcher. 


\subsubsection{Data Capture and Analysis}

I used three sources to collect video footage during the study; an over-the-desk Canon Vixia HFS10 camcorder, a Logitech C920 HD webcam mounted on the participant's laptop (VC), and the built-in webcam on the collaborator's laptop (VC). Both webcam feeds were captured using OBS Studio screen recording software. An example of the screen layout from the participant's view is shown in the top image of Figure 4.5.

I followed an iterative review of videos and transcribed selected specific full videos and portions of videos as described by Jordan \& Henderson, (1995) for interaction analysis. I reviewed all participant videos and noted communication behaviors that differed between the face-to-face condition and the video conferencing condition. I also measured the duration of answers to each researcher question. I tagged participants mentioning of problems or issues they found in the prosthetics, and instances where participants narrated their actions. My analysis focuses on participants' responses to the structured critique questions, which asked for a comparison of the models, review of comfort, usability, and performance.

\subsection{Chapter Summary}

In this chapter, I described how I arrived at my final study design through the running of a pilot study that failed to capture the complex communication I observed in e-NABLE 
video conferences described in the previous chapter. I determined that the simple objects (bottle openers) used in the pilot did not include sufficient complexity or detail to ensure an interesting and meaningful critique. Therefore, I moved on to using prosthetic hands designed by the e-NABLE community. I then described each aspect of the final study I ran including participant recruitment, materials used, the tasks and conditions, and how I captured and analyzed the resulting data. Moreover, I detailed the "structured critique" method I used to elicit critique of the prosthetic hands from participants despite their unfamiliarity with such devices.

My motivation for running the study I described in this chapter was to explore my thesis questions: 1) What strategies do people use to communicate a critique of a physical prototype over video conference and 2) How do end-users communicate physical details through video conferencing? I observed participants giving structured critique and analyzed their rich and complex, communications to understand what takes place during the critique of a physical prototype. In the following chapter, I provide detailed descriptions of my observations and findings, and discuss implications on the design and research of technology for remote critique of physical prototypes. 


\section{Chapter Five: Study Findings}

In the previous chapter, I described the design of a study where I asked participants to review physical prototypes for both a collocated and a remote audience. Through this study I observed and analyzed 20 participants' communications and their challenges in communicating critique over video. Following those challenges, I identified some of the varied strategies that participants utilized to address problems with remotely communicating about physical prototypes.

\section{I Findings}

"Material shapes our ways of doing" (Giaccardi \& Karana, 2015), and indeed it shaped how participants formed and communicated their critique for a remote audience. I begin by introducing terminology to help describe the behavior and actions of the participants during their critique. I then continue by laying out the difficulties encountered when discussing physical aspects of an object to a remote audience. I unpack participants' troubles with trying to communicate visually a predominantly 'invisible' material experience. Then, I discuss three elements that formed their prototype critique, and participants' general interactions with the prototypes. Finally, I describe how participants used their own actions and embodiment to share their subjective experiences. 


\section{I.I Epistemic and Pragmatic Action}

Participants performed action as described by Kirsh \& Maglio, (1994); both epistemic actions - actions used to discover information to understand how the prototypes worked and pragmatic actions-actions that "brings one physically closer to a goal" - to demonstrate or show the prototype. In this study, epistemic actions by participants were used to explore and inspect the physical prototypes-looking at, handling, and operating the prosthetics. Pragmatic actions within the context of critique were the actions that participants took to communicate their feedback and critique to the audience-showing, and gesturing with the prosthetic together with their own hands and arms.

\subsubsection{Remote Difficulty: What is Visible?}

Communicating about object behaviors and details at a distance is not straightforward I observed participants having difficulties throughout their critique, primarily around the core misunderstanding of what aspects of their critique were visible at a given moment. Several participants indicated in their post-task questionnaire that they were aware that their locus of attention-stuck in epistemic action-caused difficulties during video conferencing. For example, P10 said, "I was also concentrating on the hands in front of me, and sometimes forgot to check whether my partner could see what I was doing," and P2 explains, "I felt like I kept forgetting to present what I was looking at to the camera". 
During face-to-face conversations, participants may assume the collaborator can perceive more cues about the object's detail (e.g., stereoscopic view of form, hearing subtle creaks). Participants indicated in the post-task questionnaire that in the remote condition they were not able to show their collaborator what they intended, knew less about where the collaborator was looking, and felt their hands may have gotten in the way of showing things (Table 5). All of these concerns highlight a key challenge of video-mediated critique: an awareness of what the audience can and cannot see in a scene. In the following subsections, I discuss how participants struggled with the questions: (5.1.2.1) What is captured? (5.1.2.2) Where is my collaborator looking? and (5.1.2.3) Who is responsible for visibility?

\section{I.2.I What is captured?}

In the post-task questionnaire, five participants (P4, P10, P12, P13, P19) specified that they had difficulty ensuring that the views they wanted to share with their collaborator were in frame. Prior research shows that field of view can affect collaborative tasks (Johnson, Gibson, et al., 2015; Johnson, Rae, et al., 2015) and my findings support this for design critique scenarios. 
For instance, P12 indicated on the post-task questionnaire that they "had to remember to make sure what I was doing showed on the camera." In practice, objects can be out of frame intentionally (during epistemic action) or unintentionally (inadvertently moving the objects out of frame when demonstrating an action). For example, in Figure 5.1, P12 (VC) accidentally held the prosthetic too low to be in the camera view, and remarked, "Ah, $I$ don't know where the camera is," before adjusting their position and lifting the prosthetic hand back into the video frame. 

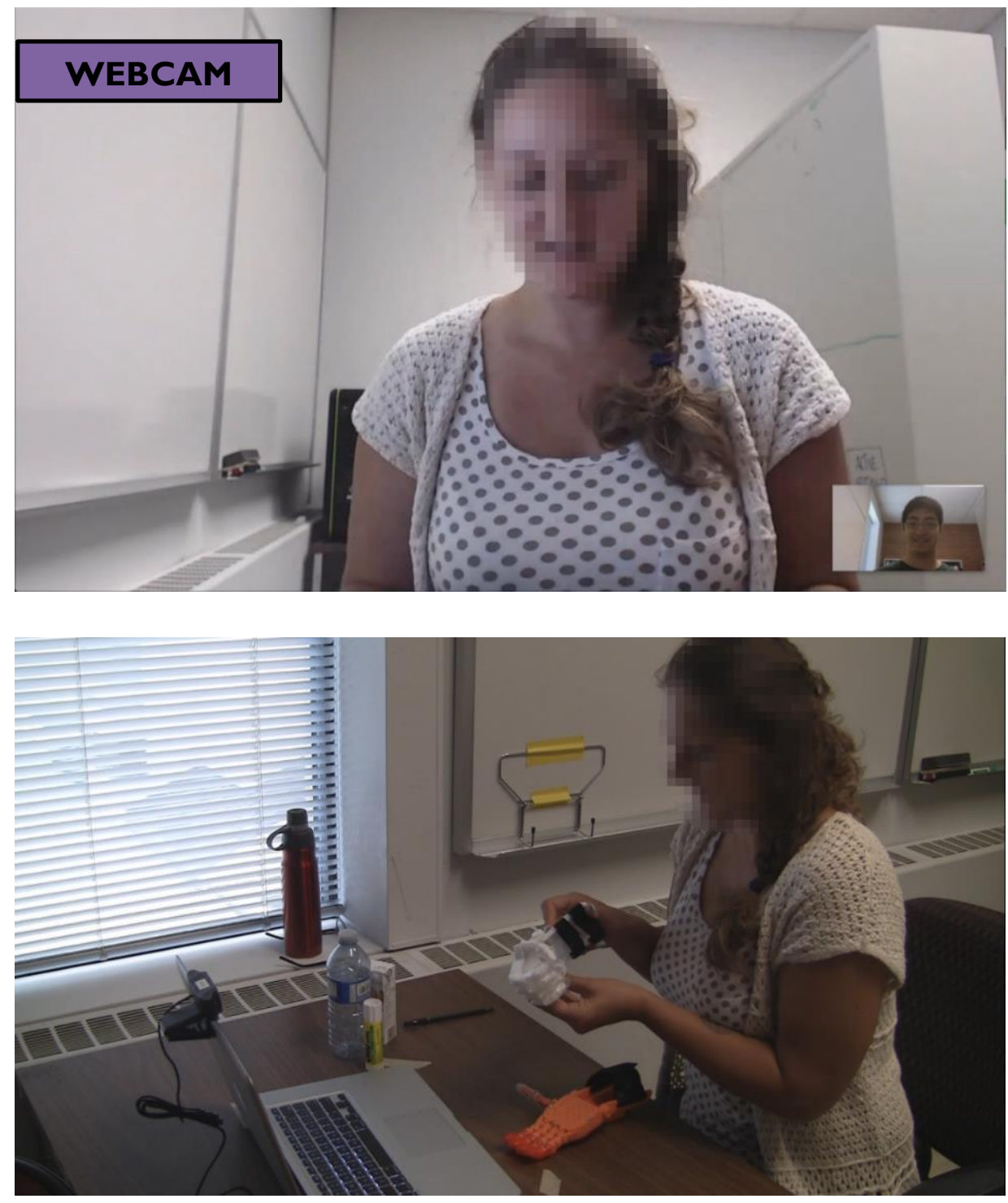

Figure 5.1. (Top) Webcam view and (Bottom) workspace view of P12 (VC) demonstrating actions with the white prosthetic hand as they realize the prosthetic is out of frame. P12 exclaims, "Ah, I don't know where the camera is," as they then lift their shoulders to bring the prosthetic hand back into frame. 
Unfortunately, participants were also unaware when their own hands were in frame and obstructing their collaborator's view of the prototypes. Six participants "Agreed", and two "Strongly Agreed" that their hands got in the way and one participant (P7) explicitly commented on this difficulty in the short answer portion of the post-task questionnaire, "My hand probably got in the way of the camera a lot of the time."

In Figure 5.2, P3 (VC) handles the prototypes such that the majority of the prosthetics cannot be seen on camera. While the prototype is in frame, it is oriented to support P3's own point of view. P3's hands are also in frame, blocking the camera's view of some of the prototype. P3 manipulates the prototypes in an epistemic action before returning to a pragmatic action to intentionally show specific views to their collaborator.

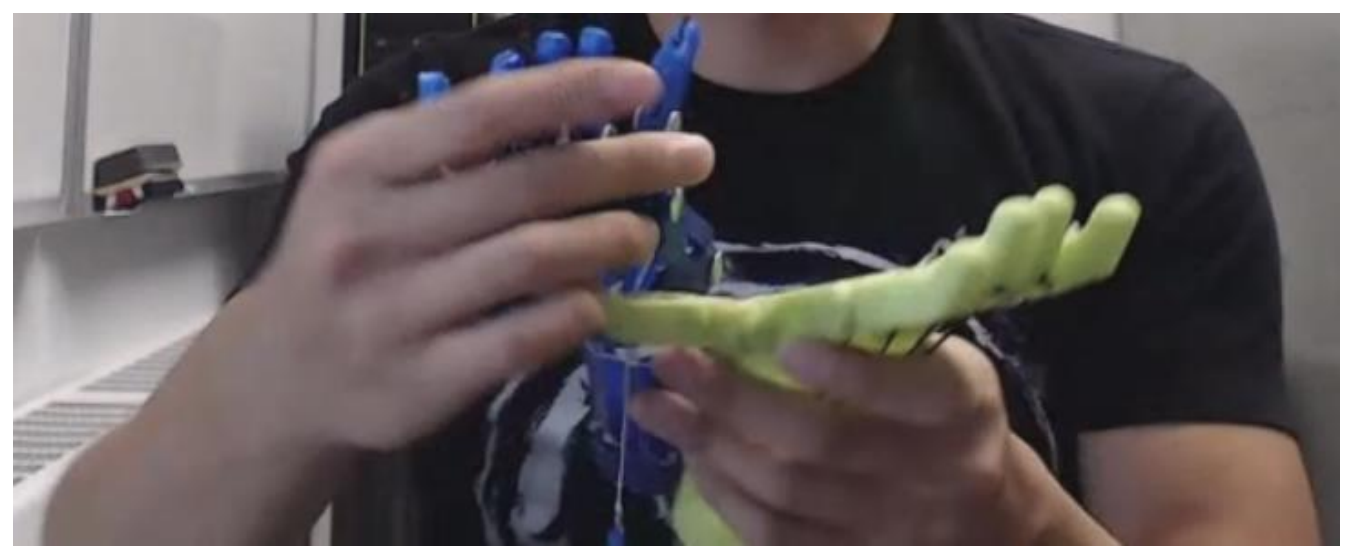

Figure 5.2. P3 (VC) inspects and compares the prosthetics, holding them such that the majority of the prosthetics are not visible due to occlusion from P3's own hands and perspective foreshortening. 
Even once the prototype is in the camera's field of view, participants were still unsure if details were in focus. Because the web camera automatically focuses, it can be difficult to predict whether or not an object held close to the camera (to make its details larger) is actually within focus. In the questionnaire, three participants (P10, P11, P18) indicated difficulty knowing or managing what was in focus. For instance, P10's response, "It was difficult for me to show the more subtle design elements to my partner. I wasn't sure if the camera was focusing, or could see small detail."

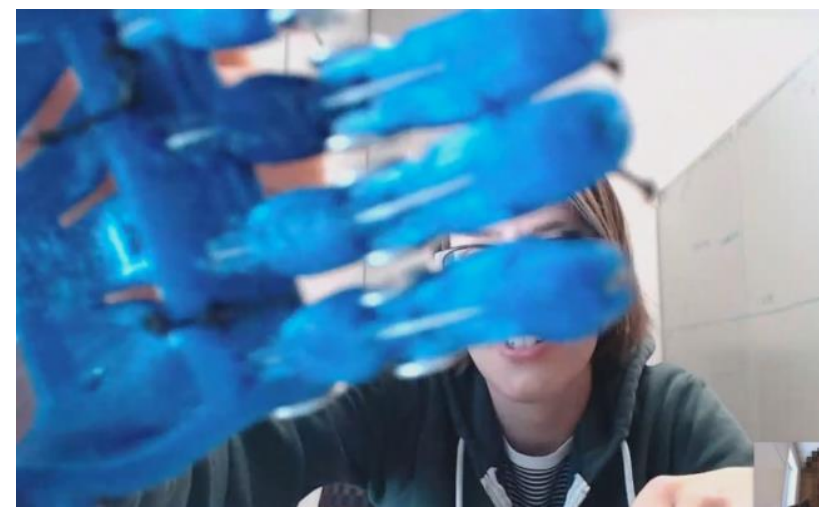

Figure 5.3. P18 (VC) holds the blue prosthetic hand close to the camera attempting to show details of the fingertips. Unfortunately, the webcam remains In Figure 5.3, P18 (VC) holds the prosthetic extremely close to the camera, focused on the P18; the image of the prosthetic is blurry to the viewer. They remark, "I don't know if you can see the surface texture."

in an attempt to show that the surface of the fingertips are made up of small plastic bumps. However, the camera's focal distance is calibrated for someone sitting several feet away, not for objects inches away from the camera. The resulting close-up of the prosthetic is very blurry. Unfortunately, P18 cannot tell that this image is blurry, as the 
preview window for the participant to see themselves is too small. During the exchange, P18 (VC) says, "I don't know if you can see the surface texture."

Once again, the size and format of standard video conferencing does not help people understand what is readily visible. Even if this limitation is overcome and the details could be perfectly shown over camera there are still more hurdles such as whether the audience is looking where the presenter expects.

\section{I.2.2 Where is my collaborator looking?}

In the post-task questionnaire, three participants (P10, P13, P16) were concerned that they could not tell where their collaborator was looking during the remote communication condition. For example, P16 wrote about their experience while video conferencing, "Flustered, can't see if their eyes are looking at exactly what I want them to." Furthermore, seven participants (P4, P6, P11, P12, P13, P14, P18) indicated not knowing what their collaborator was looking at during video communication (i.e., Likert response of "Disagree") as well as one (P10) response of "Strongly Disagree".

Comparatively, when considering the face-to-face condition only three participants (P7, P14, P20) acknowledged a lack of awareness to where their collaborator was looking (i.e., Likert response of "Disagree"). Past research has found that gaze awareness can help 
collaborators see what is currently of interest during tasks (Higuch et al., 2016). In this study scenario, understanding where a collaborator is fixated may have helped the participant focus their critique on areas in view that the collaborator is interested in. However, in the context of a critique with multiple audience members this solution may not scale well.

Additionally, I found a significant difference in response to the Likert scale agreement about whether participants were aware of what their partner was looking at. I knew what my partner was looking at most of the time: The medians of the conditions F2F and VC were 3.0 and 2.0, respectively. Wilcoxon Signed-rank test shows that there was a significant effect of condition $(W=294.5, Z=2.13, p=0.0282, r=0.337)$.

It is possible that participants were peripherally aware of cues from their face-to-face collaborator that could not be seen over the video-link. However, given participants' physical (visual and tactile) engagement on the prototypes, they may not have been aware of such cues during either condition. This resonates with past work highlighting the importance of gaze awareness in remote physical tasks (Akkil et al., 2016; Fussell, Setlock, \& Parker, 2003). 


\section{I.2.3 Who is responsible for the view?}

Not all participants consistently showed the prototypes to their collaborator as part of their communication. In the post-task questionnaire, four people (P2, P10, P11, P12) mentioned having difficulty "remembering" to show the prototypes to their collaborator during the video condition.

One possible reason participants felt that "forgetting to present" was a problem is that they felt responsible for their collaborator's video view. Prior research (e.g., Rae et al., 2014) also discusses collaborators taking on responsibility to manage experience during a remotely shared meal or while visiting a new place together to entertain other participants. My findings support the presenter's responsibility for the view; however, when forming their critique and engaged in epistemic action - intensely focusing on their material experience with the prototypes - participants had difficulty remembering this responsibility.

Having the audience being responsible for the view-explicitly asking the presenter to bring objects into frame or move obstructions - is one alternative to the above model. In my study protocol, the collaborator was not allowed to comment on how the participant chose to use the video conferencing setup. It seems at first that this protocol would be too 
constraining-putting all the responsibility on the person giving critique-but as described in my motivating scenario this is actually reflective of the real video conferencing environment in open-hardware groups. Show-and-tell feedback and critique is given with generally little interruption from the audience.

The same four participants who stated difficulty with remembering to show the prototype (P2, P10, P11, P12) along with an additional participant (P20) suggested that their collaborator could be responsible for correcting the presenter when objects are out of view. Past research in HCI has offered ways for remote participants to independently or semi-independently control the view such as with robotic telepresence (Rae et al., 2014) or a drone camera (Jones et al., 2016). However, it may be difficult to scale these solutions up to scenarios with a large audience of collaborators.

\section{I.3 Communicating with and about Prototypes}

Through a series of comparisons, the participants' goal was to evaluate and critique pairs of prototypes. In the following sections, I describe participants' tendencies in communicating their critique to a remote audience. First, I describe how participants dealt with communicating physical details. Next, I outline how participants managed their own focus and attention (to the prototype and/or to the video conference). Then, I 
detail how participants chose to show prototype behaviors and actions. Finally, I discuss the ways that participants included themselves into their critique through embodied actions and narrative language.

\section{I.3.I Communicating Physical Detail}

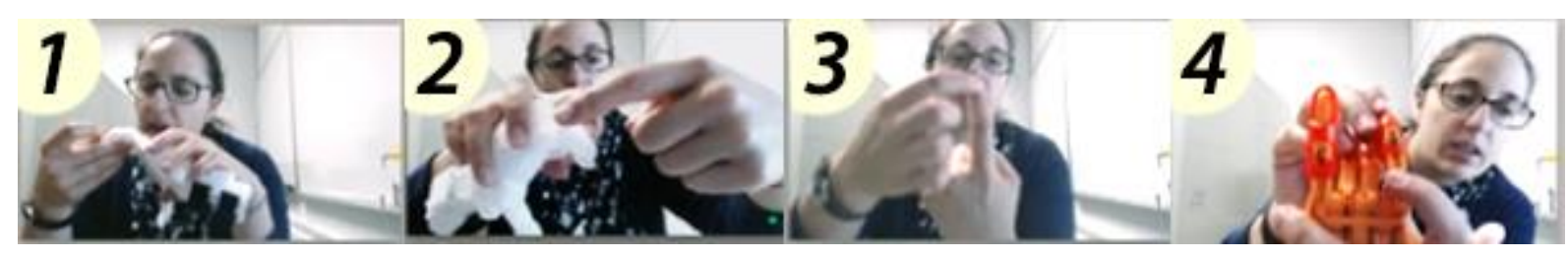

\begin{tabular}{lll} 
Time & \multicolumn{1}{c}{ Verbal } & \multicolumn{1}{c}{ Action } \\
\hline 05:57 & It's white on white but... & Holds up white hand to camera (1) \\
\hline 06:03 & ... to this part & Points to white finger tip (2) \\
\hline $06: 12$ & It would be here. & $\begin{array}{l}\text { Puts down prosthetic, points to P10's } \\
\text { own finger (3) }\end{array}$ \\
\hline $06: 20$ & $\begin{array}{l}\text { You can see the black here, that's } \\
\text { bending. }\end{array}$ & Shows black elastic on orange hand (4) \\
\hline $06: 24$ & That bending is facilitated here, & Picks up white hand \\
\hline $06: 29$ & $\begin{array}{l}\text { but it's white on white, so you can't see } \\
\text { it. }\end{array}$ & Holds up white hand to camera
\end{tabular}

Figure 5.4. P10 (VC) holds up prototypes to the camera, gestures to prototypes oncamera, and references their own physical geometry to describe the precise location of elastics on a prosthetic hand.

Particularly during the video conferencing condition, participants described differences between small details or tactile features, such as the roughness or surface texture of the 
3D printed prototype. Some physical details were difficult for the participants to discuss because they were not visible on camera due to factors such as color and resolution. For example, P10 (VC) verbally detailed the location and function of clear elastics used in the finger joints of the white hand, which are difficult to see on camera (Figure 5.4 in images (1) and (2)). The participant then resorts to using the orange Raptor Reloaded hand to demonstrate where the more visible set of black elastics are on the knuckles (Figure 5.4 in image (4)). In comparison, when participants discussed details in the collocated condition they didn't feel the need to do this type of detailed description. A possible reason for this is that participants felt that the collocated audience could see everything they could see. In the post-task questionnaire participants responded to the question "I felt like my partner was able to see what I wanted them to see" favorably in the F2F condition (average $=3.5)$ and disagreed in the VC condition (average $=2.0)$.

Verbal Video Conferencing Strategy: Elaboration of Detail

I found that during the face-to-face setting participants provided less verbal detail of the parts of the prosthetic that they were describing. These verbal descriptions differed in length between the face-to-face and remote conditions. Participants took more time in the video-mediated condition (average $=15: 00, \min =8: 00, \max =25: 13$ ) than in the face-to-face 
condition (average $=13: 00, \min =6: 42, \max =23: 18$ ) to discuss a similar amount of "topics". In total across video the conferencing condition participants discussed approximately 478 "topics", and approximately 481 while face-to-face.

As an example, when discussing comfort, participants would identify a rough texture on one of the prosthetic hands and during the face-to-face condition would mention the roughness and rub their finger along the rough surface without necessarily holding the prosthetic in a position for the researcher to see the rough texture. In comparison, during the video conferencing condition, participants provided details such as texture description (e.g., "cross hatching"), the location of rough friction points (e.g., rubbing in the knuckle joint), and imagining how the prosthetic might feel for a recipient (e.g., how the curve of the device would be tight on a recipient's residual limb). We can see an instance of this difference of descriptive elaboration in the following transcription of P5's comparisons of prosthetic comfort.

F2F [37 sec]:

I think they both have their advantages, I mean the fact that this [gauntlet] one has a bit of curve, seems a bit more ergonomic, aside from this flat piece might make it more 
comfortable. But, it's nice that this [inside of the gauntlet] is smooth and I like the double strap.

VC [1 $\min 9 \mathrm{sec}]:$

One thing about comfort... when you have these sort of points [gestures a pinching motion] it comes in. Then if it's not custom made to that person's arm then it would be pinching them quite a bit, I think, which could make it very painful. So, if it was, like, you weren't sure who was going to be using it then probably this one that doesn't have any pressure points would be better... But for daily use for someone it's probably not going to be, it might like move around on them, or they might not be able to have as much control over it as something that's customized. So it would probably worth that investment for daily use to have something that's more customized. . .

In the face-to-face condition, P5 chooses to describe three physical aspects of the prosthetic in short simple terms: curve, texture, and the number of straps. In comparison, they take approximately twice as long to elaborate on a single physical detail, the narrowing joint area between the gauntlet and the palm. They contribute to their remote critique information well beyond the simple description seen in the face-to-face condition by suggesting scenarios of use, considering options for customization, and who the user 
might be. In the case of P5, the participant performed the VC condition first so their more elaborate descriptions in the VC condition cannot be attributed to becoming more comfortable over time with exploring, assessing, and describing the prosthetic details.

Comfort was not the only comparison where participants provided additional elaboration of detail during video conferencing. For example, when asked to discuss which prosthetic hand would be easier to use the response differed greatly in length and amount of detail for P10:

F2F [54 sec]:

Well I guess I don't know about ease of use 'cause I can't test it out myself, but this, the blue has a sort of a deeper edge here [gesture to inside of gauntlet]... [pauses] The arm is, the hand is not present it could rest up, I guess, more easily against the blue than the green where it's more of a gradual grading. Where the blue is a bit more deep. So the limb might not, one could slip out I suppose in the green where it might be a little more secure in the blue. 
$\mathrm{VC}[4 \mathrm{~min} 28 \mathrm{sec}]:$

I don't know, let's see... Oh there's different weights as well to them. Umm. So let's try it cause I'm not sure. So this is an empty water bottle. So it [the finger grip] doesn't go around... The hand isn't able to go all the way around so, ya, it just sort of goes out. Let's try actually. Let's try this [attempts to grasp the water bottle with each prosthetic]. So, whh, the white hand is much better at gripping around but not so much, oh well, gripping top. Well it's just sort of hanging on ... The thumb on the white hand is pointed down more than the orange hand. I can't overlay it. But where the orange hand comes right out, you know, close to ninety degrees, the white hand doesn't. It comes down .. . The orange hand doesn't, the thumb comes up to try to grasp it, that's where the bottle keeps getting away from us. Although you get it at the right angle you can do it but I would think the white hand seems a lot easier to do ... You know what it does? It creates the space here [points to own palm]. It mimics the space here more efficiently [gestures to own hand as it forms a grip]...

During video conferencing, P10 is trying to compare details such as the angle of the thumbs, spaces in the grip, other objects they are interacting with, weight, and how they are manipulating the prosthetics to try to pick up other objects. 
This extended verbal detail and elaboration was common for participants that took longer during the video conferencing portion of the study. This may be due to the prototypes being out of frame and therefore requiring description. However, there were times where participants kept the prototype in frame and still provided verbal details. This was exemplified by one participant, P18, becoming self-aware of the change in their behavior while there were describing the prosthetic hand. P18 (F2F) explains in the following quote during the face-to-face condition:

Like this [tensioner block] part the screw bit is obviously different. I'm like just describing less detail than when we are video conferencing. Because I'm assuming you can see everything.

While they were the only participant to state their lack of communicating and elaborating on details when face-to-face, I also saw this behavior in other participants. Additionally, as part of communicating more details, participants purposefully held the prosthetic limbs very close to the webcam, or explicitly posed and oriented the objects to showcase individual parts (e.g., screws, joints) or actions (e.g., grasping). However, this strategy was not always ideal as the webcam did not focus well on close objects and the participants had trouble knowing whether the detail they were discussing was effectively 
captured. P10 described on the post-task questionnaire the difficulties they had when trying to show details to the researcher during the video conferencing condition.

It was difficult for me to show the more subtle design elements to my partner. I wasn't sure if the camera was focusing, or could see small detail. I was also concentrating on the hands in front of me, and sometimes forgot to check whether my partner could see what I was doing

\subsubsection{Focus and Attention}

All participants in both conditions dedicated most of their visual attention to the physical prototypes under consideration, looking for details, behaviors, and experiences to construct their critique that they were comparing, evaluating, and experiencing.

Participants only lifted their gaze occasionally to look at their collaborator (F2F) or the video connection (VC), and then they quickly look back down to the prototype. For example, in a 36 second response comparing the gauntlets (where the wearer places their arm) of each prosthetic design, P16 (F2F) spent only two seconds looking up at their collaborator (see Figure 5.5). The rest of the time they were focused and engaging with the prosthetics. This is consistent with past research on socialization in the presence of an 


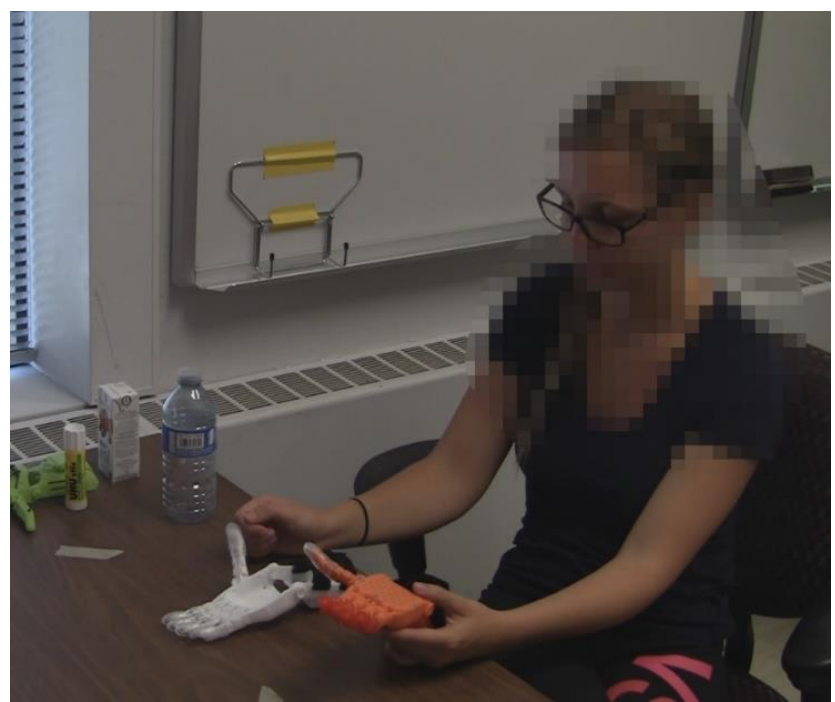

\begin{tabular}{|c|c|c|c|c|}
\hline Person & Time & $\begin{array}{l}\text { Duration } \\
\text { (s) }\end{array}$ & Verbal & Attention \\
\hline Researcher & $01: 28$ & 3 & $\begin{array}{l}\text { In the portion that goes over the arm, } \\
\text { any differences that you notice } \\
\text { there? }\end{array}$ & \\
\hline & & & $\begin{array}{l}\text { Well there's this part, for the wrist, or } \\
\text { the hand. }\end{array}$ & \\
\hline P16 & 01:31 & 20 & $\begin{array}{l}\text { In terms of the two strap versus the one } \\
\text { strap. I don't know if there would be too } \\
\text { much of a difference functionally } \\
\text { between the two. I mean with two } \\
\text { straps }\end{array}$ & $\begin{array}{l}\text { Looks at } \\
\text { prosthetics }\end{array}$ \\
\hline P16 & 01:51 & 2 & twice the chance that & $\begin{array}{l}\text { Looks at } \\
\text { researcher }\end{array}$ \\
\hline P16 & $01: 53$ & 11 & $\begin{array}{l}\text { one could break. } \\
\text { Does give you more flexibility for } \\
\text { clothing or fabric... }\end{array}$ & $\begin{array}{l}\text { Looks at } \\
\text { prosthetics }\end{array}$ \\
\hline
\end{tabular}

Figure 5.5. (Top) P16 (F2F) with their attention focused down at the prosthetics as they inspect the straps. (Right) Selected transcript from P16, when comparing each prosthetic. While the entire response takes 36 seconds, they only switch attention from the prosthetics to the researcher for 2 seconds. 
alternative visual focus (e.g., social television (Ducheneaut et al., 2008), mobile video collaboration (Jones et al., 2015)).

Participants' hands were preoccupied with the prototypes themselves. For example, when showing details of the fingertips, P2 first picked up both prototypes to examine them, then brought the prosthetics towards the camera to offer their collaborator a better view (see Figure 5.6), and finally resumed individually examining the hands. Epistemic action within the context of this study describes a participant's visual focus, inspection and physical interaction with the objects in hand that are used to help that participant better understand how the object feels and how it functions. 

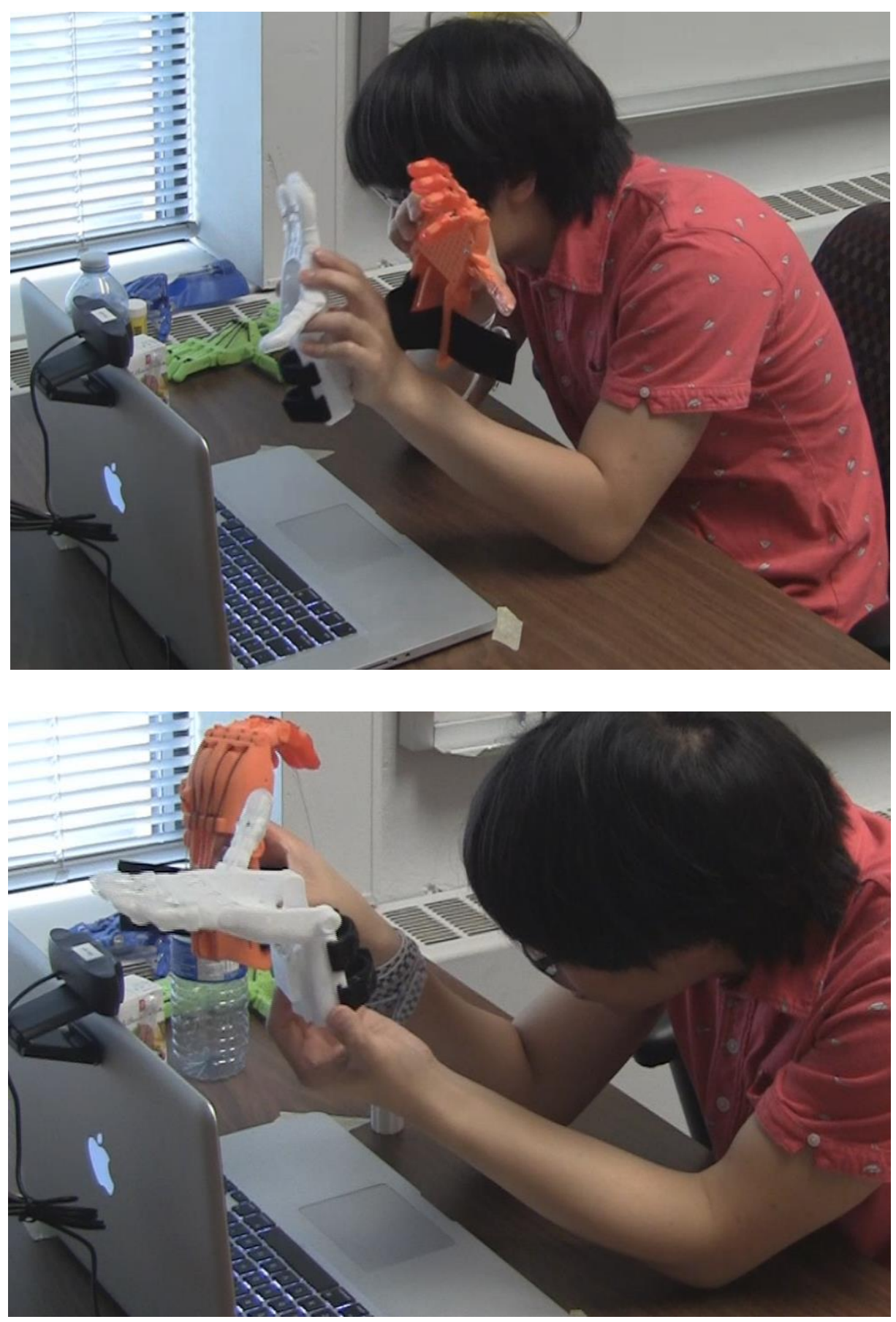

Figure 5.6. While communicating, P2 (VC) holds up two prosthetic hands close to the camera (pragmatic showing action) obscuring their own view of the video communication interface. 


\subsubsection{Prototype Behavior}

In their comparisons, participants communicated how the prototype behaved or reacted. Amount of force on the wrist needed to close the hand (P2, P5, P8); elastic tension resisting hand closure (P5, P8, P13); grip strength based on friction of fingertips on gripped objects (P2, P4, P8); fishing line strength and how they might break under tension, or repeated use (P3, P10), stability of the prosthetic when worn (P10, P16), and potential strength of the plastic to withstand use (P1, P3, P5, P13). These behaviors could be considered another set of "invisible" physical details in addition to those described in section 5.1.3.1, as they correspond to how a physical component of the design responds to a particular use case.

\section{I.3.4 Subjective Experience}

In addition to recounting prototype behavior, participants also described their own personal experiences in using the objects-their role in physically operating the prototype. For example, P18 (VC) describes the force needed to push on the back of the prosthetic to close the hand. "I push and it seems to be a little bit harder. But it still goes. But, I have to push harder."

In this case, P18 recounts both their own action - where and how much force they applied to the back of the hand - and the prototype's reaction - how the prosthetic resisted force 
yet eventually closed. The participant must personally experience the amount of effort needed to actuate each prototype, and verbally articulate this difference. However, throughout the critiques participants were simultaneously understanding and communicating physical details, prototype behaviors, and their user experience. For example, P5 (VC) (see Figure 5.7) explains their actions, "If I'm closing this one and I touch it like this, they kind of bounce around a bit." As P5 explains verbally, they are also physically trying to understand if the behavior of the fingers is a result of tension of the actuating strings or friction in the knuckle joints by testing how the prosthetic reacts to pressing on the fingers.

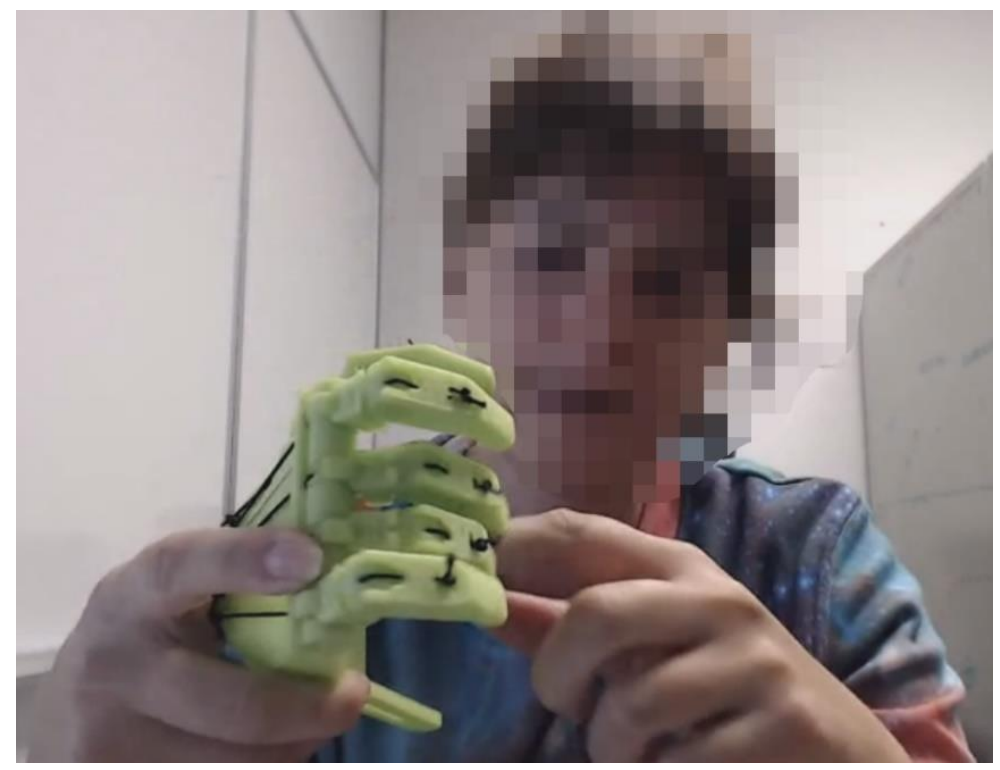

Figure 5.7. P5 (VC) shows prosthetic behavior while discussing string tension and joints. "If I'm closing this one and I touch it like this, they kind of bounce around a bit." 
Over the course of their continuous epistemic concentration on and interaction with the prototypes, participants developed an understanding of how the prototypes feel, function, and compare. As subjective experience is a key element of critique, participants inevitably brought their own actions and embodiment to the critique. Here I discuss two ways in which participants inserted themselves into the critique: self-narrating actions, and using their body as a surrogate for prototype behavior.

Narrating Actions in First Person. Both in the face-to-face (10 participants) and in the video conferencing condition (13 participants), participants narrated their actions to their collaborator in the first person. Participants used themselves as the "deictic centre" (Hanks, 1992) - using the first-person " $I$ ", and describing how the prototype behaved in response to and in reference to their own actions. For example, P18 (VC) references themselves in what they are doing. "Oh these things move, cool. I just discovered that these [tension pins] move. Maybe they don't move in the blue thing maybe they do. I'm trying to get them to move in the blue one," while they are doing it.

During analysis, I counted each sentence that was a first person described action as an instance of narration of action (e.g., "I push here.", "I'm going to pick this up."). While selfnarration occurred in the face-to-face condition (34 instances, 10 participants) (P6, P7, P8, 
P9, P12, P13, P14, P16, P18, P19), it happened more frequently during the video conferencing condition (92 instances, 13 participants) (P2, P4, P5, P6, P7, P9, P10, P14, P15, P16, P17, P18, P19). In the video conferencing condition, self-narration occurred for both on- and off-camera actions. The actions participants described included grasping objects (P2, P4, P10, P14), lifting objects (P2, P4, P7, P10, P13), mimicking the closing of the prosthetics (P5, P6, P7, P14), or vigorously shaking the prosthetics (P14). This selfnarration often occurred simultaneously with the action itself. For example, P14 (VC) describes waving the prosthetic hands, as they wave them (Figure 5.8). Participants also chose to describe off-camera action instead of bringing that action into view.

In several instances, P14 (VC) narrates off-camera actions-describing their arm resting on the edge of the table, or rotating their forearm. In observing the video results and through transcription, I found that participants would sometimes narrate their actions while video conferencing, yet this behavior rarely occurred during the face-to-face condition. For instance, P7 (F2F and VC), used gestures with their own hand to mimic movements of the prosthetic as they discussed their thoughts. In the video conferencing condition, they made specific first-person references to the actions they were taking, as they pinched their fingers together to describe a grasping motion they said, "When I'm 
holding on to this juice box, I use both joints or all three joints to grasp it, whereas this one you only have these two joints."

The same participant also used hand gestures during the face-to-face condition but without this type of first-person narration. For instance, when P7 is face-to-face they mimic the closing of one of the hands while commenting on the position of the fingers. "It would be better to have your thumb going around the object, whereas this one just looks like it doesn't even have a purpose." In another case, participant P14 verbally narrated some of their actions in both conditions but with only two instances while face-to-face and 11 instances during video conferencing. The following are two examples of different periods during P14's video conferencing condition where they narrated some of their actions oncamera (Figure 5.8) and off-camera (Figure 5.9). 


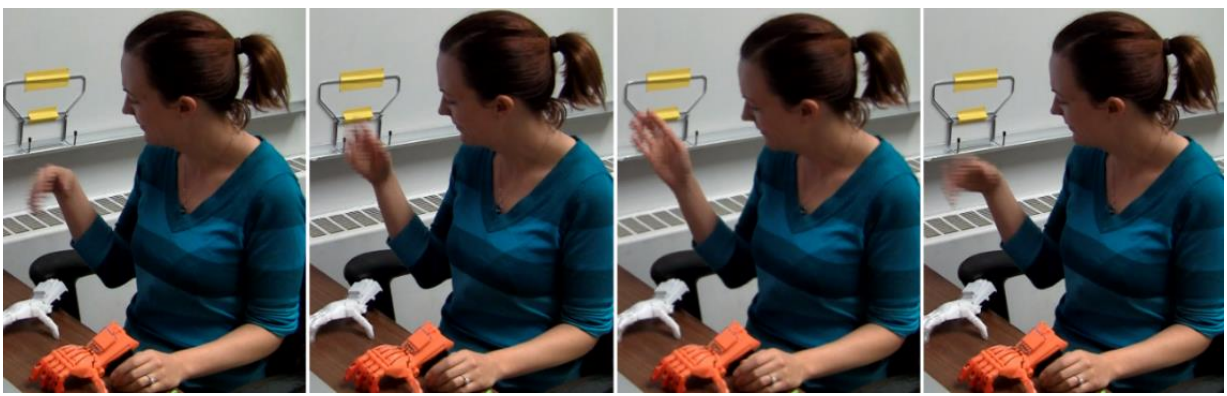

Time

Verbal

Action

02:11 So if I'm waving it, not so much is happening

02:14 If I'm waving it, a whole bunch is happening

Waving white prosthetic

Waving orange prosthetic

$02: 23$
If I'm moving my wrist my hands don't necessarily move...
Waving own wrist

Figure 5.8. P14 (VC) narrates their own actions as they wave the prosthetics and then their own hand to describe how the prosthetics move and bounce in comparison to each other and to their own hand.
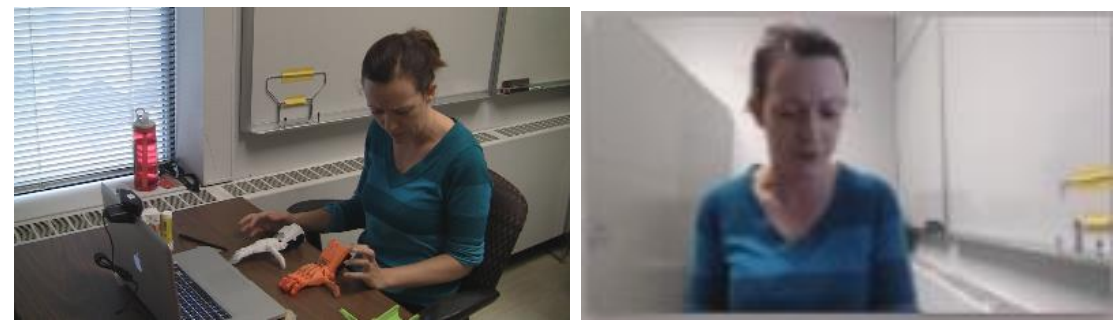

\begin{tabular}{cll} 
Time & \multicolumn{1}{c}{ Verbal } & \multicolumn{1}{c}{ Action } \\
\hline $11: 15 \begin{array}{l}\text { Let's say I just have my hand and I'm resting it on a } \\
\text { table }\end{array}$ & $\begin{array}{l}\text { Resting own hand on table } \\
\text { off-camera. }\end{array}$ \\
\hline $11: 20$ & I have to turn my whole forearm kind of off to the side. & $\begin{array}{l}\text { Rotating own hand and } \\
\text { forearm off-camera }\end{array}$
\end{tabular}

Figure 5.9. P14 (VC) narrates their off camera actions. (Left) View from the study camera overlooking the entire workspace shows the participant working with prototypes on the table. The prototypes discussed are not visible to the audience in the webcam view (Right). 
One possibility for this narrative behavior is that participants use this strategy to overcome cases where they feel that the camera is not capturing the gestures they were performing or the details they discussed. In P14's (VC) case, several instances of their actions happen off camera, such as when they are describing their arm resting on the edge of the table or rotating their forearm. Rather than bring their arm and hand into view to show actions they instead describe them.

Embodied Communication. Fifteen out of twenty participants used their own body as a surrogate for the prosthetic hand. This personal use of the participant's body parts is analogous to the use of first-person deictic language. Where the deictic language centers on the participant so too does the participant's actions-bringing their own actions into the center role as surrogate for the object. For example, P14 (VC) and P19 (VC) used their hands to demonstrate how the fingers of the prosthetic react when the wearer bends their wrist (see Figure 5.10). Similarly, the participant in Figure 5.11 uses their hand as a standin for a child's hand when discussing the shape and size of the prosthetics. 

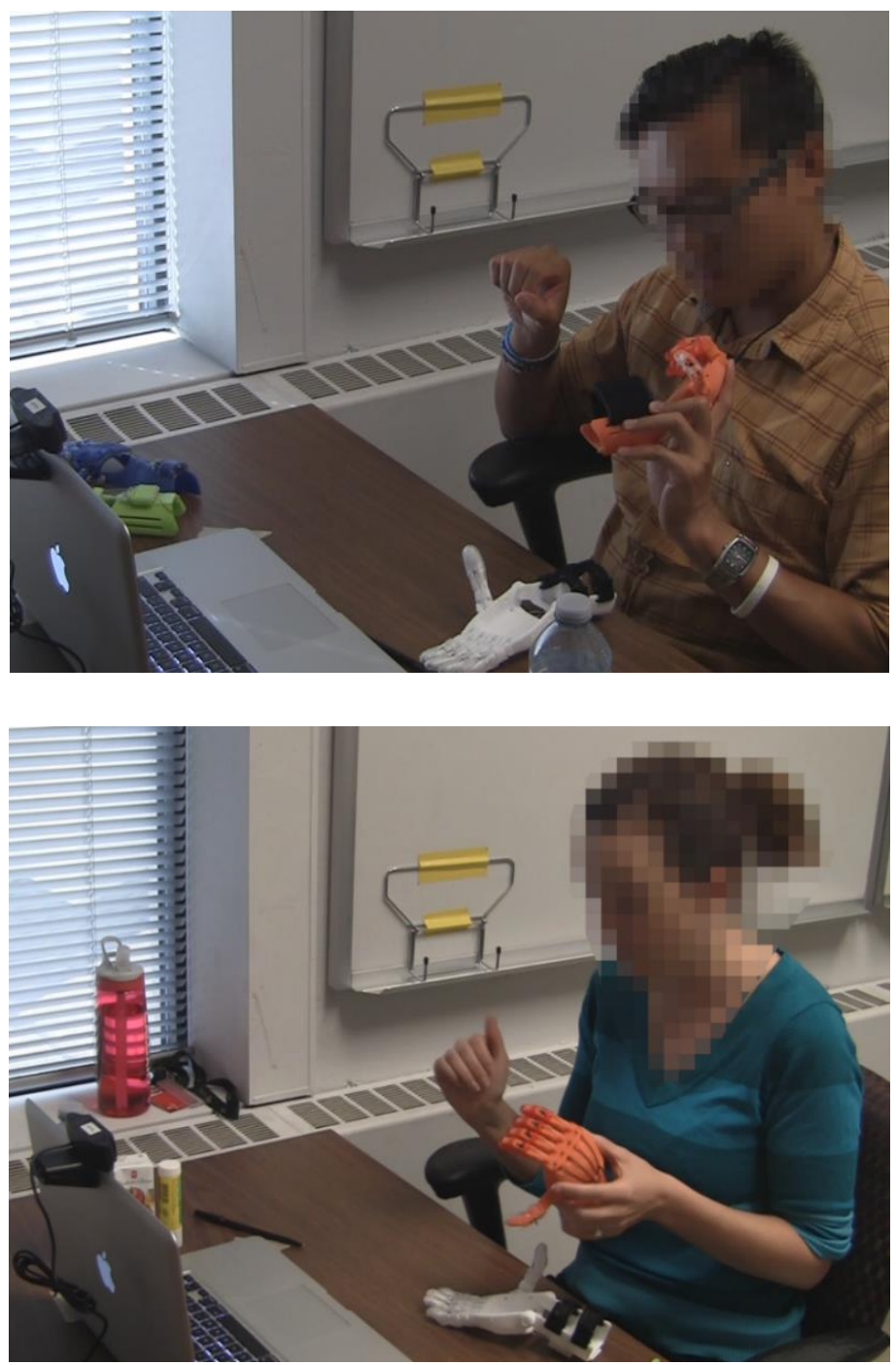

Figure 5.10. (Top) P19 (VC) and (Bottom) P14 (VC) explain the actions users of the prosthetic need to close and open the hand by performing an up and down motion with their own hand as a surrogate. P14 (VC) also narrates their actions "When they press down their palm like this." 


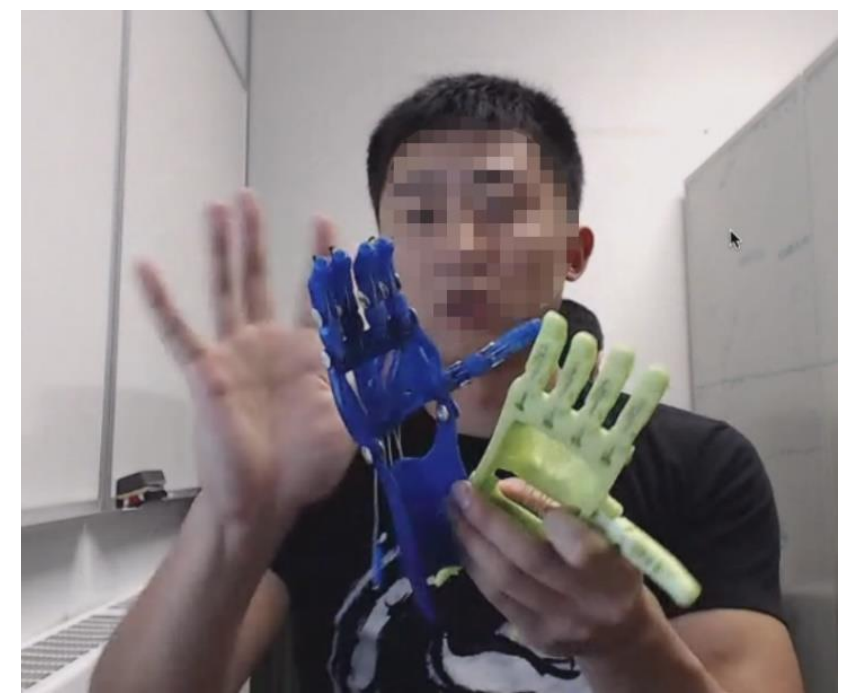

Figure 5.11. Participant P3 (VC) uses their hand as a stand-in for a child's hand to discuss the shape of the prosthetic. "Here the $[\mathrm{palm}]$ is more like the shape of a child's hand."

Participants' natural hands share similar joints and features as prosthetics, and are located where a user would wear a prosthetic. Because the prosthetics were designed to replace a natural hand, participants compared the prosthetic's form and function to their own hand, to decide which designs more closely resemble real-world anatomy. In addition, thanks to proprioception, their own hands are easy to spatially manipulate (Mine et al., 1997) and make for a particularly good surrogate for this conversation.

While using one's own body is easy when imitating prosthetics, similar types of embodied communication may appear in other contexts. For instance, discussing object's mechanical functions that can be mimicked by human physiology (e.g., showing a hinge 
by bending the wrist, showing the motion in a ball joint by rotating the shoulder) or imagining how wearable technology such as smart watches would interact with the wearer's anatomy. In a similar case, Vertesi (2012) described how human drivers of the Mars Rovers used their own arms to simulate the rover's "arm" (instrument deployment device (IDD)). Vertesi noted that drivers used embodiment of the rover arms both to communicate control intentions to other drivers but also as actions for themselves when no one else was around. In the earlier example, P14 (VC) in Figure 5.8 used an embodied comparison of the fingers on each prosthetic hand communicating how the fingers behaved when waving their own wrist. Then, their off-camera movements in Figure 5.9 are an example of embodied action more for their own understanding of the prosthetic rather than for communicating.

\subsection{Study Limitations}

I chose prosthetic hands for my study because their relative complexity led to rich critiques in the e-NABLE community. However, the scale and complexity of physical tasks changes how people communicate and the value of specific forms of telepresence (e.g., robotic telepresence (Rae et al., 2014), augmented reality (e.g., room size projections (Pejsa et al., 2016)). As I found in my pilot studies, object complexity affects the amount 
of detail and nuance in critique-increasingly complex objects may affect the strategies presenters use to communicate longer critique that is more elaborate.

Only one participant (P11) had previous experience with prosthetics. The novice participants had very few comments about assembly or print quality. While novice reviewers have valuable input, they also require more time to familiarize themselves with the prototype. 3D printing experts, prosthesis experts, or veteran prosthetic users may use alternate communication strategies, have different priorities, or focus on different types of features. Furthermore, I elicited critique that reflects the "casual" communication I observed in open-source hardware communities, as opposed to formal design critiques that might be in places such as architecture schools or companies (e.g., Dannels et al., 2008; Dannels \& Martin, 2008). Future work could look at the effect of remote communication on formal critiques.

Many people have no experience with prosthetics. It is possible that the novelty of the prosthetics and possible emotional connection (e.g., empathy or sympathy for child recipients) influenced actions of the participants (e.g., discussion of child recipient's comfort).Being asked to assess prosthetic limbs made for children may bring up emotions that would not occur if participants were given some other object instead (e.g., gear 
assembly). In future work, studies looking at remote design critique of physical objects may want to use a less evocative object to stay clear of this potential influence.

Participants in the study were aware that their remote partner was also one of the researchers. Therefore, they may have assumed that the researcher was already familiar with the prosthetics used in the study. This perceived difference in expertise may have led participants to refrain from mentioning features of the prototypes that they expected the collaborator to already know about. Using a second participant as the collaborator would let us look at how critique might be co-constructed. My study protocol also limited how the collaborator could participate-this constrained the amount of back-and-forth dialogue, and did not necessarily take into account the perspective of the person listening to the remote critique. Future studies that include back-and-forth dialogue may be able to account for both sides of the communication.

The structured interview style used during the study gave me a wealth of discussion to analyze. However, without clear task steps or end-states there were no measures such as performance and error measurements that are commonly seen in studies that evaluate remote collaborative software (e.g., Bailenson, Yee, Brave, Merget, \& Koslow, 2007; Fussell et al., 2004; Gauglitz, Lee, Turk, \& Höllerer, 2012). Thus, it may be difficult to use 
the methods in this study to determine the effectiveness of future technologies supporting remote critique of physical objects.

\subsection{Chapter Summary}

Throughout this chapter, I detailed the findings from my observational lab study of critique of physical prototypes for an audience. By looking at the critique through the lens of material experience, I identified participants' strategies and behaviors in their attempts to share their material experience with a remote partner. Participants gained knowledge and understanding of the physical prototype e-NABLE prosthetic hands through epistemic action-handling, feeling, and focusing on the objects at hand-but had issues with relaying that to the remote audience, in pragmatic action, due to the limitations of standard video conferencing technology. The challenges I identified in sharing the material experience were the struggle to effectively communicate "invisible" physical details (e.g., tension, resistance, and prototype behavior), participants' overwhelming focus on the objects being critiqued, and difficulty concurrently managing the camera and prototypes. 


\section{Chapter Six: Implications for Design and Research}

The previous chapter highlights some of the interesting strategies and difficulties that participants encountered while giving prototype critique via video conferencing. In this chapter, I reflect on those findings to address my overarching thesis question, how can technology support synchronous remote critique of physical prototypes. The primary goal of my study was to inform the development of collaboration tools and technologies for remote critique and user feedback.

To begin, I discuss key factors to consider in the development of remote communication systems for remote critique. Specifically, I focus on how we can extend existing technologies to support the person delivering physical object critique to a remote audience by:

- building around the material experience

- adding a view to share details

- focusing on the presenter's video

- managing responsibilities between the presenter and audience. 
Then, I look at how my methodological choices offer perspective on how to study critique by discussing:

- structuring conversations

- focusing on features or qualities that are not readily visible

- reviewing complex objects.

To conclude this chapter, I discuss these topics as implications for future research in the domain of remote critique.

\section{I Implications for Design}

In the following sections, I discuss important factors to consider when designing systems to support remote critique based on the findings in the previous chapter. System design needs to account for the situation of the reviewer as they communicate their experience and juggle the physical prototype (physically and mentally).

\section{I.I Build Visual Context around Material Experience}

When people are visually focused on a physical prototype (held in their hands) during a critique, their gaze is often directed downwards at their hands rather than up towards a vertical display. While traditional media spaces assume an upwards gaze or "talking heads" view, collaboration systems for physical prototype critique should build around 
the material exploration of objects at the center of the user's focus. One possibility is to include head-mounted cameras (e.g., Fussell, Setlock, \& Kraut, 2003) for the reviewer, which would keep the recorded workspace in-line with their line of sight while their focus is downward towards the object being critiqued. Head-mounted cameras ensure that the object of attention is out of frame less often.

However, this approach may introduce issues of its own. For instance, Fussell, Setlock, \& Kraut (2003) showed that during a robot assembly task a head-mounted camera provided no benefit over a scene-oriented camera and, in cases where both cameras were used, collaborators took more time to complete tasks than with the scene camera alone. The authors stated that the head-mounted camera took away the opportunity for participants to use the scene camera to create close up views of the workspace objects resulting in diminished performance.

In the context of critique, a reviewer takes deliberate time to consider an object before delivering their critique-this split focus might be useful to a remote audience. When a reviewer explicitly directs their attention to the camera, and therefore engages the 


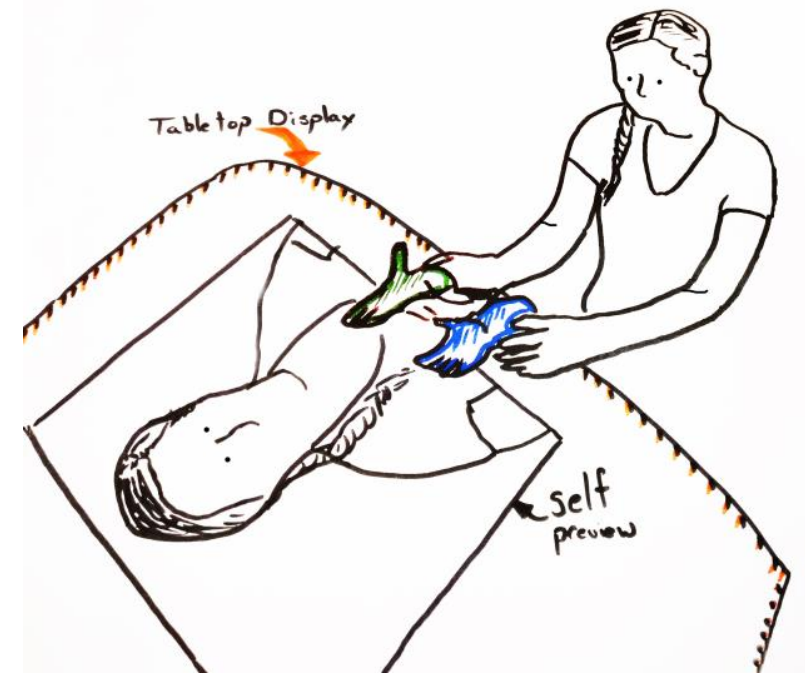

Figure 6.1. Sketch of a possible layout for a tabletop display to support a presenter during video conferencing, as they review physical prototypes. The presenter's preview video lies within their field of view as they are focused downwards on the objects in their hands. audience, it serves as a distinct cue that the audience should pay attention. When using a headmounted camera there is a lessened ability to cue the audience with actions such as showing close-up individual parts of a prototype.

I suggest that system design can build visual context around material experience to enhance the reviewer's

experience. I recommended that systems for remote critique place camera previews in line with the presenter's view of the prototype itself. For instance, as an alternative to a head-mounted camera, a collaboration system could utilize a tabletop preview screen as shown in the sketch in Figure 6.1. Such a tabletop system would allow a reviewer to keep their gaze on the object under critique and the preview of their camera feed in-line with one another. As they look down at the object they would be able to use their peripheral vision to more easily see what is in frame. However, specific placement of this type of 
tabletop screen is important as there is the possibility of a presenter obstructing their own preview with the object or their hands.

\subsubsection{Prioritize Camera Preview}

I suggest that systems for remote critique take into account the priority of the video preview for a reviewer. The framing of a typical video conferencing setup is not supportive of work with physical objects - the view of the remote audience, which consists of a "talking head", takes up most of the viewing area. Thus, the camera preview, small and positioned in the bottom corner, makes it difficult for the reviewer to see what is being recorded. Several participants physically moved closer to the display in an effort to get a better view of their own video preview during demonstrations of objects (see Figure 5.6). In the posttask questionnaire, when asked about difficulties faced during the video conferencing condition, six participants (P10, P11, P12, P13, P18, P19) indicated problems knowing what was being captured and knowing what could be seen through the video link. For example, P10 said, "Yes. It was difficult for me to show the more subtle design elements to my partner. I wasn't sure if the camera was focusing, or could see small detail." Although the participant had access to a video preview, its standard small-sized configuration was ineffective at providing awareness of what could be seen by the audience. 
One possible solution to address this is increasing the size of the presenter preview. Existing research explores how collaborators can be represented on and work with large wall-size panels (e.g., t-room (Hirata et al., 2008), CamRay (Avellino, Fleury, Mackay, \& Beaudouin-Lafon, 2017). For example, the troom

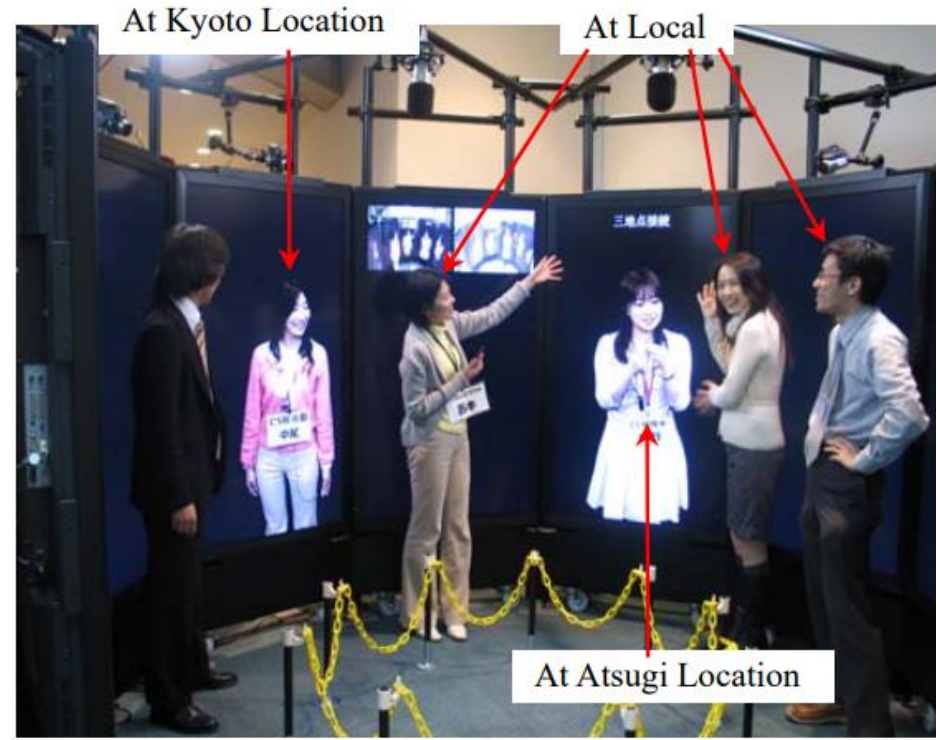

Figure 6.2. The t-room (Hirata et al., 2008) captures and displays remote collaborators at lifesize proportions. From this example we see that their is no video preview available to the "At-local" collaborators of themselves.

developed by Hirata et al. (2008) in Figure $6.2^{41}$, allowed participants to share physical or virtual objects in life-size proportions on large panels but did not provide previews to let them know what exactly was being captured and sent to collaborators. To support a presenter in providing critique to a remote audience it is important for the presenter to compose the video frame based on what their collaborators can see. Looking back to the

\footnotetext{
${ }^{41}$ Figure reproduced from Hirata et al. (2008) (p. 3)
} 
tabletop system example in Figure 6.1, the preview video stream is large so the presenter can clearly see the content being streamed to their audience. The presenter can preview the composition of the video feed during their presentation without blocking their own view of the prototype. However, the preview may distract the presenter depending on its size and location.

Moreover, I consider this implication to be a strong concept as defined by Höök \& Löwgren (2012) "solution-oriented pieces of generative knowledge [...] between instances and theories". While I discuss prioritizing the camera preview for remote critique of physical prototypes it is also more generally applicable to other forms of video communication dealing with physical objects.

Situations that require collaborators to be more aware of what is being captured and then shared with others could benefit from larger video previews than those found in standard video conferencing software. As discussed previously in Chapter Two, remote collaboration tasks in research commonly include puzzles where a helper guides a remote 
worker to complete the puzzle. For example, D'Angelo \& Gergle (2016) studied the use of gaze awareness in participants jointly solving a digital sliding puzzle (an example of a physical sliding puzzle is shown in Figure 6.342). If we consider a variation of the task where collaborators have physical puzzle sliders rather than digital ones, then sharing the state and tile positions of each

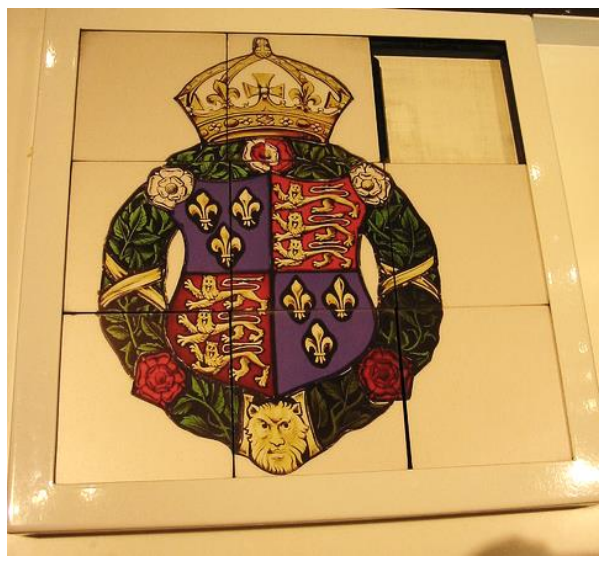

Figure 6.3. A physical slider puzzle in the solved end-goal position. The 8 tiles can be moved to create a scrambled puzzle instance.

person's physical puzzle on camera would be important in jointly solving the puzzle. In this task, prioritizing the camera preview (e.g., increasing the preview size) would allow collaborators to better see what is captured on video and could lead to improved performance in solving the puzzle. For instance, collaborators using a large preview window may be able to more clearly see whether their own pointing is visible and their gesturing is not obstructing the view of tiles to their partner.

\footnotetext{
42 Photo altered and cropped for visibility. Original by Jo Amella Finlay Bever: https://flic.kr/p/cfSA65. Creative Commons https://creativecommons.org/licenses/by/2.0/legalcode
} 


\subsubsection{Provide Means for Close-up Communication}

Our reviewers brought prototypes towards the camera when they wanted to highlight physical details (e.g., small features, textures). This does not necessarily result in an effective view; it requires the reviewer to hold up the prototype, position interesting details towards the camera (and away from them), and hope that the forward-facing webcam will properly focus on the close-up object. It is a challenge to get cameras, especially webcams that are designed to focus on the face and often lack a manual focus function, to properly focus in on very close up (short focal length) objects.

Within the context of communicating remotely about physical objects, zooming is a key factor and clearly capturing objects at a very close range may be necessary. Several times participants mentioned their inability to show small or subtle details such as a rough texture on a prosthetic finger, and attempted to work around this difficulty by providing additional detailed explanations. Systems supporting remote critique need to offer an effective means of close-up communication-potentially as a dedicated additional view. Several existing off-the-shelf technologies may offer solutions to close-up video capture. For instance, USB endoscopes, used by plumbers to examine blockages in pipes, have a short focal distance for objects very close to the lens. Figure 6.4 shows the resulting 
images from a USB endoscope used to capture details of small plastic bumps on the fingertips of the Cyborg Beast prosthetic.

Introducing this extra view may come with a cost, as discussed by Gaver et al. (1993) presenters must manage multiple views and cameras and the audience must follow multiple fragmented views. However, as a trade-off these specialized close-up views can make a participant's otherwise "invisible" material experience of small physical details now visible, relieving the presenter of detailed verbal description.
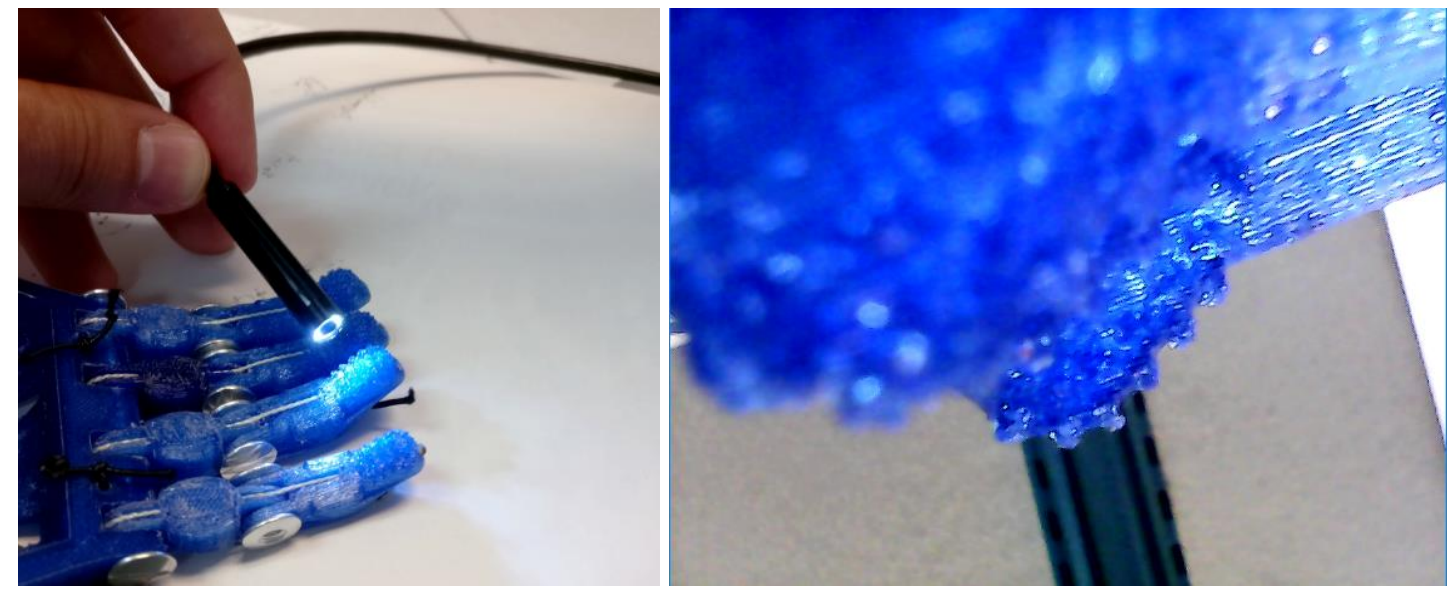

Figure 6.4. (Left) Using an off-the-shelf USB endoscope to capture detailed close-up of the fingers of a prosthetic prototype. (Right) The video capture of the endoscope camera shows small bumps on the plastic fingertips. Details like these are not normally visible with standard video conferencing webcams. Yet, the closer portion of the fingertips are still out of focus. 


\section{I.4 Leverage Pragmatic Action}

When switching to pragmatic interaction with the prototypes, participants brought objects into the camera's visual frame and focus to highlight key aspects of the object's design. In some ways, video conferencing results in more clearly articulated and explicitly expressed feedback than the face-to-face condition (Hollan \& Stornetta, 1992). Recordings from the audio and visual channels from this type of video conference could be reused in project design documentation. One example of short-term reuse could be to convert live video demonstrations into a looping GIF, an external representation. The reviewer can then refer to an 'authored' demonstration without need to continuously manage the camera view or operate the prototype. This type of system could be algorithmically controlled (similar to that proposed by Ranjan et al. (2007)) and triggered to automatically create recordings when the presenter intentionally engages the camera by bringing the prototype into closer proximity.

For example, this proximity recording could be initiated when the presenter demonstrates grasping with the prosthetic hand (bringing the prosthetic in close to the camera to emphasize the grips of the fingers) and the recording would stop once the action moves away from the camera. Once this recording is created the presenter could 
play back the video both for themselves and the audience for reference as they discuss the prosthetic, no longer burdened by simultaneously handling the objects and managing the camera view. The system could also create recordings based on the first-person narrative described in Chapter Five as when a presenter begins to describe their actions. If the presenter uses the first person singular " $\mathrm{I}$ ", for instance, when P14 (VC) says, "If I' $m$ waving it, a whole bunch is happening", a recording would be created to capture the actions they are describing. It would be necessary to test and evaluate starting and ending times for the created recording to ensure that the described actions are captured in their entirety.

\section{I.5 Manage Collaborative Responsibilities}

Who should be responsible for keeping the object in frame? Some participants thought that the remote audience should share some of the onus of keeping objects in frame and reminding the critic to show them details of the object. In the study, the protocol for the remote collaborator (i.e., researcher) artificially constrained them from providing feedback about camera framing or asking about the physical object. However, in the e-NABLE video conference meetings described in Chapter Three, the audience may not always interrupt presenters when objects fall out of frame. 
One possibility is to take away the responsibility from both presenter and the audience entirely. We could offload framing from the person handling the object to an automated, motorized, computer-controlled camera to keep the objects of interest in view. Ranjan et al. (2007) created a system using this idea to automatically track a "worker's" dominant hand during a repair task. Based on the tracked hand the camera would focus on closeups of predetermined regions in the work area or switch to a wide-angle workspace. This tracking and automated camera control showed promising performance improvements in a puzzle Lego building task. In the context of physical object critique the system would need to be modified to focus more on the object itself - to keep the object in frame and to ensure object movements and behaviors are recorded.

Object tracking systems could be used to inform the object focused camera control to support physical prototype critique. However, object tracking systems can require setup, configuration, and expensive hardware, which makes them less feasible for the at-home 
end-user. In addition, current tracking systems such as OptiTrack ${ }^{43}$ or Vicon ${ }^{44}$ use retroreflective markers attached to the tracked object either directly or first attached to sticks which are then attached to the person or object (e.g., balls shown in Figure 6.55). Properly attaching markers to moving parts of complex prototypes such as the

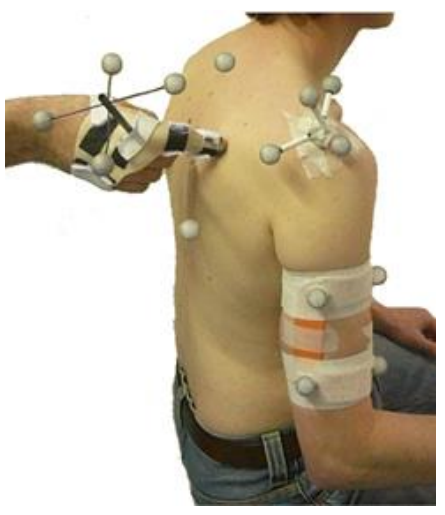

Figure 6.5. Example of retroreflective markers (white balls) attached directly to an object, person, or sticks. Tracking systems such as Vicon use these markers to identify and follow objects or people.

prosthetic hands used for the study in this thesis may be difficult. In addition, as the object is handled, the reflective markers could get in the way of the critique. For example, showing the actuation of an e-NABLE hand requires: holding multiple components, the gauntlet and palm, and the object that the prosthetic is grasping (e.g., water bottle; movement; and application of force. It would be difficult to find a suitable placement for markers that would not impede hand functions.

\footnotetext{
${ }^{43}$ http://optitrack.com/

${ }^{44}$ https://www.vicon.com/

${ }_{45}$ Public domain image reproduced from https://commons.wikimedia.org/wiki/File:Manual palpation palpator.jpg.
} 


\subsection{Implications for Research}

The primary motivation for running this study was to inform how we might design better systems for remote critique around physical prototypes. In this section, I briefly discuss how the methodology of my study can also inform research on remote critique and physical collaborative tasks more broadly.

\subsection{Critique as a Study Task}

Much of past research on remote communication dealing with physical objects focuses on constrained mechanical tasks such as part assembly. These studies may focus on quantitatively evaluating physical tasks through dependant variables such as completion time and error rate. This thesis and my study findings show that using a physical critique task is a valuable way to approach remote communication research. Despite the openended nature of the task, I could analyze the resulting data and determine patterns of behaviour across participants.

\subsubsection{Object Complexity}

In Chapter Four, I described a pilot study in which I used bottle openers as the study object. However, using such simple static objects led to simple critique and simple comparisons. Past research utilized tasks such as assembly and (perhaps implicitly) focused on relatively simple physical components such as Lego blocks. To make tasks 110 
solvable and approachable for participants, past studies have tended towards physical components that are simple and easy to manage. This thesis shows that, at least in the case of critique, complex physical objects should be used as material in a study. Using complex objects for critique pushes participants to provide non-trivial communication when compared to using simple objects.

I provided complex objects for participants to critique to address my thesis questionhow do end-users communicate physical details through video conferencing. By doing so, I observed methods of communicating that otherwise might have been missed. For instance, communicating about "invisible" details by using elaboration of detail and embodied actions, (as described in my study findings in Chapter Five) to discuss physical aspects such as tension would not occur (or be very unlikely to occur) when dealing with simple static objects. Then, seeing how participants deal with physical complexities allows us to consider how we might support them through technology. Furthermore, knowing that these behaviors exist, future studies on remote communication around physical objects can evaluate how well they might support this type of communication by using less simple objects. 


\subsection{Chapter Summary}

In this chapter I discussed the implications of the previous chapter's findings across two contexts-design and research. I described components of remote critique of physical prototypes that should be addressed when creating technology to support remote communication around physical objects. In addition, I noted how the methods of my research, the tasks and complex objects used, could apply to future work within this domain. In the following chapter, I conclude my thesis with a final discussion of my research questions, look forward to possible future systems, and end with closing remarks. 


\section{Chapter Seven: Conclusions and Future Work}

I conclude my thesis with this chapter by revisiting the thesis questions posed in Chapter

One and my contributions toward answering them with this work. I also explore avenues for future work in the space of remote collaboration around physical objects.

\section{I This Thesis}

This thesis began with background information and motivation on the issues and challenges facing open-hardware group's remote video conferencing with physical prototypes. In this chapter, I address my original overarching research problem - how can technology support remote collaboration for live critique of physical prototypesby reflecting on the thesis questions I introduced in Chapter One and reiterating on the contributions of this thesis. I provided additional details and insight on these through my study findings and discussion.

\section{I.I Returning to the Thesis Questions}

Here I address my thesis questions by providing key takeaways of my study findings from Chapter Five and study discussions from Chapter Six. 
Thesis Question 1: How do end-users communicate a critique of a physical prototype over video conference?

- It is a struggle for someone delivering critique of a complex physical object to manage their presentation. Simultaneously handling a physical prototype and determining how to effectively deliver a critique for a remote viewer is difficult.

- People's critiquing communication is split between epistemic and pragmatic actions. This split of attention can lead to difficulty (e.g., object not in frame) when remotely communicating about a physical prototype.

Thesis Question 2: How do end-users communicate physical details through video conferencing?

- There are "invisible" physical details that are difficult to communicate over a video mediated link. Important aspects of physical prototypes need to be discussed, but current common video conferencing tools fail to capture the necessary detail.

- Presenters verbally elaborate on physical details and take longer to present to a remote audience when compared to a collocated one.

- Demonstrating behavior (e.g., bending, grasping) of an object is more than simply showing that object in action. People use their own bodies and bring themselves into the narrative they provide for the audience. 
Thesis Question 3: How should technology be designed to support remote collaboration around physical prototypes?

- Video conferencing software should support the person with the physical object in their presentations. Technology such as tabletop displays may be beneficial because of the tendency to focus downwards and towards the object being critiqued.

- Technology may be able to help a presenter as they discuss a physical object by prioritizing the camera preview in the video conference. One possibility is to increase the size of the presenter's camera preview so that they can be aware of what is visible on camera.

- Make use of cameras built for close-up video capture (i.e., low focal length). Closeup cameras can show the small physical details on objects that can't be recorded by standard video conferencing webcams.

- Leverage the pragmatic actions of a presenter. The "showing" actions of a presenter can be used as cues to drive automated video conferencing software and hardware during a presentation. 
- Help the presenter or audience manage responsibility for the presentation (e.g., keeping the object in frame).

\subsection{Future Work}

Here I propose some of the possibilities for future technology to support or assist in the communication around physical objects at a distance.

\subsection{Remote Communication of Material Experience}

In contemplating the findings for the study presented in Chapter Five, I found that the idea of communicating "invisible" physical details to provide the most exciting opportunities for support from future technology. Invisible details, as previously discussed, are those physical properties that cannot be seen or are extremely difficult to see using standard video conferencing hardware and software such as tension, resistance, or texture. These physical properties are fundamental to the material experience of a physical object and supporting remotely communicating about them is an opportunity for future work.

Verbally or visually communicating about invisible physical details such as tension, resistance, force, stiffness, texture, or weight is a difficult task as previously discussed. Instead, future technology could support "physically communicating". For example, 
someone could share the weight of a local object with remote audience by remotely creating an object with a matching weight at each audience member's location. The presenter might inform the audience of the exact weight of the prototype being discussed and the audience could then adjust a set of weights (e.g., adding or removing weights from a bag) so they can experience that physical property.

However, altering this weight manually would be a time consuming and cumbersome task and technology to control and manage the weight would be beneficial. Figure 7.1

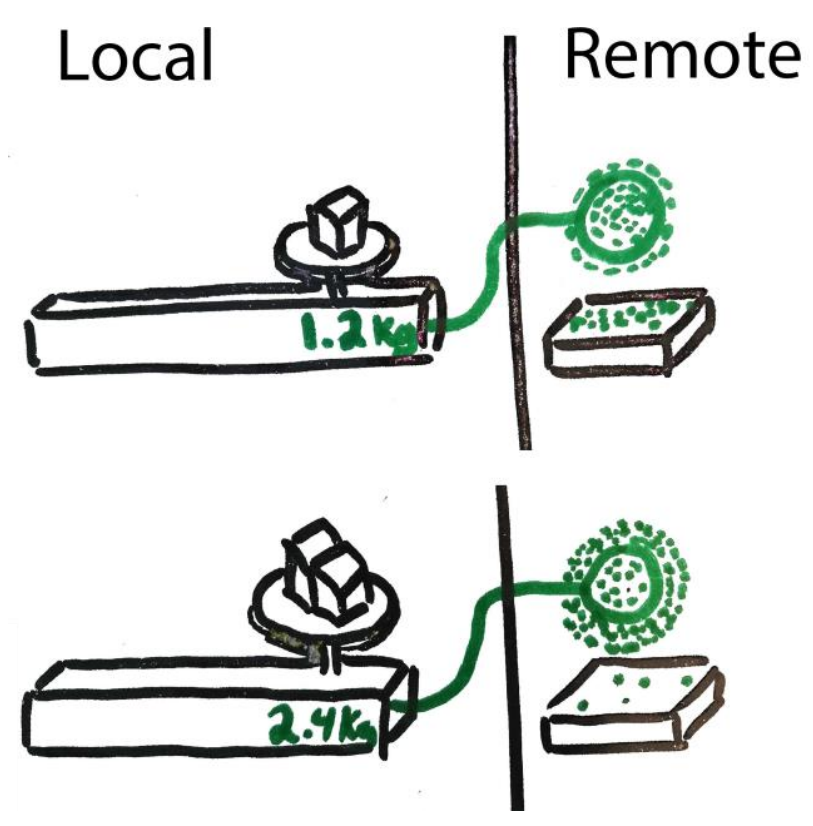

Figure 7.1. Sketch of a theoretical remote weight communication system. Local weight of an object is measured on a network connected weigh scale. The weight is communicated to a remote site where an object adjusts its weight by picking up or more (Bottom) or less (Top) magnetic material 
depicts a theoretical electromagnetic device that will pick up magnetic material based on changing current. We could create a network-connected weigh scale to measure and then send the weight of a component to all audience members. On the receiving end, the audience members would have the electromagnetic device that would then shed or gain weight to match the remote object's weight.

This allows for the communication of a single invisible physical detail-weight-from one person to an audience. However, there are additional physical properties (e.g., tension, texture, stiffness) available to support. Haptic interfaces such as the Geomagic Touch $^{46}$ and tactile friction rendering (Kim et al., 2013) are able to handle properties such as tension and friction to some degree by providing haptic feedback through a graspable pen style device and a touch screen, respectively. However, current consumer level haptic devices use software that pre-defines haptic interaction. For example, we can program a haptic pen to resist movement and simulate the tension in an elastic string. To make this applicable to remotely communicating we require tools that measure the physical properties of a prototype and not rely on pre-programmed values.

\footnotetext{
${ }^{46} \mathrm{http}: / /$ www.geomagic.com/en/products/phantom-omni/overview
} 


\subsubsection{Hands Full}

Gaining a full material experience and sharing it necessitates the use of your hands to hold, feel, operate, and show the object being experienced. If hands are full, then gestures-a critical part of communication-become difficult to perform. It may be beneficial to remote communication around physical objects to support the handling of said object while still allowing for gestures. For example, we could create a set of robotic hands that, when activated, would record the movement of the users own hands and would perform all the handling of the physical object by "playing" the recording (depicted in Figure 7.2). This would free up the presenter's own hands, when the robotic hands are playing the recorded motions, to gesture freely. Because the "mirror" hands

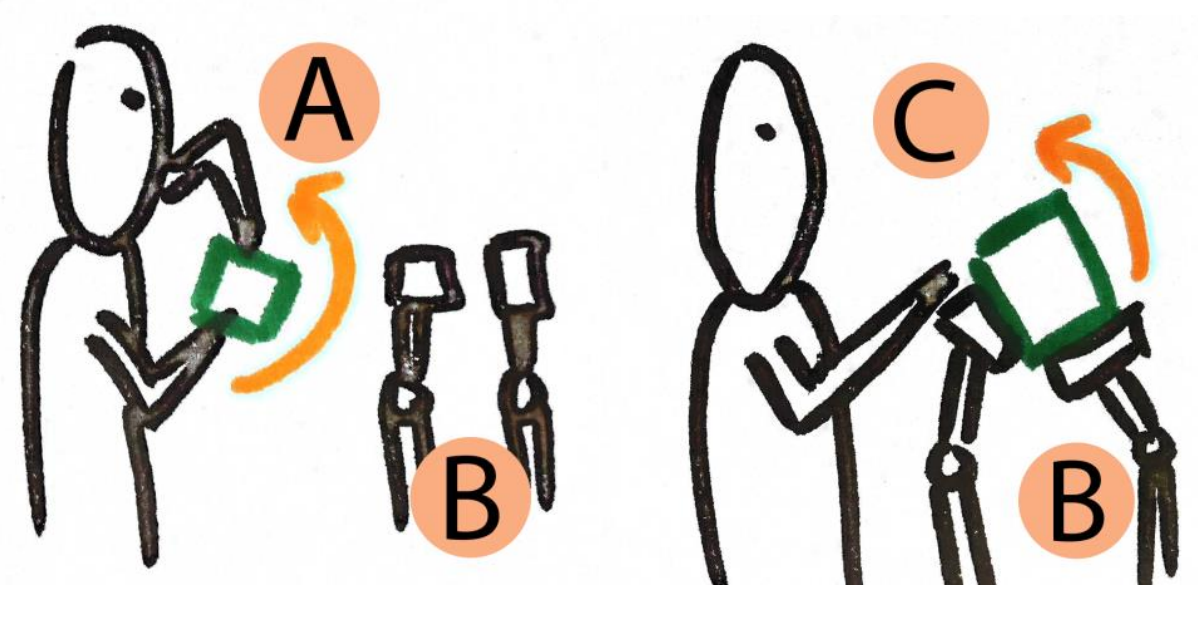

Figure 7.2. Sketch of a theoretical "mirror" hands system. Person (Left) records their hand movements $(A)$ as the handle an object. (B) mirror hands replay the recorded actions $(C)$ once given the object. This frees up the person (Right) to gesture or point to the object as it is manipulated. 
hold the object, the person can use both of their own hands to gesture and point towards the environment or the object as it moves. Furthermore, now that the critic's hands are free they could pick up and use other objects as part of their interaction with the mirror hands and the object being critiqued.

\subsection{Closing Remarks}

This thesis brings new insight on the ways people communicate - and the challenges they encounter-as they critique physical prototypes for both face-to-face and video conferencing audiences. I described a case study of one of the largest online openhardware communities, e-NABLE, to inspire and inform the observational lab study presented in Chapter Four. Each participant was given two sets of prosthetic hands to compare and critique for a collocated and remote collaborator. I analyzed how participants handled, assessed, and articulated their critiques of complex physical prototypes. My study addresses both physical remote collaborative work and openended communication, a distinct contrast from typical "helper-worker" scenarios and step-by-step tasks used in previous research.

In both conditions, participants centered their attention on their material experiences with physical prototypes under review, not the visual view of their collaborator. 
However, this led to difficulties in the video conferencing condition, as participants had difficulty staying aware of what was visible to their collaborator. Furthermore, participants felt that they should not be solely responsible for the camera view and that the audience of the critique should help manage the critique task. Participants verbally and visually noted physical details and prototype behavior and referred to their own actions and bodies when giving comparisons. I offer several design implications for how collaborative systems can alleviate these difficulties and better support a presenter's remote physical prototype critique.

3D printing and other low-cost manufacturing techniques are increasingly present in people's lives. As a result, more people will need critical discussions around physical prototypes to share expertise and offer feedback on each other's designs at a distance. My findings on video-mediated critique inform how new technologies can help reviewers effectively share their opinions and hands-on experiences with the physical objects they create and use. I look forward to future work that continues to explore new configurations for remote critique and to new systems and research that apply the implications in this thesis to help people author more effective remote communication around physical objects. 


\section{References}

Akkil, D., James, J. M., Isokoski, P., \& Kangas, J. (2016). GazeTorch: Enabling gaze awareness in collaborative physical tasks. Proceedings of the 2016 CHI Conference Extended Abstracts on Human Factors in Computing Systems (pp. 1151-1158). New York, NY, USA: ACM. https://doi.org/10.1145/2851581.2892459

Amores, J., Benavides, X., \& Maes, P. (2015). ShowMe: A remote collaboration system that supports immersive gestural communication. Proceedings of the 2015 CHI Conference Extended Abstracts on Human Factors in Computing Systems (pp. 13431348). New York, NY, USA: ACM. https://doi.org/10.1145/2702613.2732927

Avellino, I., Fleury, C., Mackay, W. E., \& Beaudouin-Lafon, M. (2017). CamRay: Camera arrays support remote collaboration on wall-sized displays. Proceedings of the 2017 CHI Conference on Human Factors in Computing Systems (pp. 6718-6729). New York, NY, USA: ACM. https://doi.org/10.1145/3025453.3025604

Bailenson, J. N., Yee, N., Brave, S., Merget, D., \& Koslow, D. (2007). Virtual interpersonal touch: Expressing and recognizing emotions through haptic devices. Human-Computer Interaction, 22(3), 325-353. 
Benavides, X., Amores, J., \& Maes, P. (2015). Remot-IO: A system for reaching into the environment of a remote collaborator. Adjunct Proceedings of 2015 ACM Symposium on User Interface Software \& Technology (pp. 99-100). New York, NY, USA: ACM. https://doi.org/10.1145/2815585.2815738

Bousseau, A., Tsandilas, T., Oehlberg, L., \& Mackay, W. E. (2016). How novices sketch and prototype hand-fabricated objects. Proceedings of the 2016 CHI Conference on Human Factors in Computing Systems (pp. 397-408). New York, NY, USA: ACM. https://doi.org/10.1145/2858036.2858159

Brereton, M., \& McGarry, B. (2000). An observational study of how objects support engineering design thinking and communication: Implications for the design of tangible media. Proceedings of the 2000 CHI Conference on Human Factors in Computing Systems (pp. 217-224). New York, NY, USA: ACM. https://doi.org/10.1145/332040.332434

Buchanan, R. (1992). Wicked problems in design thinking. Design Issues, 8(2), 5-21. https://doi.org/10.2307/1511637

Daily, M., Howard, M., Jerald, J., Lee, C., Martin, K., McInnes, D., \& Tinker, P. (2000). Distributed design review in virtual environments. Proceedings of the 2000 ACM 
Conference on Collaborative Virtual Environments (pp. 57-63). New York, NY, USA: ACM. Retrieved from http://doi.acm.org/10.1145/351006.351013

D'Angelo, S., \& Gergle, D. (2016). Gazed and confused: Understanding and designing shared gaze for remote collaboration. Proceedings of the 2016 CHI Conference on Human Factors in Computing Systems (pp. 2492-2496). New York, NY, USA: ACM. https://doi.org/10.1145/2858036.2858499

Dannels, D., Gaffney, A. H., \& Martin, K. N. (2008). Beyond content, deeper than delivery: What critique feedback reveals about communication expectations in design education. International Journal for the Scholarship of Teaching and Learning, 2(2), 1-16.

Dannels, D., \& Martin, K. N. (2008). Critiquing critiques. Journal of Business and Technical Communication, 22(2), 135-159.

Dant, T. (2008). The 'pragmatics' of material interaction. Journal of Consumer Culture, 8(1), 11-33. https://doi.org/10.1177/1469540507085724

Ducheneaut, N., Moore, R. J., Oehlberg, L., Thornton, J. D., \& Nickell, E. (2008). Social TV: Designing for distributed, sociable television viewing. Intl. Journal of HumanComputer Interaction, 24(2), 136-154. 
Faas, D., Bao, Q., \& Yang, M. C. (2014). Preliminary sketching and prototyping: Comparisons in exploratory design-and-build activities. ASME Design Engineering Technical Conference. https://doi.org/10.1115/DETC2014-34928

Fakourfar, O., Ta, K., Tang, R., Bateman, S., \& Tang, A. (2016). Stabilized annotations for mobile remote assistance. Proceedings of the 2016 CHI Conference on Human Factors in Computing Systems (pp. 1548-1560). New York, NY, USA: ACM. https://doi.org/10.1145/2858036.2858171

Fussell, S. R., Setlock, L. D., \& Kraut, R. E. (2003). Effects of head-mounted and sceneoriented video systems on remote collaboration on physical tasks. Proceedings of the 2003 CHI Conference on Human Factors in Computing Systems (pp. 513-520). New York, NY, USA: ACM. https://doi.org/10.1145/642611.642701

Fussell, S. R., Setlock, L. D., \& Parker, E. M. (2003). Where do helpers look?: Gaze targets during collaborative physical tasks. Proceedings of the 2003 CHI Conference Extended Abstracts on Human Factors in Computing Systems (pp. 768-769). New York, NY, USA: ACM. https://doi.org/10.1145/765891.765980

Fussell, S. R., Setlock, L. D., Yang, J., Ou, J., Mauer, E., \& Kramer, A. D. I. (2004). Gestures over video streams to support remote collaboration on physical tasks. 
Human-Computer Interaction, 19(3), 273-309.

https://doi.org/10.1207/s15327051hci1903_3

Gauglitz, S., Lee, C., Turk, M., \& Höllerer, T. (2012). Integrating the physical environment into mobile remote collaboration. Proceedings of the 2012 ACM Conference on Human-computer Interaction with Mobile Devices and Services (pp. 241-250). New York, NY, USA: ACM. https://doi.org/10.1145/2371574.2371610

Gauglitz, S., Nuernberger, B., Turk, M., \& Höllerer, T. (2014). In touch with the remote world: Remote collaboration with augmented reality drawings and virtual navigation. Proceedings of the 2014 ACM Symposium on Virtual Reality Software and Technology (pp. 197-205). New York, NY, USA: ACM. https://doi.org/10.1145/2671015.2671016

Gaver, W. W., Sellen, A., Heath, C., \& Luff, P. (1993). One is not enough: Multiple views in a media space. Proceedings of the INTERACT 1993 and CHI 1993 Conference on Human Factors in Computing Systems (pp. 335-341). New York, NY, USA: ACM. https://doi.org/10.1145/169059.169268

Giaccardi, E., \& Karana, E. (2015). Foundations of materials experience: An approach for HCI. Proceedings of the 2015 CHI Conference on Human Factors in Computing 
Systems (pp. 2447-2456). New York, NY, USA: ACM.

https://doi.org/10.1145/2702123.2702337

Hanks, W. F. (1992). The indexical ground of deictic reference. In A. Duranti \& C.

Goodwin (Eds.), Rethinking context: Language as an interactive phenomenon (pp. 4376). Cambridge, UK: Cambridge University Press.

Higuch, K., Yonetani, R., \& Sato, Y. (2016). Can eye help you?: Effects of visualizing eye fixations on remote collaboration scenarios for physical tasks. Proceedings of the 2016 CHI Conference on Human Factors in Computing Systems (pp. 5180-5190). New York, NY, USA: ACM. https://doi.org/10.1145/2858036.2858438

Hirata, K., Harada, Y., Takada, T., Aoyagi, S., Shirai, Y., Yamashita, N., Kaji, K., Nakazawa, K. (2008). t-Room: Next generation video communication system. In IEEE GLOBECOM 2008 - 2008 IEEE Global Telecommunications Conference (pp. 14). https://doi.org/10.1109/GLOCOM.2008.ECP.1058

Hollan, J., \& Stornetta, S. (1992). Beyond being there. Proceedings of the 1992 CHI Conference on Human Factors in Computing Systems (pp. 119-125). New York, NY, USA: ACM. https://doi.org/10.1145/142750.142769 
Höök, K., \& Löwgren, J. (2012). Strong concepts: Intermediate-level knowledge in interaction design research. ACM Transactions on Computer-Human Interaction, 19(3), 23:1-23:18. https://doi.org/10.1145/2362364.2362371

Johnson, S., Gibson, M., \& Mutlu, B. (2015). Handheld or handsfree?: Remote collaboration via lightweight head-mounted displays and handheld devices. Proceedings of the 2015 ACM Conference on Computer Supported Cooperative Work E Social Computing (pp. 1825-1836). New York, NY, USA: ACM. https://doi.org/10.1145/2675133.2675176

Johnson, S., Rae, I., Mutlu, B., \& Takayama, L. (2015). Can you see me now?: How field of view affects collaboration in robotic telepresence. Proceedings of the $2015 \mathrm{CHI}$ Conference on Human Factors in Computing Systems (pp. 2397-2406). New York, NY, USA: ACM. https://doi.org/10.1145/2702123.2702526

Jones, B., Dillman, K., Tang, R., Tang, A., Sharlin, E., Oehlberg, L.Neustaedter, C., Bateman, S. (2016). Elevating communication, collaboration, and shared experiences in mobile video through drones. Proceedings of the 2016 ACM Conference on Designing Interactive Systems (pp. 1123-1135). New York, NY, USA: ACM. https://doi.org/10.1145/2901790.2901847 
Jones, B., Witcraft, A., Bateman, S., Neustaedter, C., \& Tang, A. (2015). Mechanics of camera work in mobile video collaboration. Proceedings of the 2015 CHI Conference on Human Factors in Computing Systems (pp. 957-966). New York, NY, USA: ACM. https://doi.org/10.1145/2702123.2702345

Jordan, B., \& Henderson, A. (1995). Interaction analysis: Foundations and practice. The Journal of the Learning Sciences, 4(1), 39-103.

Karana, E., Giaccardi, E., Stamhuis, N., \& Goossensen, J. (2016). The tuning of materials: A designer's journey. Proceedings of the 2016 ACM Conference on Designing Interactive Systems (pp. 619-631). New York, NY, USA: ACM. https://doi.org/10.1145/2901790.2901909

Kim, S.-C., Israr, A., \& Poupyrev, I. (2013). Tactile rendering of 3D features on touch surfaces. Proceedings of the 2013 ACM Symposium on User Interface Software and Technology (pp. 531-538). New York, NY, USA: ACM. https://doi.org/10.1145/2501988.2502020

Kirsh, D., \& Maglio, P. (1994). On distinguishing epistemic from pragmatic action. Cognitive Science, 18(4), 513-549. https://doi.org/10.1207/s15516709cog1804_1 
Kraut, R. E., Fussell, S. R., \& Siegel, J. (2003). Visual information as a conversational resource in collaborative physical tasks. Human-Computer Interaction, 18(1), 13-49. https://doi.org/10.1207/S15327051HCI1812_2

Leithinger, D., Follmer, S., Olwal, A., \& Ishii, H. (2014). Physical telepresence: Shape capture and display for embodied, computer-mediated remote collaboration. Proceedings of the 2014 ACM Symposium on User Interface Software and Technology (pp. 461-470). New York, NY, USA: ACM. https://doi.org/10.1145/2642918.2647377

Licoppe, C., Luff, P. K., Heath, C., Kuzuoka, H., Yamashita, N., \& Tuncer, S. (2017). Showing objects: Holding and manipulating artefacts in video-mediated collaborative settings. Proceedings of the 2017 CHI Conference on Human Factors in Computing Systems (pp. 5295-5306). New York, NY, USA: ACM. https://doi.org/10.1145/3025453.3025848

Luther, K., Pavel, A., Wu, W., Tolentino, J., Agrawala, M., Hartmann, B., \& Dow, S. P. (2014). CrowdCrit: Crowdsourcing and aggregating visual design critique. Companion Proceedings of the 2014 ACM Conference on Computer Supported 
Cooperative Work \& Social Computing (pp. 21-24). New York, NY, USA: ACM. https://doi.org/10.1145/2556420.2556788

McKoy, F. L., Vargas-Hernández, N., Summers, J. D., \& Shah, J. J. (2001). Influence of design representation on effectiveness of idea generation. Proceedings of the ASME Design Engineering Technical Conference (Vol. 4, pp. 39-48). Pittsburgh, PA.

Mi, H., \& Sugimoto, M. (2011). HATs: Interact using height-adjustable tangibles in tabletop interfaces. Proceedings of the 2011 ACM Conference on Interactive Tabletops and Surfaces (pp. 71-74). New York, NY, USA: ACM. https://doi.org/10.1145/2076354.2076368

Mine, M. R., Brooks, F. P., Jr., \& Sequin, C. H. (1997). Moving objects in space: Exploiting proprioception in virtual-environment interaction. Proceedings of the 1997 SIGGRAPH Conference on Computer Graphics and Interactive Techniques (pp. 19-26). New York, NY, USA: ACM Press/Addison-Wesley Publishing Co. https://doi.org/10.1145/258734.258747

Norris, J., Schnädelbach, H., \& Qiu, G. (2012). CamBlend: An object focused collaboration tool. Proceedings of the 2012 CHI Conference on Human Factors in 
Computing Systems (pp. 627-636). New York, NY, USA: ACM.

https://doi.org/10.1145/2207676.2207765

O’Neill, J., Castellani, S., Grasso, A., Roulland, F., \& Tolmie, P. (2005). Representations can be good enough. Proceedings of the 2008 European Conference on Computer Supported Cooperative Work (pp. 267-286). New York, NY, USA: Springer-Verlag New York, Inc. https://doi.org/10.1007/1-4020-4023-7_14

Park, J., Park, Y.-W., \& Nam, T.-J. (2014). Wrigglo: Shape-changing peripheral for interpersonal mobile communication. Proceedings of the 2014 CHI Extended Abstracts on Human Factors in Computing Systems (pp. 599-602). New York, NY, USA: ACM. https://doi.org/10.1145/2559206.2574783

Park, Y.-W., Park, J., \& Nam, T.-J. (2015). The trial of bendi in a coffeehouse: Use of a shape-changing device for a tactile-visual phone conversation. Proceedings of the 2015 CHI Conference on Human Factors in Computing Systems (pp. 2181-2190). New York, NY, USA: ACM. https://doi.org/10.1145/2702123.2702326

Pedersen, E. W., \& Hornbæk, K. (2011). Tangible bots: Interaction with active tangibles in tabletop interfaces. Proceedings of the 2011 CHI Conference on Human Factors in 
Computing Systems (pp. 2975-2984). New York, NY, USA: ACM.

https://doi.org/10.1145/1978942.1979384

Pejsa, T., Kantor, J., Benko, H., Ofek, E., \& Wilson, A. (2016). Room2Room: Enabling lifesize telepresence in a projected augmented reality environment. Proceedings of the 2016 ACM Conference on Computer-Supported Cooperative Work \& Social Computing (pp. 1716-1725). New York, NY, USA: ACM.

https://doi.org/10.1145/2818048.2819965

Rae, I., Mutlu, B., \& Takayama, L. (2014). Bodies in motion: Mobility, presence, and task awareness in telepresence. Proceedings of the 2014 CHI Conference on Human Factors in Computing Systems (pp. 2153-2162). New York, NY, USA: ACM. https://doi.org/10.1145/2556288.2557047

Ranjan, A., Birnholtz, J. P., \& Balakrishnan, R. (2007). Dynamic shared visual spaces: Experimenting with automatic camera control in a remote repair task. Proceedings of the 2007 CHI Conference on Human Factors in Computing Systems (pp. 1177-1186).

New York, NY, USA: ACM. https://doi.org/10.1145/1240624.1240802

Rittel, H. W. J., \& Webber, M. M. (1973). Dilemmas in a general theory of planning. Policy Sciences, 4(2), 155-169. https://doi.org/10.1007/BF01405730 
Sater-Black, K., \& Iversen, N. (1994). How to conduct a design review. Mechanical Engineering, 116(3), 89.

Suzuki, G., Murase, T., \& Fujii, Y. (2016). Projecting recorded expert hands at real size, at real speed, and onto real objects for manual work. Companion Proceedings of the 2016 ACM Conference on Intelligent User Interfaces (pp. 13-17). New York, NY, USA: ACM. https://doi.org/10.1145/2876456.2879476

Tait, M., \& Billinghurst, M. (2015). The effect of view independence in a collaborative AR system. Computer Supported Cooperative Work (CSCW), 24(6), 563-589. https://doi.org/10.1007/s10606-015-9231-8

Ulrich, K., \& Eppinger, S. (2015). Product design and development. McGraw-Hill Higher Education.

Vertesi, J. (2012). Seeing like a rover: Visualization, embodiment, and interaction on the Mars exploration rover mission. Social Studies of Science, 42(3), 393-414. https://doi.org/10.1177/0306312712444645

Wiberg, M., Ishii, H., Dourish, P., Vallgårda, A., Kerridge, T., Sundström, P., Rosner, D., Rolston, M. (2013). Materiality matters-Experience materials. Interactions, 20(2), 54-57. https://doi.org/10.1145/2427076.2427087 
Xu, A., \& Bailey, B. P. (2011). A crowdsourcing model for receiving design critique. Proceedings of the 2011 CHI Extended Abstracts on Human Factors in Computing Systems (pp. 1183-1188). New York, NY, USA: ACM. https://doi.org/10.1145/1979742.1979745

Yuan, A., Luther, K., Krause, M., Vennix, S. I., Dow, S. P., \& Hartmann, B. (2016). Almost an expert: The effects of rubrics and expertise on perceived value of crowdsourced design critiques. Proceedings of the 2016 ACM Conference on Computer-Supported Cooperative Work \& Social Computing (pp. 1005-1017). New York, NY, USA: ACM. https://doi.org/10.1145/2818048.2819953 


\section{Appendix A: Study Materials}

\section{A.I Consent Form}

Ethics application - REB16-0079

4.1 - Consent form

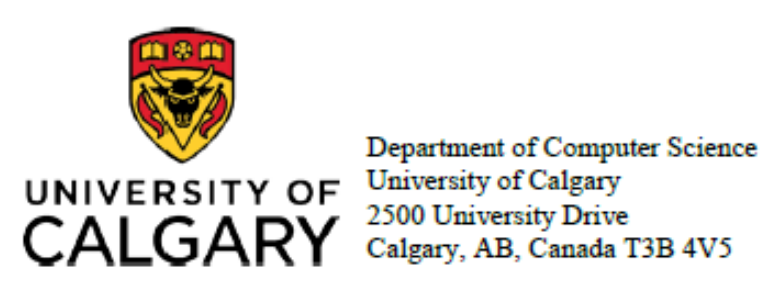

Name of Researcher, Faculty, Department, Telephone \& Email:

Dr. Lora Oehlberg, Assistant Professor - Department of Computer Science, University of Calgary

(403) 220-7711, lora.oehilberg@ucalgary.ca

Terrance Mok, Masters Student - Department of Computer Science, University of Calgary, (587) 585-8366 terrance.mok2@ucalgary.ca

Title of Project:

Developing Technology for Open-Source Hardware Design Teams

Sponsor:

NSERC Discovery Grant 2016

This consent form, a copy of which has been given to you, is only part of the process of informed consent. If you want more details about something mentioned here, or information not included here, you should feel free to ask. Please take the time to read this carefully and to understand any accompanying information.

The University of Calgary Conjoint Faculties Research Ethics Board has approved this research study.

Purpose of the Study:

Our research seeks to address the problem of communicating about physical objects over a distance by asking - How can new collaboration tools help physically distant teams of designers work together to fabricate, assemble, or evaluate new designs?

\section{What Will I Be Asked To Do?}

You will be asked to fill out several questionnaires throughout the study. These questionnaires will ask for demographic information and your thoughts and opinions on the tasks being performed.

You will also be asked to handle several physical objects and present comparisons of them to a researcher.

Your participation is entirely voluntary and you are free to decline to answer any questions. The questionnaires and tasks will last approximately one hour. You may refuse to participate altogether, or may withdraw from the study at any time without penalty by stating your wish to withdraw to the researchers.

Protocol title: Developing Technology for Open-Source Hardware Design Teams 


\section{What Type of Personal Information Will Be Collected?}

Should you agree to participate, you will be asked to provide simple demographics such as your gender, age and academic major or occupation in a questionnaire. Providing this information is optional.

There are several options for you to consider if you decide to take part in this research. You can chose all, some or none of them. Video clips referenced below include camera recordings and computer screen recording (via OBS Studio).

Please put a check mark on the corresponding line(s) that grants us your permission to:

\begin{tabular}{|c|l|c|c|}
\hline 1. & I agree to let video clips be used for data analysis only. & YES & NO \\
\hline 2. & $\begin{array}{l}\text { I agree to let video clips be used for presentation of the research } \\
\text { results. }\end{array}$ & YES & NO \\
\hline 3. & $\begin{array}{l}\text { I agree to let my conversation during the study be directly quoted, } \\
\text { anonymously, in presentation of the research results. }\end{array}$ & YES & NO \\
\hline
\end{tabular}

The main purpose for collecting the video and screen recording is for analysis of the tasks and communication during tasks.

With your permission, we may use clips or stills of the video in presentations and publications, but this can only happen if you have given your consent to point 2 above. Any clips or stills of the video will not be associated with your name or contact information. If consent is given to present video clips and/or photographs, then no anonymity can be guaranteed and you may be clearly recognizable as a participant in this study.

Please note that once photographed or videotaped images are displayed in any public forum, the researchers will have no control over any future use by others who may copy these images and repost them in other formats or contexts, including possibly on the internet.

Are there Risks or Benefits if I Participate?

There is no known risk associated with your participation in this research. You will receive $\$ 20$ remuneration for your participation in this study.

\section{What Happens to the Information I Provide?}

You are free to withdraw from this study at any point. If this occurs, we will immediately stop collecting data from you, ensuring that only data for which you have given consent is used.

All data received from this study will be kept indefinitely in a secure location. Only the investigators indicated on this form will have access to the raw data. You may request to withdraw your data from the study up to 30 days after your study participation.

In any reports created based on this study, you will be represented using a pseudonym or participant number (e.g. Participant 4). With your permission (as indicated in the table above) we may use quotes from your interview or video stills of your session in our published results; these will not be associated with your name, contact information, pseudonym, or participant number. No personal or confidential information will be published. Please note that once videotaped images are displayed in any public form, the researchers will have no control over any future use by others who may copy these images and repost them in other formats or contexts, including possibly on the internet.

Protocol title: Developing Technology for Open-Source Hardware Design Teams 2/3 Ethics application - REB16-0079 | PI: Lora Oehlberg | 09/07/2016 
Signatures (written consent)

Your signature on this form indicates that you 1) understand to your satisfaction the information provided to you about your participation in this research project, and 2) agree to participate as a research subject.

In no way does this waive your legal rights nor release the investigators, sponsors, or involved institutions from their legal and professional responsibilities. You are free to withdraw from this research project at any time. You should feel free to ask for clarification or new information throughout your participation.

Participant's Name: (please print)

Participant's Signature Date:

Researcher's Name: (please print)

Researcher's Signature:

Date:

\section{Questions/Concerns}

If you have any further questions or want clarification regarding this research and/or your participation, please contact:

\section{Lora Oehlberg}

Assistant Professor - Department of Computer Science

Phone: (403) 220-7711

lora.oehlberg@ucalgary.ca

Terrance Mok

Masters Student - Department of Computer Science,

Phone: (587) 585-8366

terrance.mok2@ucalgary.ca

If you have any concerns about the way you've been treated as a participant, please contact the Research Ethics Analyst, Research Services Office, University of Calgary at (403) 220-4283/210-9863; email cfreb@ucalgary.ca.

A copy of this consent form has been given to you to keep for your records and reference. The investigator has kept a copy of the consent form.

Protocol title: Developing Technology for Open-Source Hardware Design Teams 


\section{A.2 Pre-task Questionnaire}

\section{Pre-task Questionnaire}

A) Gender

$$
\text { _ Female _ Male __ Prefer not to answer }
$$

B) Age

C) Professional Background/Discipline:

D) How experienced are you with performing critique (e.g., design critique, design reviews, architectural critique, in-depth product reviews)?

\begin{tabular}{|c|c|c|c|c|}
\hline Not at all & Slightly & Moderately & Very & Extremely \\
\hline 0 & 1 & 2 & 3 & 4 \\
\hline
\end{tabular}

E) Do you have experience in designing physical objects? If so, please describe:

F) How often do you use video conferencing software such as Skype, Google Hangouts Video, FaceTime etc.?

_ I have not used any video conferencing software before

_ less than once a week

_ once a week

_ several times a week

_ daily 
G) What type of activities have you used video conferencing for? Select all that apply.

_ I have not used any video conferencing software before

_ chat 1-on-1

_ chat with multiple people

_ share video of a product or object

_ get help with a task

_ give help to others on a task

_ other (please describe):

H) Do you have any experience with prosthetic limbs?

- Yes _ No

If Yes please describe your experience: 


\section{A.3 Post-task Questionnaire}

A) Which setting did you prefer when doing your presentation?

_ face-to-face _ video-conferencing _ no preference

B) For the face-to-face setting, how much do you agree with the following (circle one number for each question):

\begin{tabular}{|c|c|c|c|c|c|}
\hline & $\begin{array}{c}\text { Strongly } \\
\text { Disagree }\end{array}$ & $\begin{array}{c}\text { Disa- } \\
\text { gree }\end{array}$ & $\begin{array}{c}\text { Neither Agree } \\
\text { nor Disagree }\end{array}$ & Agree & $\begin{array}{c}\text { Strongly } \\
\text { Agree }\end{array}$ \\
\hline $\begin{array}{c}\text { I had an easy time communi- } \\
\text { cating to to my partner }\end{array}$ & 0 & 1 & 2 & 3 & 4 \\
\hline $\begin{array}{c}\text { It was easy to handle the pros- } \\
\text { thetic hands }\end{array}$ & 0 & 1 & 2 & 3 & 4 \\
\hline $\begin{array}{c}\text { I felt like my partner was able to } \\
\text { see what I wanted them to see }\end{array}$ & 0 & 1 & 2 & 3 & 4 \\
\hline $\begin{array}{c}\text { I knew what my partner was } \\
\text { looking at most of the time }\end{array}$ & 0 & 1 & 2 & 3 & 4 \\
\hline $\begin{array}{c}\text { My hands got in the way of } \\
\text { showing things to my partner }\end{array}$ & 0 & 1 & 2 & 3 & 4 \\
\hline
\end{tabular}

C) When in the video conferencing setting presentation how much do you agree with the following (circle one number for each question):

\begin{tabular}{|c|c|c|c|c|c|}
\hline & $\begin{array}{c}\text { Strongly } \\
\text { Disagree }\end{array}$ & $\begin{array}{c}\text { Disa- } \\
\text { gree }\end{array}$ & $\begin{array}{c}\text { Neither Agree } \\
\text { nor Disagree }\end{array}$ & Agree & $\begin{array}{c}\text { Strongly } \\
\text { Agree }\end{array}$ \\
\hline $\begin{array}{c}\text { I had an easy time communi- } \\
\text { cating to to my partner }\end{array}$ & 0 & 1 & 2 & 3 & 4 \\
\hline $\begin{array}{c}\text { It was easy to handle the pros- } \\
\text { thetic hands }\end{array}$ & 0 & 1 & 2 & 3 & 4 \\
\hline $\begin{array}{c}\text { I felt like my partner was able to } \\
\text { see what I wanted them to see }\end{array}$ & 0 & 1 & 2 & 3 & 4 \\
\hline $\begin{array}{c}\text { I knew what my partner was } \\
\text { looking at most of the time }\end{array}$ & 0 & 1 & 2 & 3 & 4 \\
\hline
\end{tabular}




\begin{tabular}{|c|c|c|c|c|c|}
\hline & $\begin{array}{c}\text { Strongly } \\
\text { Disagree }\end{array}$ & $\begin{array}{c}\text { Disa- } \\
\text { gree }\end{array}$ & $\begin{array}{c}\text { Neither Agree } \\
\text { nor Disagree }\end{array}$ & Agree & $\begin{array}{c}\text { Strongly } \\
\text { Agree }\end{array}$ \\
\hline $\begin{array}{c}\text { My hands got in the way of } \\
\text { showing things to my partner }\end{array}$ & 0 & 1 & 2 & 3 & 4 \\
\hline $\begin{array}{c}\text { The camera focused on what I } \\
\text { wanted to show }\end{array}$ & 0 & 1 & 2 & 3 & 4 \\
\hline
\end{tabular}

D) Did you encounter any difficulties while presenting in the face-to-face setting? If so, please describe them:

E) If you had any difficulties in the face-to-face setting do you have any suggestions on what could be done to address those problems?

F) Did you encounter any difficulties while presenting in the video conferencing setting? If so, please describe them: 
G) If you had any difficulties in the video conferencing setting do you have any suggestions on what could be done to address those problems?

H) Rank the hands (Blue, Orange, Green, White) from best (1) to worst (4) using your own criteria

1.

2.

3.

4.

I) What factors and criteria are you taking into consideration when ranking the hands? 


\section{A.4 Study Prosthetic Interviewer Protocol}

You may: answer yes/no to visibility questions (e.g., "Can you see this part?")

You may: ask participant to elaborate (e.g. "Could you explain more?", "What do you mean when you say $X$ ?")

You may: use/take the prosthetic hand briefly if the participant directly gives it to you

Do not: ask participant to perform actions not in the list below

Do not: give feedback on participant presentation

\section{Interview Guide}

Introduce yourself

1. Can you show me how each hand works?

2. Could you show me some of the differences between the two hands?

(Ask about these parts if they do not mention them) Difference in the:

- Fingers

- Palm

- Strings

- Gauntlet (the part that goes over the arm)

3. Which do you think is easier to use and why?

4. Do you think one would be more comfortable to wear than the other? Why?

5. Which hand do you think would be easier to repair if a part breaks? Why?

\section{Defects and Issues}

6. Do you see any issues with how the hands were 3D printed?

7. Do you see any issues with how the hands were assembled or put together?

a. Do you have ideas for how could we fix those issues or defects?

\section{Improvements}

8. Do you have any ideas for how to change the design of the hands?

a. For more comfort?

b. For better grasping?

9. Do you have any other suggestions on how you might improve the designs? 


\section{A.5 Pilot Study Interviewer Protocol}

You may: answer yes/no to visibility questions (e.g., "Can you see this part?")

You may: ask participant to elaborate (e.g. "Could you explain more?", "What do you mean when you say $X$ ?")

Do not: ask participant to perform actions not in the list below

Do not: give feedback on participant presentation

\section{Interview Guide}

Introduce yourself

1. Can you show me how each bottle opener works?

2. Could you show me some of the differences between the bottle openers?

3. Which do you think is easier to use and why?

4. Is one of them more likely to break and why?

\section{Defects and Issues}

5. Do you see any issues with how the bottle openers were 3D printed?

1. Do you have ideas for how could we fix those issues or defects?

\section{Improvements}

6. Do you have any ideas for how to change the designs?

c. To make the easier to hold?

d. Make them better at opening the bottles?

7. Do you have any other suggestions on how you might improve the designs? 


\section{Appendix B: Additional Materials}

\section{B.I Cyborg Beast Hand Materials Kit List}

The e-NABLE "Cyborg Beast" Hand Materials Kit (https://shop3duniverse.com/products/e-nablehand-assembly-materials-kit-cyborg-beast-edition) includes all the off-the-shelf materials necessary to build the Cyborg Beast prosthetic. Material kits for other prosthetic hand design are similar:

- (4 feet) Velcro, double-sided (2" wide)

- (8 feet) Non-flexible braided fishing line

- $\quad(5$ feet) Flexible elastic cord (1 $\mathrm{mm}$ diameter, for smaller hands)

- (5 feet) Flexible elastic cord ( $2 \mathrm{~mm}$ diameter, for larger hands)

- (1) Aluminum Chicago Screw - 21/2"

- (1) Aluminum Chicago Screw - 23/4"

- (1) Aluminum Chicago Screw - 3"

- (1) Aluminum Chicago Screw - 31/4"

- (1) Aluminum Chicago Screw - 31/2"

- (1) Aluminum Chicago Screw - 33/4"

- (4) Stainless Steel Chicago Screws - 1/4"

- (3) Stainless Steel Chicago Screws - 3/8"

- (6) Stainless Steel Chicago Screws - 1/2"

- (6) Tensioner screws (extra small)

- (6) Tensioner screws (small)

- (6) Tensioner screws (medium)

- (6) Tensioner screws (large)

- (10) Lee Tippi Micro Gel Fingertip Grips

- (12 inches) Firm Foam Padding (5 3/4" wide)

- (1 roll) Teflon tape

B.2 List of e-NABLE Town Hall and Research and Development Meetings Observed

\begin{tabular}{|l|l|l|l|}
\hline \multicolumn{1}{|c|}{ Title } & \multicolumn{1}{|c|}{ URL } & Date & Duration \\
\hline $\begin{array}{l}\text { e-NABLE Weekly Town } \\
\text { Hall - May 20, 2016 }\end{array}$ & https://youtu.be/aNiyBY5KeOQ & $\begin{array}{l}\text { May 20, } \\
2016\end{array}$ & $59 \mathrm{~m} \mathrm{15s}$ \\
\hline $\begin{array}{l}\text { e-NABLE Town Hall - } \\
\text { May 13, 2016 }\end{array}$ & https://youtu.be/cmA443B-U7g & $\begin{array}{l}\text { May 13, } \\
2016\end{array}$ & $57 \mathrm{~m} 34 \mathrm{~s}$ \\
\hline $\begin{array}{l}\text { Enable Town Hall - My 6, } \\
\text { 2016 }\end{array}$ & https://youtu.be/8ju39Bzleoo & $\begin{array}{l}\text { May 6, } \\
2016\end{array}$ & $27 \mathrm{~m} \mathrm{15s}$ \\
\hline $\begin{array}{l}\text { e-NABLE Community } \\
\text { Town Hall 4/22/16 }\end{array}$ & https://youtu.be/Pap6bryj-g8 & $\begin{array}{l}\text { Apr 22, } \\
2016\end{array}$ & $30 \mathrm{~m} \mathrm{54s}$ \\
\hline $\begin{array}{l}\text { Enable Community Town } \\
\text { Hall 4/29/16 }\end{array}$ & https://youtu.be/-sPł383wr7E & $\begin{array}{l}\text { Apr 29, } \\
2016\end{array}$ & $33 \mathrm{~m}$ \\
\hline
\end{tabular}




\begin{tabular}{|l|l|l|l|}
\hline $\begin{array}{l}\text { e-NABLE R\&D Hangout- } \\
\text { On-Air }\end{array}$ & https://youtu.be/dTbWgnWbY18 & $\begin{array}{l}\text { Feb 1, } \\
2016\end{array}$ & 1h 36m 4s \\
\hline e-NABLE R\&D Hangout & https://youtu.be/SWs3WyXjWjo & $\begin{array}{l}\text { Feb 29, } \\
2016\end{array}$ & $2 \mathrm{~h} 4 \mathrm{~m} \mathrm{59s}$ \\
\hline e-NABLE R\&D Hangout & https://youtu.be/ntzOzHOP5Yg & $\begin{array}{l}\text { Mar 14, } \\
2016\end{array}$ & $2 \mathrm{~h} 46 \mathrm{~m} 30 \mathrm{~s}$ \\
\hline $\begin{array}{l}\text { e-NABLE R\&D Hangout- } \\
\text { On-Air }\end{array}$ & https://youtu.be/yHJZFzxgCIU & $\begin{array}{l}\text { Mar 28, } \\
2016\end{array}$ & 1h 7m 46s \\
\hline e-NABLE R\&D Hangout & https://youtu.be/miBM1 niaq4 & $\begin{array}{l}\text { Apr 27, } \\
2015\end{array}$ & 1h 12m 25s \\
\hline
\end{tabular}

\section{B.3 List of e-NABLE Community Videos Observed}

\begin{tabular}{|c|c|c|}
\hline Title & URL & Duration \\
\hline $\begin{array}{l}\text { The Osprey Hand: First } \\
\text { Impressions }\end{array}$ & https://www.youtube.com/watch?v=cUkcngYY-OY & $7 \mathrm{~m} \mathrm{13s}$ \\
\hline $\begin{array}{l}\text { Ody Hand Mechanical } \\
\text { Demo }\end{array}$ & https://www.youtube.com/watch?v=jE4xYu7EqU4 & $1 \mathrm{~m} 13 \mathrm{~s}$ \\
\hline Ody Hand Intro & https://www.youtube.com/watch?v=gM8aV6coqEE & $7 \mathrm{~m} \mathrm{5s}$ \\
\hline Talon Hand 2.72 & https://www.youtube.com/watch?v=rtojLN BHts & $1 \mathrm{~m} \mathrm{3s}$ \\
\hline Talon Hand Footage & https://www.youtube.com/watch?v=2L0zBrq43E4 & $7 \mathrm{~m} \mathrm{36s}$ \\
\hline $\begin{array}{l}\text { Experimental Curved } \\
\text { Knuckles for Osprey } \\
\text { Hand }\end{array}$ & https://www.youtube.com/watch?v=B ko2fzduz0 & $4 m 36 s$ \\
\hline $\begin{array}{l}\text { E-nable Raptor } \\
\text { Reloaded Myoelectric } \\
\text { Demo }\end{array}$ & https://www.youtube.com/watch?v=6tgZbp5DT2o & $3 \mathrm{~m} 35 \mathrm{~s}$ \\
\hline $\begin{array}{l}\text { Demonstrating an e- } \\
\text { NABLE hand in Nigeria / } \\
\text { CyberLogik Foundation }\end{array}$ & https://www.youtube.com/watch?v=8qFMHy1D7Qs & Om 20s \\
\hline $\begin{array}{l}\text { e-NABLE's Raptor } \\
\text { Reloaded Test Hand } \\
\text { Mechanical } \\
\text { testing/tuning }\end{array}$ & https://www.youtube.com/watch?v=YEMINao5 BE & $0 \mathrm{~m} \mathrm{50s}$ \\
\hline $\begin{array}{l}\text { Demo of the Flexy Hand } \\
2 \text { - a 3D Printed } \\
\text { Prosthetic Device by } \\
\text { Steve Wood }\end{array}$ & https://www.youtube.com/watch?v=ceyZsKzNNpY & $6 m$ 37s \\
\hline K-1 Hand Demonstration & https://www.youtube.com/watch?v=FfDnH-XKZHY & $2 \mathrm{~m} \mathrm{41s}$ \\
\hline K 1 Hand & https://www.youtube.com/watch?v=dJOBbRAHgSI & $4 \mathrm{~m} \mathrm{30s}$ \\
\hline
\end{tabular}




\begin{tabular}{|l|l|l|}
\hline $\begin{array}{l}\text { e-NABLE Prosthetic } \\
\text { Update: Tying My Shoes }\end{array}$ & https://www.youtube.com/watch?v=AUgG6zNI9zU & $3 \mathrm{~m} 3 \mathrm{~s}$ \\
\hline $\begin{array}{l}\text { How a whippletree works } \\
\text { in an e-NABLE hand }\end{array}$ & https://www.youtube.com/watch?v=dW5B CeJtd8 & $5 \mathrm{~m}$ 32s \\
\hline Gripper box test & $\underline{\text { https://www.youtube.com/watch?v=Ou715-H7NGY }}$ & $1 \mathrm{~m} 2 \mathrm{~s}$ \\
\hline $\begin{array}{l}\text { 3D Printed e-NABLE } \\
\text { Hand \& Team Unlimbited } \\
\text { Arm }\end{array}$ & https://www.youtube.com/watch?v=a 9BZgHOblk & $9 \mathrm{~m} 40 \mathrm{~s}$ \\
\hline $\begin{array}{l}\text { Sophia Testing her new } \\
\text { 3D Printed arm }\end{array}$ & https://www.youtube.com/watch?v=C3FV6juMPhI & $2 \mathrm{~m} 16 \mathrm{~s}$ \\
\hline $\begin{array}{l}\text { Prosthetic Emulator by } \\
\text { e-NABLE }\end{array}$ & https://www.youtube.com/watch?v= bpnDOAz7FU & $12 \mathrm{~m} \mathrm{58s}$ \\
\hline
\end{tabular}




\section{Appendix C: Copyright Permission}

\section{C.I Simplify3D Image Usage Permission}

SS Simplify3D Support <support@simplify3d.com>

Terrance Mok $\approx$

Inbox

To help protect your privacy, some content in this message has been blocked. To re-enable the blocked features, click here.

To always show content from this sender, click here.

Terrance

The composite image of our webpage is perfectly acceptable in your paper. Please do not use/reproduce individual images from our website in your paper. I noticed that your own image (of the red gauntlet) is quite nice, so we wish you the best adding images that show your own work. Good luck!

Simplify3D Support

\section{C.2 e-NABLE Image Usage Permission}

\section{(19)}

I am a Master's student in Canada and I my work is dealing with 3D printing and open-hardware communities. I would like to use some of the images found on the enablingthefuture.org website in my thesis. I will cite/reference the website whenever the images are used.

For now I would like to use images from hittp://enablingthefuture.org/2015/05/04/enabling-rd-thermo-forming-trials/ such as the image with the red thermoformed gauntlet. I would reference that URL wherever that image is used.

Please let me know how I should go about being able to use images and how you would like those images cited if I may use them.

Cheers,

Terrance Mok

Master's Student Computer Science

University of Calgary

Calgary, Alberta, Canada

Hi Terrance

Yes! Feel free to use anything you need from the website!! :)

Good luck with your paper! 